University of South Florida

DIGITAL COMMONS

@ UNIVERSITY OF SOUTH FLORIDA
Digital Commons @ University of

South Florida

$12-1-2004$

\title{
Identifying the Characteristics of Successful Local Transit Circulator Systems in Residential Areas of Southeast Florida
}

CUTR

Follow this and additional works at: https://digitalcommons.usf.edu/cutr_nctr

\section{Scholar Commons Citation}

CUTR, "Identifying the Characteristics of Successful Local Transit Circulator Systems in Residential Areas of Southeast Florida" (2004). Research Reports. 243.

https://digitalcommons.usf.edu/cutr_nctr/243

This Technical Report is brought to you for free and open access by the National Center for Transit Research (NCTR) Archive (2000-2020) at Digital Commons @ University of South Florida. It has been accepted for inclusion in Research Reports by an authorized administrator of Digital Commons @ University of South Florida. For more information, please contact digitalcommons@usf.edu. 


\section{PUBLIC TRANSPORTATION SYNTHESIS SERIES}

Identifying the Characteristics of Successful

Local Transit Circulator Systems in Residential Areas of Southeast Florida

Marlo Chavarria

Principal Investigator

Joel Volinski

Co-Principal Investigator

NCTRR

December 2004 


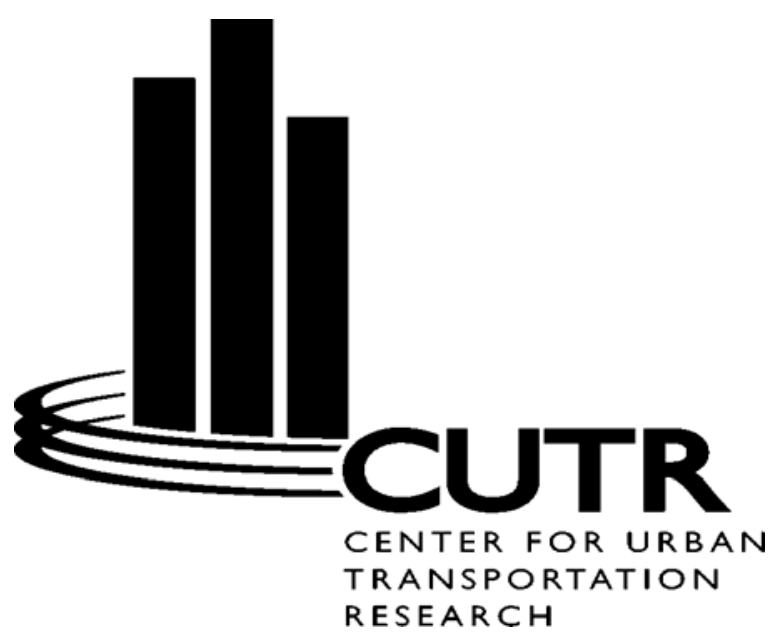

\author{
CENTER FOR URBAN TRANSPORTATION RESEARCH \\ University of South Florida \\ 4202 E. Fowler Avenue, CUT100 \\ Tampa, FL 33620-5375 \\ (813) 974-3120, SunCom 574-3120, Fax (813) 974-5168
}

Edward Mierzejewski, P.E., CUTR Director

Joel Volinski, NCTR Director

Dennis Hinebaugh, Transit Program Director

The contents of this report reflect the views of the author, who is responsible for the facts and the accuracy of the information presented herein. This document is disseminated under the sponsorship of the Department of Transportation, University Research Institute Program, in the interest of information exchange. The U.S.

Government assumes no liability for the contents or use thereof. 


\begin{tabular}{|c|c|c|c|}
\hline $\begin{array}{l}\text { 1. Report No. } \\
\text { NCTR 57601-2, FDOT BD 549-3 }\end{array}$ & 2. Government Accession No. & \multicolumn{2}{|c|}{ 3. Recipient's Catalog No. } \\
\hline \multirow{2}{*}{\multicolumn{2}{|c|}{$\begin{array}{l}\text { 4. Tite and Subtite } \\
\text { Identifying the Characteristics of Successful Local Transit } \\
\text { Circulator Systems in Residential Areas of Southeast Florida }\end{array}$}} & \multicolumn{2}{|c|}{$\begin{array}{l}\text { 5. Report Date } \\
\text { December } 2004\end{array}$} \\
\hline & & \multicolumn{2}{|c|}{ 6. Performing Organization Code } \\
\hline \multicolumn{2}{|l|}{$\begin{array}{l}\text { 7. Author(s) } \\
\text { Marlo Chavarria and Joel Volinski }\end{array}$} & \multicolumn{2}{|c|}{$\begin{array}{l}\text { 8. Performing Organization } \\
\text { Report No. }\end{array}$} \\
\hline \multirow{2}{*}{\multicolumn{2}{|c|}{$\begin{array}{l}\text { 9. Performing Organization Name and Address } \\
\text { National Center for Transportation Research } \\
\text { Center for Urban Transportation Research } \\
\text { University of South Florida } \\
4202 \text { E. Fowler Avenue, CUT 100, Tampa FL 33620-5375 }\end{array}$}} & \multicolumn{2}{|c|}{ 10. Work Unit No. } \\
\hline & & \multicolumn{2}{|c|}{$\begin{array}{l}\text { 11. Contract or Grant No. } \\
\text { DTRS 98-9-0032 }\end{array}$} \\
\hline \multirow{3}{*}{\multicolumn{2}{|c|}{$\begin{array}{l}\text { 12. Sponsoring Agency Name and Address } \\
\text { Office of Research and Special Programs } \\
\text { U.S. Department of Transportation, Washington, D.C. } 20690 \\
\text { Florida Department of Transportation } \\
605 \text { Suwannee Street, MS 26, Tallahassee, FL } 32399\end{array}$}} & \multirow{2}{*}{\multicolumn{2}{|c|}{$\begin{array}{l}\text { 13. Type of Report and Period } \\
\text { Covered }\end{array}$}} \\
\hline & & & \\
\hline & & \multicolumn{2}{|c|}{ 14. Sponsoring Agency Code } \\
\hline \multicolumn{4}{|c|}{$\begin{array}{l}\text { 15. Supplementary Notes } \\
\text { Supported by a grant from the Florida Department of Transportation and the U.S. Department of } \\
\text { Transportation }\end{array}$} \\
\hline \multicolumn{4}{|c|}{$\begin{array}{l}\text { This research synthesis seeks to identify the key factors that determine the success of a community } \\
\text { shuttle system by focusing on the Community Bus Program operating in Broward County, Florida. } \\
\text { A measure of success commonly used in transit is passengers per revenue hour. Passengers per } \\
\text { revenue hour is most commonly influenced by densities and income levels but this research also } \\
\text { examines whether service promotion, management techniques, effectiveness of connections, and } \\
\text { other such factors influence success. The research includes a review of literature, feedback from } \\
\text { passengers, bus operators and service administrators, and census data analysis and GIS mapping. } \\
\text { The objective of this synthesis was to learn lessons that might be valuable to other areas } \\
\text { considering the establishment of similar services. The research indicates that the elements of } \\
\text { density, income, and car ownership remain significant to the success of local circulators as do } \\
\text { connections with regional transit service. The research also shows that the composition of } \\
\text { passengers is significantly different than originally expected. }\end{array}$} \\
\hline $\begin{array}{l}\text { 17. Key Words } \\
\text { Community Shuttle, Neighborhood Circulator }\end{array}$ & $\begin{array}{l}\text { 18. Distribution Statement } \\
\text { Available to the public thr } \\
\text { Technical Information Ser } \\
\text { Port Royal, Springfield, V } \\
\text { 487-4650 }\end{array}$ & $\begin{array}{l}\text { ugh the } \\
\text { ce (NTI } \\
22181 \text { I }\end{array}$ & $\begin{array}{l}\text { ational } \\
5285 \\
(703)\end{array}$ \\
\hline $\begin{array}{l}\text { 19. Security Classif. (of this report) } \\
\text { Unclassified }\end{array}$ & $\begin{array}{l}\text { 20. Security Classif. (of this page) } \\
\text { Unclassified }\end{array}$ & $\begin{array}{l}\text { 21. No. of } \\
\text { pages } \\
81\end{array}$ & 22. Price \\
\hline
\end{tabular}

Form DOT F 1700.7 (8-69) 


\section{Table of Contents}

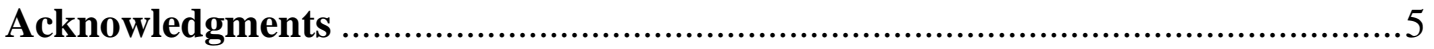

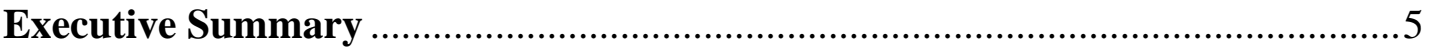

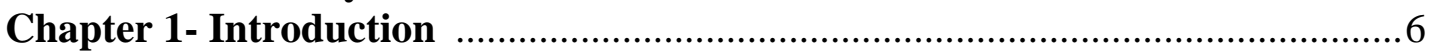

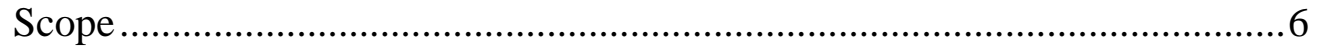

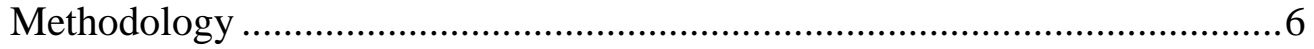

Chapter 2- Summaries of Municipal Case Studies and BCT Meeting ................8

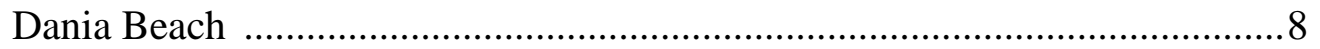

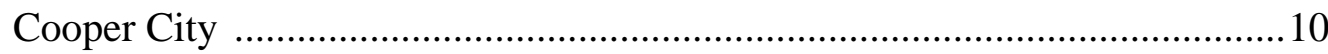

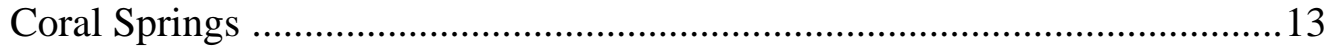

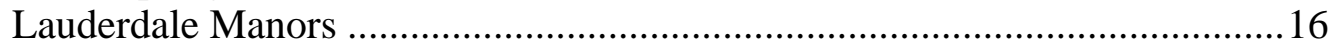

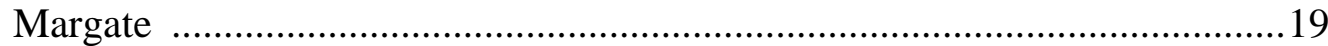

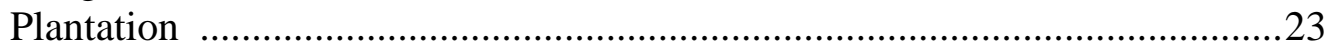

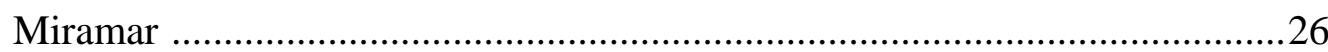

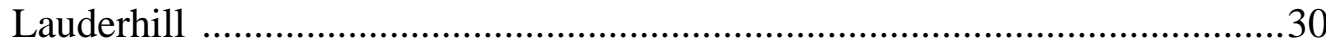

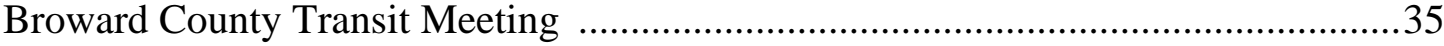

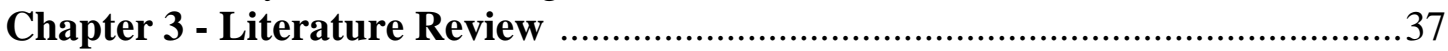

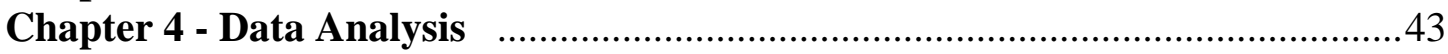

Passengers Per Revenue Hour Analysis.......................................................43

The Correlation Between Passengers Per Revenue Hour and

Transit Utilization Factors ........................................................................... 45

Correlation Matrix ......................................................................................46

Transit Utilization Census Data ................................................................4 47

Chapter 5- Characteristics of a Successful Local Circulator and Conclusions ...48

Factors That Determine a Successful Local Circulator.................................49

Concluding Thoughts and Suggestions for Future Studies ...........................55

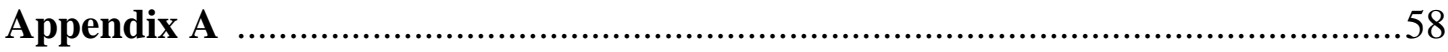

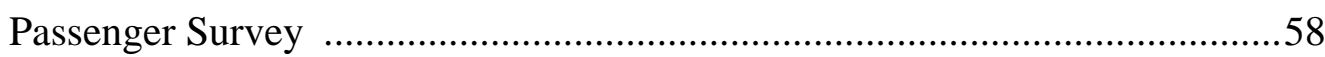

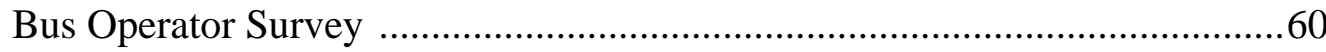

Service Administrator Survey ....................................................................61

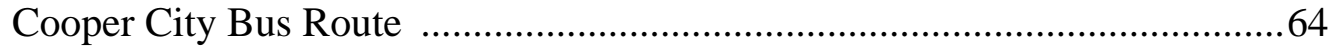

Coral Springs Green Bus Route ......................................................................6 65

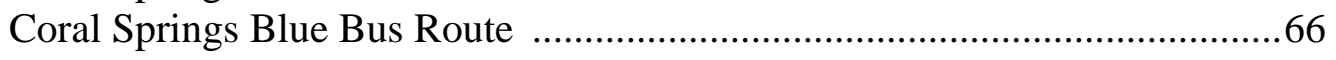

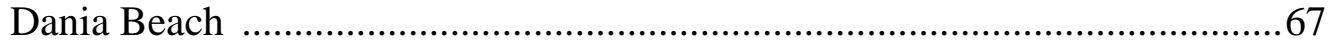

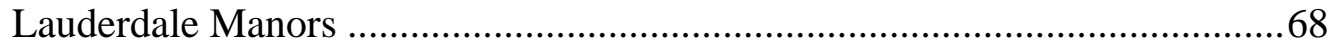

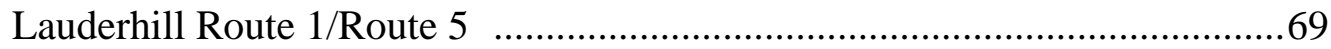

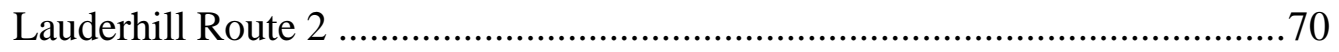

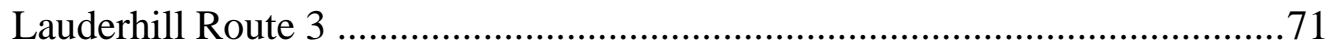

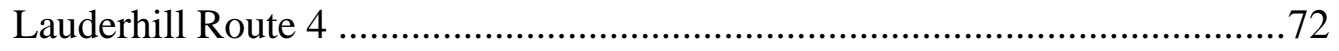

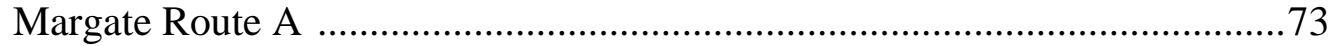

Margate Route B ........................................................................................ 74

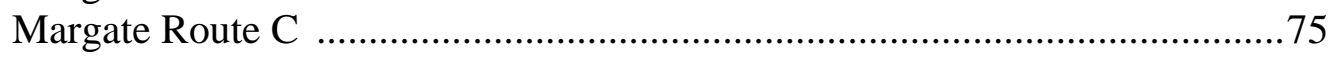

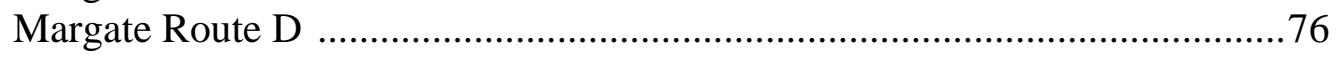

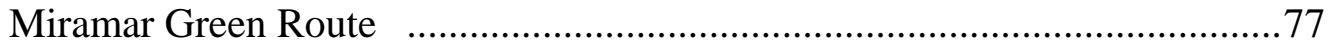

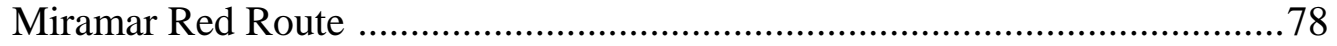

Plantation Route A .............................................................................79

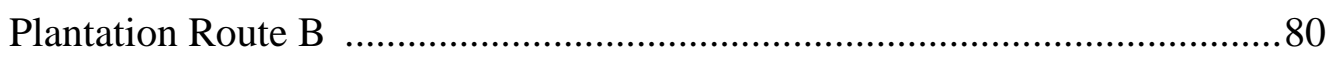

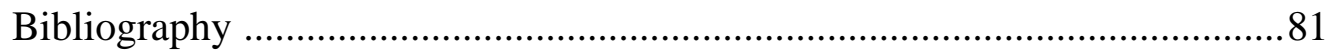




\section{Acknowledgments}

This report is prepared by the National Center for Transit Research through the sponsorship of the Florida Department of Transportation and the U.S. Department of Transportation.

\section{FDOT Project Team:}

Tara Bartee, Planning Administrator, Florida Department of Transportation

\section{CUTR Project Team:}

Principal Investigator:

Marlo Chavarria

Co- Principal Investigator:

Joel Volinski

Contributors:

William Morris, CUTR

\section{Project Review Team:}

Internal Reviewers:

William Morris, CUTR

Dennis Hinebaugh, CUTR

\section{Acknowledgements for Interviews and Data Resources:}

1. Paul Carpenter, Downtown Ft. Lauderdale TMA

2. Elisabeth Bryant, City of Plantation- Department of Public Works

3. Cynthia Healy, City of Cooper City-Senior Services

4. Mark Poirier, Margate Inner-City Transit

5. Kurt Blaides, City of Lauderhill- Parks \& Leisure Services

6. Irv Kiffin, City of Lauderhill- Parks \& Leisure Services

7. Geri Freedman, City of Miramar- Social Services Department

8. Marva Graham, City of Miramar- Social Services Department

9. Gary Bannister, City of Miramar- Social Services Department

10. Kristen L. Jones, City of Dania Beach- Parks and Recreation Department

11. Rick L. Engle, City of Coral Springs- Parks and Recreation Department

12. Irv Minney, Broward Country Transit

13. Robert "Bob" Fossa- Broward County Transit

14. Dwain Rutherford- Broward County Transit

15. Mark Levitt- Limousines of South Florida

16. Mike Clemente- Limousines of South Florida 


\section{Scope}

\section{INTRODUCTION}

This project proposes to identify the factors that make some local residential transit circulator systems more successful than others. In Broward County, there are 20 municipalities that operate local circulator systems. Some of these systems carry over 22 passengers an hour, while others carry fewer than 6 passengers per hour. Although some differences in ridership between circulator systems might be relatively easy to explain (density of development served, car ownership patterns), this project will dig a little deeper into the other possible reasons for differences in performance. Possible factors could be the way the service is promoted, the effectiveness of connections with the regional transit system, fare structure (if there is any), facilities along the route, trip attractors, etc. Information on ridership statistics are maintained by city and county transit managers. However, the project also involved site visits to get a better appreciation of the nuances of services by talking with passengers, bus operators, and service administrators. The factors contributing to system performance found in this project will be useful to all existing providers of such service, and to those municipalities that are contemplating establishing new service.

\section{Methodology}

1. Literature Review - This project included a review of current studies and practices that address the identification of successful factors that influence the performance of a local transit circulator system. Specific emphasis was given to Florida due to the nature of the study, but other areas are also briefly reviewed.

2. Census Data - GIS analysis was conducted to create quarter-mile buffer zones with corresponding census block data for the entire system and for each route in each of the eight municipalities that were reviewed in this study. Among the characteristics that were reviewed were demographic attributes such as income levels, population composition, vehicle ownership, renter and owner occupied units, and population density.

3. Ridership Data - This report reviewed ridership and revenue hours data that is routinely collected by all 20 municipalities participating in the Broward County Community Bus Program. Since funding for this project was very minimal $(\$ 12,000)$, only a limited number of local circulator systems could be examined. The results of reviewing the ridership data were used to help select systems with low, medium, and high passenger per revenue hour ridership levels for the purposes of further representative analysis. 
4. Design of Survey/Interview Instrument and Site Visits - The four important partners in a circulator's system as identified by the project are the bus operators, passengers, project administrators and the contract providers. During site visits and ride checks to gather one-on-one responses from these partners, the following information was gathered:

\author{
口 Service levels \\ 口 Passenger trip purposes \\ - Operational aspects (operators/administrators) \\ a Management techniques including service promotion efforts \\ affectiveness of connection with the regional transit systems \\ - Fare structure \\ - Facilities on route and trip incentives/attractions
}

5. Statistical Analysis - Data analysis of correlations between passengers per revenue hour and demographic and socioeconomic characteristics was conducted based on census data from buffer zones along routes. The report is intended to identify indicators that determine successful community shuttle systems.

The census data and GIS analysis, as well as the on-site visits, provide the basis for a case study for each respective site chosen. Each site was analyzed at the route level to best determine the causes of route and system performance. The case study sites included Lauderhill, Dania Beach, Miramar, Cooper City, Coral Springs, Lauderdale Manors, Margate, and Plantation.

Chapter 2 provides a summary of each of the case studies. 


\section{CHAPTER 2 - SUMMARIES OF MUNICIPAL CASE STUDIES}

\section{Dania Beach}

The City of Dania Beach has a total land area of 6.1 square miles and a population of 20,119 residents. Using a quarter mile buffer zone along the Dania Beach transit circulator system, an effective land area of 3.21 square miles was measured along with a population of 10,528, resulting in a population density of 3,271.6 persons per square mile served by the local minibuses. In the quarter mile buffer, the median household income was \$32,043. There are 4,677 total housing units in the zone. In terms of people by demographic profiles likely to utilize transit services, the elderly segment of the population is $15.72 \%$ and the student-age segment of the population is $9.52 \%$. In the Dania Beach Circulator service area there are 2,219 total owner-occupied units and 2,455 renteroccupied units. In terms of the owner-occupied units, $5.41 \%$ have no car and $50.9 \%$ have one car in the household. In the renter-occupied housing units, $19.59 \%$ have no car and $56.13 \%$ have one car. These statistics are usually a strong indication of the level of potential transit utilization.

The City of Dania Beach provides a fare-free community bus service that circulates residents to and from major residential areas to shopping centers, major BCT transfer points, and the beach. The Community Bus Service operates three routes known as the West Route, the East Route, and the Beach Route. The days and hours of operation are Monday to Friday from 9 a.m. to 5:10 p.m. Transit service on each route is provided with 40 minute frequency. Ridership data provided by the City of Dania Beach Community Shuttle shows (see Fig. 4.1) the average monthly passengers per revenue hour during 20012004. The community bus service has been promoted to local residents through brochures with maps and schedules, senior citizen club meetings, and other city events. City staff noted that they meet monthly with over 20 community groups, and these forums provide an opportunity to disseminate information about the service and to get feedback from the community. The City is currently in the process of service evaluation and route redesigning due to input from riders and the contractor. The city was not satisfied with the performance of its previous contractor due to untimely reporting, sometimes not having sufficient equipment or accessible equipment, and other passenger complaints that were not resolved. However, the city is now very satisfied with its current contractor and reports no problems at all. Ms. Kristen Jones, of Dania Beach's Parks and Recreation Department who oversees the contract, has found that the weekly status meetings with the contractor permit her to be confident in the caliber of service being delivered to patrons. When asked if she had considered bringing the service in-house, she noted it was not possible due to what she considered would be much higher costs and increased liability.

On the visit to Dania Beach, passengers and bus operators were surveyed. Passengers on the Beach Route found the drivers to be customer service oriented, and to be resourceful in terms of route schedules, information about connections within the system, and information about BCT transfers. Passengers on the Beach Route indicated a need for the implementation of Sunday service and reduced headway times to accommodate their mobility patterns. The survey of passengers asked for an overall assessment of the service considering all service elements. The average from the three respondents on a ten-point scale was 9.33. On the East Route, two passengers responded to the survey, both 
indicating a need for weekend service to accommodate certain leisure trips to area sites. Both respondents gave the service a perfect rating of 10 on a 10 point scale. On the West Route, two passengers responded to the survey. One rider found that the seats needed to be repaired due to rips and tears from riders who were destructive. Both respondents gave the service a rating of 9 on a 10 point scale. The bus operators were also asked to provide feedback about the service. The Beach Route Operator indicated that he had been with the system for a month. In a rough estimate of the trip purpose and ridership characteristics, the operator indicated that approximately 20\% of the users were seniors whose main purpose was shopping, commuters were estimated to be $40 \%$ of the riders, and students were $40 \%$. The operator noted a clear trend in ridership daily, with peak ridership at noon, when riders make lunch trips to a restaurant on the beach.

The East Route operator indicated that the day he was interviewed was his first day on the job. Even though his experience was obviously limited, he offered his observations that approximately $30 \%$ of the users were commuters, seniors whose main purpose was shopping were estimated to be $10 \%$ of the ridership, and students were $60 \%$ of the riders. The operator indicated that about $10 \%$ of the riders using the route were either connecting to or from a BCT route. The route served a K-Mart that is a major shopping trip attractor as well as a major employer for area residents.

The West Route operator indicated that he had been with the service for about three months but had previously driven public transit for twenty-seven years. The operator reported that approximately $15 \%$ of the riders were seniors with $5 \%$ going to and from Publix and $10 \%$ going to and from K-Mart. Commuters were estimated to be $20 \%$ of the share of riders using the route, and the largest share were students who comprised an estimated $65 \%$ of total ridership. The operator indicated that about $10 \%$ of the passengers on the route connected from BCT, mostly from BCT \#1.

Ms. Jones indicated that there have been conflicts in the past between senior citizen passengers and students who can get rowdy and sometimes a bit destructive. The contractor for the service now has a supervisor that rides the bus that goes past the school when school lets out in the afternoon, providing a presence and deterrent to disruptive behavior. The supervisor will call the Broward Sheriff if he deems it necessary. There have been no complaints about such behavior since this practice has been put in place.

Dania's community shuttles allow connections with seven different BCT routes. Unfortunately, there is no true bus transfer center in Dania, so connections with regional routes are not as precise as they might be at a timed-transfer center.

The city has operated a community bus service for over six years. In terms of funding sources, $66.67 \%$ of the operating funds are provided by BCT, with the remainder provided by the city. The on-board surveys conducted for this study yielded an average rating of 9.4 on a ten-point scale from passengers of all three routes. The Dania Beach Community Bus Service currently carries 8.7 passengers per hour and has enjoyed an average annual growth rate in passengers per revenue hour of 31\% during 2001-2004. 


\section{Cooper City}

Cooper City has a total land area of 6.4 square miles and a population of 27,685 residents. Using a quarter mile buffer zone along the Cooper City Circulator System, an effective land area of 7.8 square miles was measured (the discrepancy is due to the buffer zone slightly exceeding the city limits). The population within the buffer zone is 25,897 with a population density of 3,317 persons per square mile. In the quarter mile buffer, the average median household income is $\$ 69,995$ and there are 8,723 total housing units. In terms of people by demographic profiles likely to utilize transit services, the elderly segment of the population is $7.4 \%$ and the student-aged segment of the population is $17 \%$. In the Cooper City Circulator Service area, there are 7,798 total owner-occupied units and 923 renter-occupied units. Transit utilization is often a function of vehicle ownership. Of the owner-occupied units, $2.1 \%$ have no car and $23.3 \%$ have one car in the household. In the renter-occupied housing units, $8.3 \%$ have no car and $46.3 \%$ have one car.

The City of Cooper City in partnership with Broward County Transit operates a farefree community shuttle system connecting residents to major activity centers throughout the city. The days and hours of operation are Monday to Saturday from 8 a.m. to 4 p.m. and the headway time is 60 minutes. Ridership data provided by the Cooper City Community Shuttle shows (see Fig. 4.1) the average monthly passengers per revenue hour during 2001-2004. For FY 2003, the total cost of providing the service excluding administrative costs was approximately $\$ 58,000$. BCT provided $87.9 \%$ of this cost and the city the remainder. The service is administered by city employees under the supervision of Ms. Cynthia Healy, Adult Leisure Services Coordinator for Cooper City. She spends 25\% of her total work time addressing the needs of the local circulator system. Ms. Healy was a pioneer in terms of community shuttles, having been associated with the service from the start approximately 12 years ago. She was involved in the initial route design which now benefits from technical assistance provided by Broward County Transit (GIS analysis, population density calculations, transit utilization profiling, and major trip attractors). Subsequent adjustments have been made to the initial route based on increased demand for such services as the city has expanded. The customer feedback mechanism in place includes the posting of Ms. Healy's office telephone number aboard shuttles, surveying of residents for all city services, and a Recreation Advisory Board that incorporates the input from residents into their planning and policy decisions.

Ms. Healy shared some unique lessons she has learned in her thirteen years of managing the service that have helped to explain the growth the circulator system has enjoyed from both a ridership perspective as well as improved customer service feedback. These lessons are listed below:

口 Encouragement of a "user-friendly" shuttle system with drivers becoming inherently involved in service as stakeholders.

- Ensure the presence of "back-up" drivers with the appropriate CDL certification as well as having back-up buses in the event of mechanical failure

a Evaluate the needs of the community as dynamic changes in growth and expansion occur to meet new mobility demands. 
The site visit sought feedback through surveys of passengers and bus operators. A total of nine passengers responded to questions about service reliability, future areas for service improvements, service awareness, and rating the service. Regarding the passengers' frequency of use of the shuttle system, the breakdown of their use is as follows: one indicated he was a daily rider, two rode three/four times a week, three rode twice a week, one rode once a month and the other two riders were using the shuttle service for the first time. These riders utilized the service to get to work (44.44\%), for shopping (44.44\%) and for leisure activities (11.11\%). The patrons reported that the drivers were customer service oriented, being helpful in terms of route schedules, connections within the system and information about BCT transfers. The passenger survey asked respondents for an overall assessment of the service considering all service elements (wait times, reliability, comfort etc.). The average rating from the nine respondents on a ten-point scale was nine (9).

The Cooper City route bus operator was interviewed to provide estimates of trip purpose and passenger demographics. The operator indicated that she had been with the system for almost a year. In a rough estimate of the trip purpose characteristics, the operator indicated that approximately $12.5 \%$ of the users were seniors whose main purpose was shopping, commuters were estimated to be $12.5 \%$ of the riders, and students were $75 \%$ of the riders. The operator reported that patrons commented that the service was a critical part of their ability to be mobile and that there were no improvements needed at the time. Ms. Healy noted that there have been virtually no incidents of conflicts between students and seniors. She indicated that the students have been very well behaved throughout the years, with the one exception occurring at the times the middle school ended in the afternoon and as many as 30 teenagers would try to board the bus at one stop. That "critical mass" of young riders was simply overwhelming. In response, the city modified the route slightly to require the students to walk a little more than a block to catch the bus, and this route modification resulted in far less students using the bus on that trip.

Cooper City has conducted its services in-house for over twelve years. The drivers are city employees and there is a low turnover of operators. In fact, the primary operator of this single-vehicle service has been with the shuttle system since its inception in 1991. The service promotion efforts have included advertisements by direct mailing, periodic press releases, newspaper articles, and brochures on the shuttles. BCT has provided assistance in terms of service marketing and promotion in conjunction with South Florida Commuter Services that boosted passengers per revenue hour during a low ridership period in 2001. This level of technical assistance provided by BCT as a supportive entity to Cooper City has been quite valuable and has been proven to increase service awareness. Another low-cost technique that Ms. Healy credits with helping ridership is the placement of schedules in used tennis ball containers that are fastened to each bus stop sign. She also believes that another helpful factor in ridership increases is the fact that the local circulator now connects with a new BCT route (\#23 at Sheridan Street and Flamingo) and two relatively new municipal shuttle routes in Pembroke Pines and Davie, in addition to the traditional BCT route it has connected with (\#2). In Ms. Healy's words, these additional connections “give more people reasons to ride the bus”.

There have been no on-board surveys conducted specifically to gain passenger feedback. Ms. Healy did note that as she has expanded service by adding stops she has done so based on advice from operators. The Cooper City Community Bus Service has an average growth rate in 
passengers per revenue hour of 19.1\% during 2001-2004, and as of mid-2004 the service was carrying approximately 7.5 passengers per hour. The City of Cooper City has future plans to work with the planning department and developers to do mitigation of traffic impacts through transit circulator services to allow for the development of a new multi-use business facility. 


\section{Coral Springs}

The City of Coral Springs has a total land area of 23.9 square miles and a population of 117,482 residents. Using a quarter mile buffer zone along the Coral Springs Circulator System, an effective land area of 9.2 square miles was measured along with a population of 51,045, resulting in an average population density of 5,548 persons per square mile. In the quarter mile buffer, the median household income is $\$ 52,946$. There are 18,531 total housing units in the zone. In terms of people by demographic profiles likely to utilize transit services, the elderly segment of the population is $7.9 \%$. In the Coral Springs circulator service area there are 10,793 total owner-occupied units and 6,669 renter-occupied units. Transit utilization is often a function of vehicle ownership. In terms of the owner-occupied units, 3.9\% have no car and $25.1 \%$ have one car in the household. In the renter-occupied housing units, $11.5 \%$ have no car and $47.3 \%$ have one car. Route level analysis was conducted for this system to determine the level of transit utilization that would contribute to likelihood of success.

Using a quarter mile buffer zone along the Coral Springs Blue Route, an effective land area of 5.10 square miles was measured along with a population of 33,053, resulting in an average population density of 6,477 persons per square mile. In the quarter mile buffer, the median household income is $\$ 52,794$. There are 11,992 total housing units in the zone. In terms of people by demographic profiles likely to utilize transit services, the elderly segment of the population is $9 \%$ and a student-age segment of the population is $14 \%$. Transit utilization is often a function of vehicle ownership. In the Coral Springs Blue Route buffer zone there are 6,839 total owner-occupied units and 5,156 renter-occupied units. Of the owner-occupied units, $5 \%$ have no car and $29 \%$ have one car in the household. In the renter-occupied housing units, $14 \%$ have no car and $49 \%$ have one car.

Using a quarter mile buffer zone along the Coral Springs Green Route, an effective land area of 4 square miles was measured along with a population of 27,400, resulting in an average population density of 6,850 persons per square mile. In the quarter mile buffer, census block data reveal that the median household income is $\$ 48,137$. There are 9,858 total housing units in the zone. In terms of people by demographic profiles likely to utilize transit services, the elderly segment of the population is $12 \%$ and the student-aged segment of the population is $15 \%$. In the Coral Springs Green Route Buffer there are 6,884 total owner-occupied units and 2,978 renteroccupied units. Of the owner-occupied units, $6 \%$ have no car and $32 \%$ have one car in the household. In the renter-occupied housing units, 10\% have no car and $45 \%$ have one car.

The City of Coral Springs facilitates a fare-free community bus service that connects residents to and from major residential areas to shopping centers, medical centers, local parks, and a recreational center. The Community Bus Service operates two routes, a Blue Route that circulates on the south side of the city and the Green Route that operates on the north side. The days and hours of operation are Monday to Friday from 8 a.m. to 5:55 p.m. The headway time on both routes is 60 minutes. Ridership data provided by the City of Coral Springs Community Shuttle shows (see Fig. 4.1) the average monthly passengers per revenue hour during 2001-2004.

The service is provided by LLS Inc., a private transit contractor, and it is supervised by Mr. Rick Engle, Director of Parks and Recreation for the City of Coral Springs. Mr. Engle 
meets regularly with the contractor's supervisor on site to ensure efficiency and effectiveness of the service. The contractor has provided the service in a professional manner, being accessible and enabling Mr. Engle to have to spend only three to four percent of his time on the community bus system. Mr. Engle reported that the current route design originates from initial consultations with Broward County Transit in which demographic data and GIS analysis were employed in formulating the initial route. Thereafter, adjustments have been made to current routes based on increased demand for such services in the residential communities. The city has taken steps to facilitate input from residents about the adequacy of service. The City Commission oversees operations and, via public hearings where all concerns are heard, citizens can address transportation issues where applicable.

Additional information was provided by the passengers and bus operators. A total of twelve passengers were surveyed on both routes (Blue and Green) answering questions relating to level of service and trip purpose. Passengers reported that their frequency of usage of the system is as follows: five indicated they were daily riders and the other six were occasional users (once a week, every other day) and one rider was a first time user. These riders utilized the service to get to work (25\%), to attend school and engage in other recreational activities (25\%), and the rest for shopping (50\%). Passengers noted that the drivers were customer service oriented rendering assistance in terms of route schedules, connections within the system, and information about BCT transfers. The passenger survey asked respondents for an overall assessment of the service considering all service elements (wait times, reliability, comfort etc.). The average from the twelve respondents on a ten-point scale was 7.6. One respondent did not provide a rating. Many passengers surveyed were teenagers who indicated that though the service was reliable and comfortable, ratings of nine and ten were too high to give. Being students who are constantly evaluated themselves by grade, they believed that high grades should be difficult to earn.

The City of Coral Springs bus operators were also interviewed and were asked to provide estimates of trip purpose and passenger demographics. The Blue Route operator indicated that he had been with the system for a year and a half. In a rough estimate of the trip purpose characteristics, the operator indicated that approximately $75 \%$ of the users were seniors whose main purpose was shopping, commuters were estimated to be $20 \%$ of the riders, and students constituted 5\%. The operator found that no service improvements were necessary and noted that the service provided critical mobility that the community needs. The bus operator on the Green Route indicated that he had been with the system for almost a year. His estimate of trip purpose and rider demographics was that approximately $40 \%$ of the users were seniors whose main purpose was shopping, commuters were estimated to be $10 \%$ of the riders, and students constituted 50\%. The operator noted a clear trend in ridership daily, with peak ridership between 7 a.m. - 9 a.m. and then between 3 p.m. - 5 p.m. During these hours students and commuters moved to and from school and work respectively. During the course of the day the elderly used the shuttle system to run errands and go to grocery stores. The operator commented that route expansion and more frequent service would certainly improve levels of service to the community, with an additional bus being added to reduce the load of passengers that board at the Wal-Mart stop in the evening peak. 
The number of teenage students who use the local circulator was somewhat surprising to the city's program managers. In the early months of implementation, there were problems with rowdy students, particularly from middle schools that were served by the Green Route. Complaints were received from senior passengers who stated that students were stealing groceries from their bags. After discussing these issues with the city's police department, the department assisted the Community Bus Program by installing video cameras on the two buses. These tapes are reviewed whenever there is an incident reported by an operator of the bus. In addition, undercover police officers ride sometimes ride the routes, particularly during the time schools let out students and board the circulators. A few interventions were made by the police which have helped deter future incidents. Those passengers caught engaging in disruptive behavior are barred from the bus for 90 days, and if they violate that suspension, charges can be pressed against them.

In spite of such challenges, the Coral Springs Community Bus program is enjoying considerable growth in ridership. During 2003-2004 ridership on the Green Route grew by $79 \%$ and on the Blue Route by 62\%. Mr. Engle was confident that should the BCT funding be reduced, the city would increase its share and avoid any reduction in the level of service. The Coral Springs Community Bus System is promoted to area residents by flyers, advertisements in the local newspaper, a quarterly magazine, the city television station, and in town meetings held in six areas of the city. Future plans for the system include an expansion of hours of operation on Saturdays, adding distance on the Green route for coverage of a local high school (accommodating students), and adding another bus for reductions in headway times. There are possibilities for this to happen if the county chooses to modify some of its meandering routes in the city and provide substantial funding to the city to replace BCT service with additional community bus service. The Coral Springs Community Bus is funded by both BCT (52\%) and the city (48\%). This diversity in funding between both sources illustrates the commitment by the city to meeting the transportation needs of the community and its long-term potential to be a sustainable mobility service. 


\section{$\underline{\text { Lauderdale Manors }}$}

The Downtown Ft. Lauderdale TMA (DFLTMA) offers circulator services that operate in the downtown business district and also sponsors neighborhood shuttles that the city refers to as City Cruiser Services. The system is free of charge, operating seven routes that permit local residents to move within the downtown area and out to neighborhoods adjacent to downtown. One of the neighborhood shuttles offered by the city that this report analyzes is in a community known as Lauderdale Manors. A quarter mile buffer zone along the Lauderdale Manors circulator route was used to define an effective land area of 1.98 square miles. A population of 13,085 persons (average population density of 6,542 persons per square mile) is served by the local circulator system. In the quarter mile buffer zone, the median household income is $\$ 29,417$. There are 3,810 total housing units in the zone. In terms of people by demographic profiles likely to utilize transit services, the elderly segment of the population is $7.4 \%$ and the student-aged segment of the population is $18 \%$. In the Lauderdale Manors circulator service area, there are 2,277 total owner-occupied units and 1,534 renter-occupied units. Transit utilization is often a function of vehicle ownership and housing status. In terms of the owneroccupied units, $8 \%$ have no car and 34.8\% have one car in the household. In the renteroccupied housing units, $32.9 \%$ have no car and $38.6 \%$ have one car.

The Downtown Ft. Lauderdale TMA circulator services have total annual operating costs of $\$ 741,652$ with $87 \%$ of those costs being linked directly to circulator operations and $13 \%$ being support services. The annual budget was financed with assistance from Broward County Transit (53.18\%), the City of Fort Lauderdale (39.33\%), Tri-Rail (4.25\%) and the Downtown Development Authority (3.24\%). The Lauderdale Manors route (15.9\% of the total cost) serves the residential community northwest of the $\mathrm{CBD}$, and connects passengers to shopping centers and to a local elementary school. The days and hours of operation are Monday to Friday from 6:30 a.m. to 6:30 p.m. and the headway time is 60 minutes. Ridership data provided by the Downtown Ft. Lauderdale TMA shows (see Fig. 4.1) the average monthly passengers per revenue hour during 2001-2004.

The service administrator is Mr. Paul Carpenter, the Executive Director of The Downtown Ft. Lauderdale TMA. He monitors and manages the contract carried out by Luxury Limousine Services. A Board of Directors has recently been created with representation from the funding stakeholders (BCT, DDA, City of Ft. Lauderdale and Tri-Rail). The circulator system initially only served the CBD but has been expanded to serve surrounding neighborhoods within the past few years due to population growth and expansion. The system spans, on average, twelve hour of service per day, varying from route to route given the Park and Ride route is based on special events. The initial route design was developed by Broward County Transit with the use of GIS analysis and taking into account major trip attractors (shopping centers, schools and offices) to serve the needs of the local population. The Downtown Ft. Lauderdale TMA has conducted customer feedback surveys to rate the quality of the park and ride shuttle route. However, a specific level of service (headway times, reliability, and comfort) assessment had not been conducted for the Lauderdale Manors route prior to the onsite visit. DFTLTMA has promoted the "City Cruiser System" service through local periodicals such as the Promenade in the Las Olas area of the CBD. Another marketing effort has been direct mail post cards and maps and schedules to area residents to generate awareness of the existence of the 
service. Mr. Carpenter also believes it is very helpful if not necessary to "brand" the service by giving all the buses used in the "City Cruiser System" the same color, and to make sure each day that the vehicle placed in service has that color.

The site visit included a passenger and bus operator survey. The bus operator surveyed indicated that he had been with the system for three and a half years. He found that the service provided an excellent source of mobility for the community and was not in need of any improvements. There were notable peaks in ridership between 6:35 a.m. and $10 \mathrm{a} . \mathrm{m}$. and in the evenings between 2:00 p.m. and 5:30 p.m. as students and commuters made their way to school and work respectively. The operator estimated that $25 \%$ of the riders were elderly, $25 \%$ were students and the other $50 \%$ were commuters using the service to get to and from their places of employment. He noted some workers also shopped on their way home. The shopping trips were to the main center along the route, a Winn-Dixie supermarket. Given the direct connections between the residential and business community along the route, and the minimal number (two) of connections to BCT routes, the amount of transferring to BCT service is minimal. Service promotion took the form of "word of mouth" and by people seeing the service in operation. Passengers surveyed were asked to provide an overall assessment of the service. The average of the ratings was 9.5 on a ten-point scale. The surveyed passengers found the bus operators to be quite resourceful in terms of providing information about transfer connections and scheduling. Passengers also noted that improvements to the service should include extended hours of operation, especially on the weekends.

Although the customer service ratings assessed by riders on the passenger surveys show that riders are satisfied with the level of service being delivered, Mr. Carpenter is currently concerned with the accuracy of his passenger per revenue hour counts supplied by the contractor. The contractor has provided average ridership as high as 40 passengers per hour, yet figures obtained from both the city and the County indicate ridership in the 20+ range. It was beyond the scope of this study to conduct a full survey of ridership on this route, but it appears an objective survey conducted by a disinterested third party would be helpful. The passengers per revenue hour remains impressive for a single-vehicle, 60-minute neighborhood circulator, with an average growth rate of 31.6\% since 2001 (see Figure 4.1). Mr. Carpenter explained that this decline is due to certain unforeseen circumstances with loss of bus equipment and other service issues that are being corrected. He believes the ridership will increase substantially now that these issues are being addressed.

The service is meeting critical mobility needs of residents, especially students and commuters. There is an issue with the passenger loads that the 20-passenger vehicle picks up at the elementary school in the community. There are sometimes as many as 50 students waiting to be picked up at the school stop when school lets out, which leads to pushing and shoving to get on board a 20-seat vehicle. While the elementary school children are smaller and can often fit three in a two-seat configuration, and standing is allowed, this crush load and boarding can be a problem. There have also been instances where the mixture of senior passengers and grade school children has not been the best. The local school administrators have not provided any supervision at the school stop, and in fact don't want the stop on their property since it interferes with the activity of parents picking up their children, and with their own school bus activity. Mr. Carpenter indicated that it is likely the stop will be moved a block away if possible to eliminate 
any conflicts, and hopefully to reduce the crush loads when school lets out. It is also possible new buses with a higher capacity will alleviate most of this issue.

Mr. Carpenter indicated that future plans for the total DFLTMA service includes the following:

a Fleet change to trolley-buses (6-8) with a street heritage design

a Increase services to SE $17^{\text {th }}$ Street to accommodate new demand for service

a Correcting current maintenance issues such as improvements to air conditioning systems and wheel-chair lifts on the buses. 


\section{Margate}

Margate has a total land area of 8.8 square miles and a population of 53,852 residents. Using a quarter mile buffer zone along the Margate Inner City System, an effective land area of 11 square miles was measured along with a population of 63,510 resulting in a population density of 5,773 persons per square mile. In the quarter mile buffer, the median household income is $\$ 45,697$. There are 27,619 total housing units in the zone. In terms of people by demographic profiles likely to utilize transit services, the elderly segment of the population is $17.7 \%$. In the Margate Circulator Service area there are 18,597 total owner-occupied units and 6,618 renter-occupied units. Of the owner-occupied units, $8 \%$ have no car and $41 \%$ have one car in the household. In the renter-occupied housing units, $12.7 \%$ have no car and $48 \%$ have one car. Route level analysis was conducted for this system as described in the following paragraphs.

Using a quarter mile buffer zone along Route A within the Margate Inner-City Transit system, an effective land area of 3.97 square miles was measured along with a population of 23,123 , resulting in a population density of 5,824 persons per square mile served by the route. In the quarter mile buffer zone, the median household income is $\$ 44,243$. There are 9,537 total housing units in the zone. In terms of people by demographic profiles likely to utilize transit services, the elderly segment of the population is $17 \%$ and the student-age segment of the population is $11 \%$. Along the Route A buffer zone area there are 6,868 total owner-occupied units and 2,673 renter-occupied units. Transit utilization is often a function of vehicle ownership. Of the owner-occupied units, $7 \%$ have no car and $41 \%$ have one car in the household. In the renter-occupied housing units, $14 \%$ have no car and $46 \%$ have one car.

Using a quarter mile buffer zone along Route B within the Margate Inner-City Transit system, an effective land area of 5.15 square miles was measured along with a population of 27, 882, resulting in a population density of 5,419 person per square mile. In the quarter mile buffer zone, the median household income is $\$ 42,488$. There are 12,236 total housing units in the zone. In terms of people by demographic profiles likely to utilize transit services, the elderly segment of the population is $25 \%$ and the student-aged segment of the population is $9 \%$. Within the Route B buffer zone area, there are 9,967 total owner-occupied units and 2,270 renter-occupied units. Within the owner-occupied units, $10 \%$ have no car and $47 \%$ have one car in the household. In the renter-occupied housing units, $16 \%$ have no car and $48 \%$ have one car.

Using a quarter mile buffer zone along Route $\mathrm{C}$ of the Margate Inner-City Transit system, an effective land area of 4.99 square miles was measured along with a population of 32, 615 , resulting in a population density of 6,535 person per square mile. In the quarter mile buffer around Route $\mathrm{C}$, the median household income is $\$ 42,788$. There are 13,892 total housing units in the zone. In terms of people by demographic profiles likely to utilize transit services, the elderly segment of the population is $23 \%$ and the student-aged segment of the population is $10 \%$. Along the Route C buffer zone area, there are 10,346 total owner-occupied units and 3,549 renter-occupied units. Within the owner-occupied units, $10 \%$ have no car and $44 \%$ have one car in the household. In the renter-occupied housing units, $12 \%$ have no car and $47 \%$ have one car. 
Using a quarter mile buffer zone along Route D within the Margate Inner-City Transit system, an effective land area of 3.9 square miles was measured along with a population of 22, 073 resulting in a population density of 5,657 person per square mile. In the quarter mile buffer around Route $\mathrm{D}$, the median household income is $\$ 38,128$. There are 8,349 total housing units in the zone. In terms of people by demographic profiles likely to utilize transit services, the elderly segment of the population is $16 \%$ and the student-aged segment of the population is $12 \%$. Within the Route D buffer zone area, there are 6,384 total owner-occupied units and 1,964 renter-occupied units. In the owner-occupied units, $9 \%$ have no car and $40 \%$ have one car in the household. In the renter-occupied housing units, $17 \%$ have no car and $48 \%$ have one car.

Margate Inner-City Transit has been in operation for almost eleven years and now has four distinct shuttle routes. The system charges riders twenty-five cents per trip and has a service span of twelve hours (7 a.m. - 7 p.m.) between Monday and Saturday. The total operating cost for fiscal year 2003-2004 was \$583,285 with 46.5\% $(\$ 271,142)$ being funded by Broward County Transit through proceeds of the county's local option gas tax, $17 \%(\$ 99,000)$ from fare revenues collected, 6.1\% $(\$ 36,000)$ from bus advertisements, $4.1 \%(\$ 24,000)$ from shelter advertisements, and 3.4\% $(\$ 20,000)$ from bench advertisements. The City of Margate funds the remaining $22.8 \%(\$ 133,143)$. Over 200,000 passengers per year (daily average of 639 patrons) are carried on the local circulators. Ridership data provided by Margate Inner-City Transit during 2001-2004 shows the passengers per revenue hour growth (See Figure 4.1).

Mr. Mark Poirier, Transit Coordinator for Margate Inner-City Transit, has management duties for the service. Bus operators are hired as city employees and the turnover rates are quite low. Mr. Poirier indicated that the current route design originates from technical assistance provided by Broward County Transit at service inception. Subsequent adjustments have been made in terms of addition of new routes and alterations to current routes based on increased demand for such services. The design for Route A is based on its service as a shopper's route to the north end of Margate. Route B (one of two original routes, A being the other) was designed to first cover the south end, but has now been altered due to the presence of routes $C$ and $D$ to run a north-south loop along US 441. Route C emerged due to customer calls for a mall shuttle, providing connections between Holiday Springs, Oriole Gardens, Paradise Gardens, and the Coral Square Mall. Route D serves the south end and typically connects commuters, estimated at 8,000-9,000 within the city by Mr. Poirier, to worksites. Route D also has connections to BCT routes $(18,31$, and 83$)$ for commuters who transfer to and from the regional system.

Margate Inner City Transit has been able to gain customer feedback about the service via a hotline for patrons where any complaints or compliments about the service can be expressed. The city maintains its fleet of minibuses with its own Public Works Department personnel, performing maintenance on the vehicles every 5,000 miles. The mechanics within the Public Works Department check over 130 items at every maintenance interval. These efforts are aimed at ensuring that the overall quality of service delivery is professional and reliable. Service promotion and marketing for MICT has been in the form of the city's website that posts schedules and maps of the respective routes. Brochures and packets with this information have been sent upon request to prospective riders. There are also continuous meetings with residential condominium communities to discuss the service. 
Mr. Poirier shared some unique lessons that have helped to explain the success the circulator system has enjoyed for almost eleven years. These are listed below:

a Stay on major streets in terms of service especially serving residential areas focusing on higher density condominium developments and higher density commercial land uses.

a Have plastic seats to avoid vandalism losses

口 Maintain reliable, customer-friendly service to patrons

a Promote advertising on buses, shelters, and benches to gain additional revenue.

a The major advantage of keeping services in-house is that there is a strong sense of control using city personnel. The additional annual estimated cost of operating the service with in-house personnel is $\$ 65,000$ (approximately $13 \%$ higher than it would cost to contract for the service), but the city believes it is worth the extra cost.

- He noted that the majority of riders were elderly, and that the consistency of having the same operators on the buses day in and day out is very important to those passengers. He believes that contractors tend to have higher turnover in their drivers' roster than the city of Margate has had, where at least three of the drivers have been with the city for over six years.

a Mr. Poirier emphasized that the bus drivers are the primary customer service personnel. Thus it is critical to any bus system for drivers to have a good attitude, a smile, and the ability to answer questions from passengers with courtesy and respect. By hiring the drivers directly, Mr. Poirier believes the city can better ensure that they secure drivers with these characteristics.

Feedback was gathered from the passengers and bus operators on the circulator system. A total of eighteen passengers responded to questions about reliability, future areas for service improvements, service awareness, and rating the service. Passengers reported their usage frequency as follows: ten indicated they were daily riders (five or six days a week), one patron used the service four days a week, three riders used the service three times a week, and the other four were infrequent users (once a week, every other day, twice a week). Reasons for their usage ranged from the first twelve riders noting they used it to get to and from work (66.7\%), one (5.55\%) patron was going to school, and five (27.7\%) riders were utilizing the service for shopping. Passengers indicated that the drivers were customer service oriented and were very helpful in terms of route schedules, connections within the system, and information about BCT transfers. The passengers surveyed were asked to provide an overall assessment of the service considering all service elements (wait times, reliability, comfort etc.). The average from the eighteen respondents on a ten-point scale was 9.58 .

The bus operator surveyed on Route A reported that he had been with the system for five years. In a rough estimate of the trip purpose characteristics, the operator indicated that approximately $85 \%$ of the users were seniors whose main purpose was shopping, commuters were estimated to be $10 \%$ of the riders, and students were $5 \%$. The operator expressed interest in seeing the implementation of service improvements such as incorporating more time for the driver to have breaks and for the air conditioning units to operate more consistently and efficiently. The bus operator on Route B indicated that he had been with the system for five years. The operator's estimate of trip purpose and rider demography was that approximately 
$70 \%$ of the users were seniors whose main purpose was shopping, commuters were estimated to be $20 \%$ of the riders, and students were $10 \%$. The operator noted that Sunday service and route expansion would certainly improve the level of service to the community. He estimated that $30 \%$ of the riders were transferring from BCT buses and the remaining $70 \%$ were intra-city riders. The bus operator on Route $\mathrm{C}$ indicated that he had been with the system for four and a half years. The operator's estimate of trip purpose and rider demography was that approximately $75 \%$ of the users were seniors whose main purpose was shopping, commuters were estimated to be $12.5 \%$ of the riders and students were $12.5 \%$. The operator noted that route expansion and more frequent service would certainly improve the level of service to the community. The bus operator on Route D reported that he had been with the service for two years. His estimate of trip purpose and rider demography was that approximately $75 \%$ of the patrons were seniors whose main purpose was shopping, commuters were estimated to be $5 \%$ of the riders, and students were $20 \%$. The operator added that the implementation of Sunday service and more BCT connections would improve and meet the mobility needs of the local residents.

Margate has had minimal problems with student passengers that might exhibit rowdy behavior. The few times that it has occurred in the past six years, parents were asked to come in with the student and sign a waiver that essentially stated that the student would be banned from the service if he or she engaged in any disruptive behavior in the future. MICT also modified the boarding permission at one of its stops to prevent students from round-tripping on the bus for almost a half hour to get to their final destination. The alternative permitted boarding stop required only a five minute ride. One problem that MICT has is that when students board in any prominent numbers at one stop, a boarding student might say something to the effect that "I don't have change, but one of the other students will pay for me". Too often, no other student pays. Mr. Poirier believes it is possible that more than a third of the students board without paying in such circumstances. He is considering offering a yearly pass that parents or the school system could buy to serve as a flash pass for all students.

Margate Inner-City Transit's four routes connect with seven BCT routes as well as other municipal local circulators provided by the cities of Coconut Creek and Coral Springs. Some of these connections occur at a modest designated transfer center a half block from city hall.

Margate Inner-City Transit has future plans to expand service to a new Route "E" which will provide service to employees of TAG, a call center service company with 4,500 employees. The new route could also provide needed relief for the excessive ridership on Route C. Another innovation planned is a shift to fare boxes to sell passes which will assist more committed riders and eliminate the inconvenience of finding loose change. Mr. Poirier would like more advertising space to be sold, and he would like to interact more directly with the community more often to describe the service in different forums. In order to do that, he intends to hire a staff assistant that can take care of the paperwork elements of administering the program so he can concentrate more on route structures and developing relationships in the community. In short, he wants to focus on the activities that will improve the system and add value to the city rather than spend time on preparing activity reports and required performance reports. 


\section{$\underline{\text { Plantation }}$}

The City of Plantation has a total land area of 21.74 square miles and a population of 83,274 residents. The Community Bus Service has been in fare-free operation for three years with two routes that cover the same roads bi-directionally. Route A runs in a counter-clockwise loop and Route B runs in a clockwise loop. Using a quarter mile buffer zone along the city's local circulator routes, an effective land area of 7.32 square miles was measured along with a population of 36,058 . This results in a population density of 4,920 persons per square mile in the area served by the local circulator system. In the quarter mile buffer zone, the median household income is $\$ 45,272$. There are 15,276 total housing units in the zone. In terms of people by demographic profiles likely to utilize transit services, the elderly segment of the population is $18 \%$ and the student-aged segment of the population is $11 \%$. In the buffer zone area there are 9,798 total owner-occupied units and 5,479 renter-occupied units. In terms of the owneroccupied units, $7 \%$ have no car and $43 \%$ have one car in the household. In the renter-occupied housing units, $12 \%$ have no car and $53 \%$ have one car.

The City of Plantation community bus service circulates to many of the popular destinations within the city including the library, community center, major shopping malls, parks, schools, hospitals and medical office complexes, adult education centers, city hall, banks, clinics, and transfer points with Broward County Transit. The days and hours of operation are Monday to Friday from 7:00 a.m. to 4:30 p.m. and the headway time on both routes is forty-five minutes.

The service is operated by a private contractor, Limousines of South Florida, on behalf of the City of Plantation. The service had an FY 2004 estimated cost of $\$ 389,700.60$ (\$30 per revenue hour for 12,990.02 revenue hours) for both routes, with BCT funding \$20 per revenue hour, or $\$ 259,800$ of the total cost of the circulator service. Consequently, BCT covers about two-thirds of the total operating cost and the City of Plantation covers the remaining third. Ridership data provided by the City of Plantation Tram shows (see Fig. 4.1) the average monthly passengers per revenue hour during 2001-2004.

Among the elements determining a system's success are administration, initial planning efforts, and good use of customer feedback. Mrs. Elisabeth M. Bryant, Administrative Assistant for the City of Plantation, has oversight duties over the service, which began in 2001. She conducts impromptu inspections from time to time, checking for schedule adherence and cleanliness of the vehicles, and has brief weekly meetings with the supervisor for the service provided by Limousines of South Florida. However, overseeing the local circulator contract takes only $10 \%$ of her time at the city, where she is responsible for a host of other city services. The initial routes were designed to capture ridership in the areas where elderly apartments were clustered and to circulate through major retail areas, activity centers, and city parks and facilities, primarily in the central and eastern portion of the City. The Planning and Zoning Department developed the route with input from Broward County and physically mapped it out making modifications along the way based on traffic flow, lights, and street connectivity. Ridership data has since been used to make adjustments to eliminate areas with low ridership and include areas with greater potential ridership. Customer feedback is encouraged by listing the telephone number in the minibuses for patrons to call and express either satisfaction or dissatisfaction with 
the service. Ms. Bryant provides a monthly report to the City manager that is also shared with Planning and Zoning staff who might use information in the report to review route structure based on patron's calls. Service promotion efforts involve brochures with schedules and maps in both printed and electronic versions (on the website), laminated maps in two local Publix supermarkets, and advertisements in the Plantation Quarterly Report. New residents are mailed information packets which include maps and schedules, and advertisements are placed in local periodicals. Ms. Bryant believes these efforts have attracted ridership from the target population. The service has had a passenger per revenue hour growth rate of over 30\% during 2002-2004 due partially to the extensive public outreach programs. These efforts are encouraged to sustain ridership and ensure that the transit utilizing population is fully aware of the presence of this community service.

Plantation's Tram service connects with 10 BCT routes as well as other local circulator routes provided by the cities of Lauderhill, Lauderdale Lakes, and the Town of Davie. Many of these connections are made at major BCT transfer facilities at the Lauderhill Mall and the West Terminal in Plantation. The presence of these facilities make transferring for passengers much more convenient than transfers that take place on the street.

The onsite visit also sought feedback from passengers and bus operators. On Route B, a total of seven passengers responded to questions about reliability, future areas for service improvements, service awareness and an overall rating of the service. Passengers indicated their frequency of usage as follows: three (42.9\%) indicated they were daily riders, three (42.9\%) riders indicated they used the service three times a week and one (14.2\%) rider used the service once a month. In terms of trip purpose, riders were using the system to get to a medical center, to go shopping, to the Central Park, to work and to the library. The passengers surveyed found the drivers to possess good customer service skills, being helpful in terms of route schedules, connections within the system, and information about BCT transfers. The passengers noted also that the particular driver on the route was exemplary as he went out of his way to ensure customer satisfaction. The survey of passengers asked for an overall assessment of the service considering all service elements (wait times, reliability, comfort, etc.). The average from the seven respondents on a ten-point scale was 8.64. On Route A, a total of thirteen passengers responded to questions about reliability, future areas for service improvements, service awareness and an overall rating of the service. Passengers indicated their frequency of usage as follows: three (23.1\%) indicated they were daily riders, two (15.4\%) riders indicated they used the service two times a week, two (15.4\%) riders used the service between two and three times a week, three (23.1\%) riders indicated they used the service once a week, one $(7.7 \%)$ rider indicated he used the service twice a month, and two (15.4\%) riders were first time users and so had no usage pattern. In terms of trip purpose, seven riders were going shopping, three riders were going to work, two riders were going to the Plantation Museum, and one other rider was headed to a local school. The passengers surveyed found the drivers to possess good customer service skills, being helpful in terms of route schedules, connections within the system, and information about BCT transfers. The survey of passengers asked for an overall assessment of the service considering all service elements (wait times, reliability, comfort, etc.). The average from the thirteen respondents on a ten-point scale was 8.5. 
The bus operator surveyed on Route A reported that he had been an operator with the system for approximately six months. The operator believed that $40 \%$ of all passengers are going to or from work, 35\% are going to or from shopping (primarily grocery shopping) or medical appointments, and $20 \%$ of all passengers are students. The operator offered different numbers when asked this question a different time, noting a higher propensity for shopping trips to be taking place on the circulator. The operator provided another estimate regarding the connection patterns of these riders. Approximately 35\% connect to BCT buses for inter-city travel and the rest simply use the system for intra-city circulation. The operator recommended that service be expanded to accommodate a new Publix (Pines and Cleary) being built in the north end of Plantation. He indicated that safety is a primary concern aboard his shuttle and that requested stops were permitted where there was no official bus stop. The operator also noted a clear trend in daily ridership, with peak ridership between 7:30 a.m. and 9:00 a.m. and then between 3:00 p.m. and 5:00 p.m. During these time intervals, students and commuters moved to and from school and work respectively. On Route B, the operator reported that he had been with the Plantation Tram Shuttle System for approximately two and a half years. In a rough estimate of trip purpose characteristics, the shuttle operator indicated that approximately $40 \%$ of the users were seniors whose main trip purposes were shopping, doctor's visits, and other errands. Commuters were estimated to be $33.3 \%$ of all passengers and students comprised $26.7 \%$. The operator suggested that different stops with benches and shelters need to be implemented so that passengers have a designated place to wait for the bus. The operator felt this would stop the practice of making requested stops. The driver of Route B reported that $70 \%$ of the riders came from the BCT system and the other 30\% used the service for intra-city transportation within Plantation. This observation was somewhat surprising since Routes A and B cover the exact same streets while going in opposite directions, yet the two drivers had vastly different observations of how many passengers transferred to and from the BCT service.

Ms. Bryant noted that just before she had responsibility for the Plantation Tram, the city provided a circulator route that served Plantation High School in the southeastern portion of the city. Unfortunately, there were incidents where high school students would bully other passengers, intimidate seniors, vandalize seats, and engage in general rowdiness. Plantation's mayor wrote to the School Board to see if they would help in deterring this behavior, but the school administrators indicated there was little they could do once the students were off school property. As a result, the city decided to terminate its service to that portion of the city. While the negative incidents were eliminated, so was service to a portion of the city where other passengers would like to have accessed the tram. The city is considering if there could be ways to serve those areas near the school without going past the school. 


\section{$\underline{\text { Miramar }}$}

The City of Miramar has a total land area of 29.5 square miles and a population of 72, 674 residents. Using a quarter mile buffer zone along the Miramar Circulator System, an effective land area of 13.2 square miles was measured along with a population of 58,533, resulting in a population density of 4,434 persons per square mile. In the quarter mile buffer zone, the median household income is $\$ 44,786$. There are 22,392 total housing units in the zone. In terms of people by demographic profiles likely to utilize transit services, the elderly segment of the population is $11 \%$. In the Miramar Circulator service area there are 14,660 total owneroccupied units and 5,560 renter-occupied units. Of the owner-occupied units, $6.8 \%$ have no car and $32.5 \%$ have one car in the household. In the renter-occupied housing units, $12.4 \%$ have no car and $49 \%$ have one car. Route level analysis was conducted for this system to determine the level of transit utilization that would contribute to likelihood of success.

Using a quarter mile buffer zone along the Green Route within the Miramar Community Shuttle System, an effective land area of 11.83 square miles was measured along with a population of 50,190, resulting in a population density of 4,241 persons per square mile. In the quarter mile buffer zone around the Green Route, the median household income is \$45,721. There are 17,580 total housing units in the zone. In terms of people by demographic profiles likely to utilize transit services, the elderly segment of the population is $12 \%$ and the studentaged segment of the population is $13 \%$. In the Green Route Buffer zone area, there are 12,777 total owner-occupied units and 4,802 renter-occupied units. Within the owner-occupied units, $7 \%$ have no car and 34\% have one car in the household. In the renter-occupied housing units, $11 \%$ have no car and $49 \%$ have one car.

Using a quarter mile buffer zone along the Red Route within the Miramar Community Shuttle System, an effective land area of 6.93 square miles was measured along with a population of 41,268 , resulting in a population density of 5,953 persons per square mile. In the quarter mile buffer zone around the Red Route, the median household income is $\$ 44,787$. There are 14,209 total housing units in the zone. In terms of people by demographic profiles likely to utilize transit services, the elderly segment of the population is $10 \%$ and the student-aged segment of the population is $14 \%$. In the Red Route Buffer zone area, there are 9,713 total owner-occupied units and 4,498 renter-occupied units. Within the owner-occupied units, 6\% have no car and 33\% have one car in the household. In the renter-occupied housing units, 12\% have no car and $49 \%$ have one car.

The City of Miramar facilitates a Community Bus Service that has two distinct routes serving the mobility needs of its riders since service inception in 1995. The system charges a twenty-five cent fare to its riders per trip and has a service span of twelve hours during weekdays. The days and hours of operation are Monday to Friday from 6:45 a.m. to 6:55 p.m. and the headway time for both routes is 60 minutes. A key service objective was to circulate residents to and from major residential areas to provide adequate connections to shopping centers, senior centers, churches, schools, and local civic centers (library, city hall, and the courthouse). The total operating costs for fiscal year 2003-2004 was \$329,400 with \$265,333 (80.6\%) being provided by BCT, $\$ 15,000$ (4.5\%) obtained from fare box recovery, and the 
remaining \$49,067 (14.9\%) is subsidized from the City's general fund. These expenses do not include the costs incurred with general overhead activities (legal, payroll, finance, etc.). Although the revenue collected in fares is relatively small, the city intends to continue charging a fare since the revenue gained through its collection can be used to pay for at least minimal capital or operating improvements. Ridership data provided by the City of Miramar Community Shuttle shows (see Figure 4.1) the average monthly passengers per revenue hour during 20012004. Graphical analysis (Table 2.1) of the passenger per revenue hour data from August 2001 to May 2004 illustrates a clear seasonal decline in the summer months (July and August) and peaks in May and October.

Ms. Geri Freedman, Director of Social Services for the City of Miramar Community Bus Service, has oversight duties for the service. She has appointed a Transportation Coordinator, Mr. Gary Bannister who handles day to day operations. She indicated that the current route design originates from technical assistance provided by Broward County Transit in the form of transit utilization profiling, GIS analysis, and travel patterns data. Subsequent adjustments have been made in terms of the addition of new routes and alterations to the current route based on increased demand for such services. The drivers are city employees and there is a low turnover of operators. The city always considers the possibility of contracting out services versus providing them with in-house personnel in order to save money. However, Ms. Friedman is concerned that the city will lose the flexibility it now has where they cross-train their community bus drivers and their senior transportation vehicle drivers. All of these city employees are also available to provide special event service when needed by another department within the city. The drivers used in the community bus service are part-time employees, and the city has enjoyed pretty good stability with this work force in spite of their part-time nature. The drivers are normally retired from another job, and enjoy working the more limited hours for the community bus service.

Service promotion and marketing for the City of Miramar have been in the form of the city's website that posts schedules and maps of the respective routes, brochures given to seniors, and continued meetings with residential condominium communities to discuss the service. The service promotion efforts have also included advertisements by direct mailing and schedules available all over the city. The city prides itself on serving the needs of the community with the highest quality for all social services provided. Accordingly, the City of Miramar adheres to a standard of service and sets guidelines ensuring that the fleet is maintained on a schedule conducted by the city's maintenance division, and that buses are kept clean. In addition to standards for the buses, operators are required to become certified by BCT which involves training in defensive driving, bus maneuvering, passenger relations, emergency procedures, and accident procedures. Ms. Freedman believes that these efforts have attracted higher ridership, especially as there has been growth in population, reinforcing the need for transit services. The service had passengers per revenue hour growth of $63 \%$ on the Red Route and $13 \%$ on the Green Route during 2002-2004.

Feedback was provided via surveys of passengers and bus operators. A total of eight passengers responded to questions about reliability, future areas for service improvements, service awareness, and rating the service. In terms of frequency of use of the shuttle system, five passengers indicated they were daily riders and the rest used the service twice a week. These 
riders utilized the service to get to work (62.5\%), to school (25\%) and the rest for shopping (12.5\%). The passengers surveyed found the drivers to be customer service oriented and helpful in terms of route schedules, connections within the system, and information about BCT transfers. The passengers surveyed were asked to provide an overall assessment of the service considering all service elements (wait times, reliability, comfort etc.). The average from the eleven respondents on a ten-point scale was 8.56. This revealed preference survey serves as a point of comparison for a survey conducted by the City of Miramar in 2003.

In 2003, the City of Miramar conducted a Community Bus Survey to determine the age demographics, frequency of usage patterns and overall service ratings of its passengers. Based on the 61 surveys returned, $19 \%$ are under the age of $18,14 \%$ are between the ages of $19-60$ and $67 \%$ are over 60 years old. The frequency of ridership question revealed that $26 \%$ of the riders use the shuttle bus one time per week, 37\% use it 2-3 times a week, and 37\% use it more than 3 times a week. The trip purpose characteristics question of the shuttle bus illustrated that $16 \%$ of the riders used the shuttle bus for school, $12 \%$ used it for work, and $72 \%$ used it for pleasure. An overall satisfaction rating assessed by the respondents of the shuttle bus service showed that $51 \%$ of the riders found the service to be rated as excellent, $42 \%$ rated it as good, and $7 \%$ rated the service as fair.

The bus operators were also asked to provide feedback about the service. The operator on the Green Route indicated that he had been with the system for thirteen months. In a rough estimate of the trip purpose characteristics, the operator indicated that approximately $15 \%$ of the users were seniors whose main purpose was shopping. Commuters were estimated to be $35 \%$ of the riders and students comprised 50\%. The operator indicated that riders had expressed the desire to have reduced headway times by adding more buses to the routes. The bus operator on the Red Route indicated that he had been with the system for two months. His estimate of trip purpose and rider demography was that approximately $25 \%$ of the users were seniors whose main purpose was shopping, commuters were estimated to be $25 \%$ of the riders, and students comprised $50 \%$ of the riders. The operator stated that route expansion and more frequent service would certainly improve levels of service to the community. Some unique features noted onboard were that the drivers used cell phones provided by the bus system as a means of communication, and a sign was posted clearly stating that drivers were not permitted to accept tips.

It is interesting to note that the bus operators' reflections on the demographics of system users are very different from the results of the city's survey conducted in 2003, and from the minimal surveying done by CUTR while on two trips. It is possible that conditions have changed since 2003, or that the surveys were not done thoroughly enough to ensure a complete representation of ridership. Ms. Friedman indicated that their municipal circulator services have had lots of issues with teenage passengers, particularly from a middle school located along one of the routes. There have been incidents of vandalism of seats by the students, and a concern for the safety of the operator if there are kids with instruments that can slash seats. As a result, Miramar has installed security cameras on their buses. As was the case with Cooper City and Lauderdale Manors, Miramar was experiencing crush loads of students on certain trips. The city uses a spare bus in the morning to carry the overflow of students that the system carries on one of the runs each morning. This is made necessary due to the city's policy to not allow standees 
while the bus is in motion. The city is self-insured, has experienced accidents with its local circulators, and by requiring everyone to be in a seat, the city believes it is minimizing the possibility of claims against it in the event of future accidents.

The outlook for success of the service in the future looks promising with growth in the population that might use transit. Ms. Friedman noted that the availability of the community circulator helps relieve pressure from the city's paratransit service that is provided to its seniors. This not only helps to keep the cost of such services as low as possible, but also gives the seniors who were using the paratransit service more independent mobility to get around the city. The City of Miramar has future plans to expand service to accommodate for a new developing area of the city near $186^{\text {th }}$ Street and $67^{\text {th }}$ Avenue that will serve as a neighborhood transit hub with connections to BCT routes.

Table 2.1 - Average Ridership per Hour for the Miramar Circulator Service

\begin{tabular}{|l|c|c|c|c|c|c|c|c|}
\multicolumn{9}{|c}{$\mathbf{2 0 0 1}$} \\
\hline MONTH & Green & Red & Green & Red & Green & Red & Green & Red \\
\hline January & n/a & n/a & 8.33 & 2.56 & 8.54 & 5.27 & 10.11 & 8.16 \\
\hline February & n/a & n/a & 8.47 & 4.26 & 9.40 & 5.88 & 10.58 & 7.99 \\
\hline March & n/a & n/a & 8.55 & 3.42 & 11.30 & 5.82 & 11.01 & 8.50 \\
\hline April & n/a & n/a & 8.82 & 3.79 & 10.21 & 4.86 & 9.59 & 6.73 \\
\hline May & n/a & n/a & 8.94 & 4.66 & 11.75 & 5.79 & 11.86 & 9.22 \\
\hline June & n/a & n/a & 6.43 & 3.72 & 8.02 & 5.09 & 8.13 & 6.18 \\
\hline July & n/a & n/a & 4.58 & 3.24 & 5.40 & 4.77 & NA & NA \\
\hline August & 5.64 & 0.34 & 5.82 & 4.42 & 5.95 & 5.37 & NA & NA \\
\hline September & 7.22 & 0.53 & 7.96 & 5.11 & 10.88 & 6.91 & NA & NA \\
\hline October & 8.84 & 0.51 & 8.69 & 5.43 & 11.90 & 7.70 & NA & NA \\
\hline November & 7.83 & 0.53 & 8.96 & 5.90 & 11.58 & 8.63 & NA & NA \\
\hline December & 7.31 & 0.93 & 7.71 & 5.64 & 9.89 & 8.38 & NA & NA \\
\hline Averages & 7.368 & 0.568 & 7.77167 & 4.34583 & 9.56833 & 6.20583 & 10.2133 & 7.80 \\
\hline $\begin{array}{l}\text { Standard } \\
\text { Deviation }\end{array}$ & 1.160978 & 0.217532 & 1.41292 & 1.041463 & 2.20388 & 1.363561 & 1.282196 & 1.135018 \\
\hline
\end{tabular}




\section{$\underline{\text { Lauderhill }}$}

The City of Lauderhill has a total land area of 7.3 square miles and a population of 57,274 residents. Using a quarter mile buffer zone along the Lauderhill Circulator System, an effective land area of 8.96 square miles was measured along with a population of 73,289, resulting in a population density of 8,179 persons per square mile. In the quarter mile buffer zone, the median household income is $\$ 32,070$. There are 33,651 total housing units in the zone. In terms of people by demographic profiles likely to utilize transit services, the elderly segment of the population is 18\%. In the Lauderhill Circulator service area there are 18,218 total owneroccupied units and 11,218 renter-occupied units. Of the owner-occupied units, 9.9\% have no car and $50 \%$ have one car in the household. In the renter-occupied housing units, $12.1 \%$ have no car and $32.3 \%$ have one car. Route level analysis was conducted for this system as described below.

Using a quarter mile buffer zone along Route 1 and Route 5 within the Lauderhill Circulator System, an effective land area of 2.34 square miles was measured along with a population of 23,300 resulting in a population density of 9,944 persons per square mile. In the Route 1 and Route 5 quarter mile buffer zone the median household income is $\$ 26,078$. There are 9,801 total housing units in the zone. In terms of people by demographic profiles likely to utilize transit services, the elderly segment of the population is $18 \%$ and the student-aged segment of the population is $12 \%$. There are 5,641 total owner-occupied units and 4,159 renteroccupied units. Of the owner-occupied units, $15 \%$ have no car and $54 \%$ have one car in the household. In the renter-occupied housing units, 20\% have no car and 56\% have one car.

Using a quarter mile buffer zone along Route 2 within the Lauderhill Circulator System, an effective land area of 2.38 square miles was measured along with a population of 28,623, resulting in a population density of 12,016 persons per square mile. In the Route 2 quarter mile buffer zone, the median household income is $\$ 34,671$. There are 9,668 total housing units in the zone. In terms of people by demographic profiles likely to utilize transit services, the elderly segment of the population is $9 \%$ and the student-aged segment of the population is $14 \%$. In the Route 2 buffer zone area there are 4,456 total owner-occupied units and 5,212 renter-occupied units. Of the owner-occupied units, $9 \%$ have no car and $47 \%$ have one car in the household. In the renter-occupied housing units, 22\% have no car and $48 \%$ have one car.

Using a quarter mile buffer zone along Route 3 within the Lauderhill Circulator System, an effective land area of 3.07 square miles was developed along with a population of 19,271, resulting in a population density of 6,281 persons per square mile. In the Route 3 quarter mile buffer zone, the median household income is $\$ 32,070$. There are 9,385 total housing units in the zone. In terms of people by demographic profiles likely to utilize transit services, the elderly segment of the population is 32\% and the student-aged segment of the population is $7 \%$. In the Route 3 buffer zone area there are 6,773 total owner-occupied units and 2,611 renter-occupied units. Of the owner-occupied units, $11 \%$ have no car and $58 \%$ have one car in the household. In the renter-occupied housing units, 19\% have no car and 54\% have one car.

Using a quarter mile buffer zone along Route 4 within the Lauderhill Circulator System, an effective land area of 2.97 square miles was measured along with a population of 17,619, 
resulting in a population density of 5,924 persons per square mile. In the Route 4 quarter mile buffer zone the median household income is $\$ 35,811$. There are 7,484 total housing units in the zone. In terms of people by demographic profiles likely to utilize transit services, the elderly segment of the population is $23 \%$ and the student-aged segment of the population is $10 \%$. In the Route 4 buffer zone area there are 5,133 total owner-occupied units and 2,350 renter-occupied units. Of the owner-occupied units, $7 \%$ have no car and $47 \%$ have one car in the household. In the renter-occupied housing units, $22 \%$ have no car and $49 \%$ have one car.

The City of Lauderhill operates its fare-free community shuttle system as part of a mandate to "increase the number of destinations within town limits that can be reached through public transit”. The days and hours of operation for Route 1 is Monday to Friday from 6:30 a.m. to 6:55 p.m. For Routes 2, 3, and 4 the hours of operation are from Monday to Friday from 6:30 a.m. to 6:25 p.m., and for Route 5 from Monday to Friday from 8:45 a.m. to 8:45 p.m. The headway time for Routes 1, 3, 4, and 5 is forty-five minutes, for Routes 2 it is half an hour. The system's five routes connect residents to banks, community centers, major shopping centers, a medical center, and a major BCT transfer station. Connections can be made with nine different BCT routes at various points around the city, as well as with the community bus routes of Lauderdale Lakes, Plantation, Tamarac, and Sunrise. The service began operations in October 2001 and has since expanded and improved tremendously with the fifth route being added in November 2003. The service had a fiscal year 2004 estimated cost of \$492,214 (\$30 per revenue hour with 16,449.6 revenue hours) for all routes, with BCT covering $\$ 20$ per revenue hour $(\$ 328,992)$. Therefore, BCT covers about two-thirds of the total operating cost and the City of Lauderhill covers the remaining third.

Mr. Kurt Blaides, Transportation Coordinator for the City of Lauderhill, Division of Parks and Leisure has oversight duties for the service that began in 2001. The initial route design was organized by Earl Hahn, the Planning and Zoning Director. He indicated that travel times and patterns of Lauderhill residents, along with areas of high land use densities, were the instrumental variables that shaped the initial route design during consultations with BCT. Another critical factor during the route design stage was major trip attractors. These include shopping centers, medical centers, the post office, and other such facilities that residents and employees want to access.

The city values customer satisfaction highly and provides an opportunity for passengers to voice their opinions. The customer feedback mechanism involves the listing of a telephone number for patrons to call and express either satisfaction or dissatisfaction with the service. Concerns are also fielded at public hearings. These complaints are then investigated and the appropriate action is taken to ensure a professional customer-service oriented service is delivered to patrons. Mr. Blaides splits his work time between management of the Lauderhill Paratransit System and the Lauderhill Community Bus Service. He estimates that half of the time he spends on the Lauderhill Community Bus Service is in addressing patron complaints, of which 20\% involve phone conversations and 30\% doing field queries into these incidents. Service promotion efforts involve brochures with schedules and maps in both printed form and electronic versions on the website, and advertisements in local periodicals. Initially service awareness efforts included advertisements on the local television station. The growth in passengers per revenue hours has been 25\% for Route 1, 32\% for Route 2, 37\% for Route 3 and 5\% for Route 4 . 
The City of Lauderhill has hired a private contractor, Limousines of South Florida, to operate the shuttle service. The contract between the city and the contractor clearly states the terms for constant maintenance of vehicles, regular inspections, the availability of back-up buses ready to be placed in service, and cleanliness of the shuttles. The relationship between Limousines of South Florida and the City involves weekly meetings with the contractor's onsite supervisor as well as requested consultations when level of service issues have been raised by patrons. The community bus service is heralded as one of the critical services the city provides. The Mayor is Chairperson of the Broward MPO and a strong supporter of public transit. Mr. Blaides believes that if there was an absence of BCT funding, the service would probably still be provided with cut-backs in headway times and hours of operation.

The site visit also sought feedback from passengers and bus operators. On Route 1, a total of four passengers responded to questions about reliability, future service improvements, service awareness, and an overall rating of the service. Passengers indicated their frequency of usage as follows: two (50\%) indicated they were daily riders, one (25\%) used the service twice a week and one (25\%) used the service three times a week. All the riders on this route utilized the service to go shopping between the Lauderhill Mall and the Shoppes of Inverrary. The passengers surveyed found the drivers to possess good customer service skills, being helpful in terms of route schedules, connections within the system, and information about BCT transfers. The survey of passengers asked for an overall assessment of the service considering all service elements (wait times, reliability, comfort, etc.). The average from the four respondents on a tenpoint scale was 9.63.

On Route 5, a total of four passengers responded to questions about reliability, future areas for service improvements, service awareness, and an overall rating of the service. Passengers indicated their frequency of usage as follows: two (50\%) indicated they were daily riders, one (25\%) used the service twice a week and one (25\%) used the service three times a week. In terms of trip purpose, two riders were headed to work and the other two were shopping at either the Lauderhill Mall or the Shoppes of Inverrary. The passengers surveyed found the drivers to possess good customer service skills, being helpful in terms of route schedules, connections within the system, and information about BCT transfers. The survey of passengers asked for an overall assessment of the service considering all service elements (wait times, reliability, comfort, etc.). The average from the four respondents on a ten-point scale was 9.75.

On Route 3, a total of seven passengers responded to questions about reliability, future areas for service improvements, service awareness, and an overall rating of the service. Passengers indicated their frequency of usage as follows: one $(14.28 \%)$ indicated that he was a daily rider, three $(42.8 \%)$ riders used the service four times a week, one (14.28\%) rider used the service three times a week, and two (28.57\%) used the service twice a week. All the riders on this route utilized the service to go shopping between the Lauderhill Mall and the Shoppes of Inverrary. The passengers surveyed found the drivers to possess good customer service skills, being helpful in terms of route schedules, connections within the system, and information about BCT transfers. The survey of passengers asked for an overall assessment of the service considering all service elements (wait times, reliability, comfort, etc.). The average from the four respondents on a ten-point scale was 9.14. 
On Route 4, a total of six passengers responded to questions about reliability, future areas for service improvements, service awareness, and an overall rating of the service. Passengers indicated their frequency of usage as follows: two (33.33\%) indicated that they were daily riders; one rider was a first time rider and had no defined usage pattern. The other three (50\%) riders were infrequent users (once a month, once a week). In terms of trip purposes, two riders were heading to the hospital and the others were either connecting to the Tamarac Community Shuttle System or going shopping to Target. The passengers surveyed found the drivers to possess adequate customer service skills, being helpful in terms of route schedules, connections within the system, and information about BCT transfers. The survey of passengers asked for an overall assessment of the service considering all service elements (wait times, reliability, comfort, etc.). The average from the four respondents on a ten-point scale was 8.75.

On Route 2, a total of five passengers responded to questions about reliability, future areas for service improvements, service awareness, and an overall rating of the service. Passengers indicated their frequency of usage as follows: three (60\%) reported being daily riders, one (20\%) rider used the service between two and three times a week, and the last user (20\%) used it once a month. In terms of trip purposes, three riders were commuting to work, one rider was going to visit a friend, and the last rider was going shopping. The passengers surveyed believed that the drivers to possess good customer service skills being helpful in terms of route schedules, connections within the system, and information about BCT transfers. The survey of passengers asked for an overall assessment of the service considering all service elements (wait times, reliability, comfort, etc.). The average from the four respondents on a ten-point scale was 9.7.

The bus operator on Route 1 was asked to provide feedback about the service. The operator on Route 1 reported being with the system for over two years and had gained experience on all five routes within the system. In a rough estimate of the trip purpose characteristics, the operator indicated that approximately $50 \%$ of the users were seniors whose main purpose was shopping, doctor's visits and other errands, and students constituted the other 50\% (Lauderhill High School and Elementary School). The operator noted that a suggestion for improvement would be a means to eliminate the rampant lack of respect by certain patrons for others. On Route 5, the operator reported that he had been with the Lauderhill Shuttle System for approximately six months. In a rough estimate of the trip purpose characteristics, the shuttle operator indicated that approximately $35 \%$ of the users were seniors whose main purpose was shopping, doctor's visits, and other errands. Commuters were estimated to comprise $45 \%$ of all passengers and students comprised $20 \%$ of the riders. The operator expressed that other drivers needed to be better trained and reported that certain patrons had indicated their desire to see a more efficient schedule and the addition of weekend service. On Route 3, the operator reported that he had been with the Lauderhill Shuttle System for approximately three months. In a rough estimate of trip purpose characteristics, the shuttle operator indicated that approximately $30 \%$ of the users were seniors whose main purpose was shopping, doctor's visits, and other errands. Commuters were estimated to be $50 \%$ of all passengers and students comprised $20 \%$ of the riders. A key factor for success of a regional transit network is the facilitation of transfers. The driver reported that $30 \%$ of the riders came from the BCT system and the other $70 \%$ used the service for intra-city transportation within Lauderhill. On Route 4, the operator reported that he had been with the Lauderhill Shuttle System for approximately a year and a half. In a rough 
estimate of trip purpose characteristics, the shuttle operator indicated that approximately $15 \%$ of the users were seniors whose main purpose was shopping, doctor's visits, and other errands. Commuters were estimated to be $25 \%$ of all passengers and students comprised $60 \%$ of the riders. The driver reported that $20 \%$ of the riders came from the BCT system and the other $80 \%$ used the service for intra-city transportation within Lauderhill.

Currently, a major challenge to the Lauderhill Community Service is security. Recent incidents involving younger patrons who have been unruly has threatened the safety of other riders. In response to this issue, the city is in the process of installing security cameras onboard its buses to help minimize the likelihood that passengers will engage in uncivil behavior. The city has used police officers to ride on the bus, and if a student is found to engage in any destructive behavior, the city contacts the parents and requires the parents to pay for any damage expenses. Another issue involving students are the crush loads that they cause around the time school lets out. This becomes more of a challenge due to the city's policy to not allow standees on the bus. Needless to say, the competition for limited seats can cause pushing and shoving. In fact, according to Mr. Blaides, students have even been know to stand in front of a full-capacity bus to prevent it from moving unless they are allowed on the bus. The city has asked deputies from the Broward Sheriff's Office to monitor the boarding activities at such sites, but they are not always available to do so.

Otherwise, Lauderhill's Community Bus Program has enjoyed great success in its goals to provide mobility opportunities to its citizens and those who travel throughout the city. In fact, the city enjoys the highest ridership per mile of all cities in the program, and hopes to expand service in the future to include weekend hours and later evening hours. 


\section{Meeting with Broward County Transit Staff}

The principle investigators of this report met for three hours with the county staff that manages the community bus program. The main objective was to first brief the staff of Broward County Transit (BCT) on the preliminary findings of this study. The information that was shared outlined the methods being employed to complete the study including the census data analysis (income, vehicle ownership, and transit utilization factors), GIS analysis (quarter-mile buffer zones around routes), passengers per revenue hour analysis, and the on-site visits (passenger, bus operator, and service administrator surveys). Another objective of the meeting was to gather BCT's expectations for the community shuttle systems in terms of performance, operations, service delivery, management techniques, and marketing efforts.

Discussions during the meeting led to the issue of BCT's experience with the cities conducting services in-house versus contracting out to a third party. BCT expressed that the accuracy of data reported by cities with third party contractors had recently become a central issue. BCT staff noted that the cities that provide transit services with their own personnel have more control over the services and data gathering. BCT indicated that as a part of their technical assistance to the cities, workshops are held that provide maintenance guidelines and instructions for operations, customer relations, safety, and rules of the road.

BCT evaluates the quality of the various community bus systems by using a "ghost rider" program conducted by PMG Associates, Inc. to rate the level of service delivered to patrons. The ratings for the cities being reviewed for this study averaged 3.1 out of five possible points. The criteria used for evaluation is based on the drivers degree of attention, ability to show valid identification, avoidance of cell phone use, bus cleanliness, schedule reliability, and the drivers' resourcefulness to passengers in answering questions. There is no customer service feedback gained directly from passengers to determine their perception of the quality of service as a part of this survey. It is interesting to note that CUTR's surveying of passengers, though limited, resulted in customer satisfaction ratings much higher than PMG's evaluation might suggest. The cities are required to submit operations costs, invoices, driver logs, complaint reports, and other supplementary documents on a quarterly basis.

BCT serves as a primary source of funding for these community shuttles. The County provides well over fifty percent of the funds necessary to operate the service. In addition, BCT provides spare buses, marketing assistance where needed to boost ridership, and other technical assistance. In Cooper City, low performance during FY 2001 led to marketing (direct mail to new and existing residents by South Florida Commuter Services) and route design improvements that resulted in increased passengers per revenue hour (6\%-9\%). Broward County Transit has requested an additional $\$ 750,000$ from general revenue sources to fund more community bus shuttles. Municipalities have requested over $\$ 1$ million for new circulator services. Approximately $\$ 400,000$ has been approved. These requests are submitted to the Community Bus Service Evaluation Committee comprised of members from the Broward Alliance, Broward MPO, Broward County Transit, Broward League of Cities, Broward County Commission, and The City/County Manager Association. 
The Committee reviews a city's new request for service based on prior performance (operational costs, passengers per revenue hour) of other routes, connections to BCT and to other cities, equity considerations, and requests from areas applying for service for the first time. A key stipulation in the interlocal agreements between the county and the city is that there be no route deviation service, since paratransit service is available in the cities. Whether this is truly the best way to operate is subject to question, but the rationale of the county is that they want to avoid any practice that could cause the local circulator to fall off its schedule and miss its connections with the regional system or with other local circulator services. The County believes the existing county-wide paratransit service can accommodate those with disadvantages or disabilities who find it difficult to access the circulator route. 


\section{CHAPTER 3- LITERATURE REVIEW}

Current studies on the subject of local circulators were reviewed and the following was drawn from the literature. A study conducted in Miami-Dade County entitled, "The Local

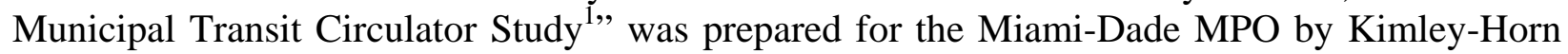
and Associates. In this report, the operational guidelines for a successful circulator system are outlined. The benefits of a circulator noted by the study are easing traffic congestion by providing an alternative to the private single occupancy vehicle and providing transportation opportunities for a number of mobility-deprived citizens (e.g., senior citizens, indigent/low income members of the community). The study's objectives were to "develop a set of guidelines and standards for establishing local transit circulators and to develop measures of effectiveness (MOE) for evaluating theses services". The methodology employed to achieve these goals was through data collection and research (review of recent studies and development of a local circulator database), surveys of county and municipal staff to measure levels of interest in establishing local transit circulators, and to identify issues that may factor into establishing such services.

The data analysis stage involved reviewing the database of circulators gathered from existing systems in Miami-Dade, Broward County, one in Orlando, and one from Illinois. The study identified conditions and characteristics that may be a prerequisite to establishing such services. This analysis led to the development of procedures for developing and monitoring the performance of local transit circulators. The study included findings of a survey of local circulator managers that the climate for a feasible circulator system includes high-density populated areas with mixed uses and a target population of riders that includes seniors, students and low-income workers. The percentage of rental housing in a community is another significant indicator of transit dependency noted from the results of the survey. Circulator service was found to be more widespread in higher-income municipalities due to their ability to have sufficient funds to subsidize the service, even though the need for circulators might be greater in lower income communities.

The study involved collecting data from the various communities and transit operators with existing circulator systems in the Miami-Dade and Broward County area as well as one in Orlando and one in Niles, Illinois. The study gathered socioeconomic, operational and geographic characteristics, and identified funding sources for local transit services. The intent was to understand the conditions from which to develop the measures of effectiveness (MOE). The socioeconomic characteristics included total population, household income, homeownership (measured by percentage of rental housing within the community) and age cohorts (to determine percentage of population over 65 years old). In geographic characteristics, a key factor in assessing the need for transit service was land use patterns. A mixture of residential and nonresidential land uses facilitates transit usage by having clear trip origins and destinations within close proximity. Operational characteristics compiled for these communities included the number of circulator routes, service span (service days of the week and hours of operation), headways (measure of service frequency), fares, and vehicle types (number of seats). System characteristics looked at how well the circulator was linked to the main regional transit system and the ease in the ability for riders to transfer. Funding sources for transit circulators were mainly general municipal, county, state and federal programs. Not surprisingly, the operating 
revenues were found to be unable to fully cover operating cost, hence the need for additional funding.

The local circulator systems in Miami-Dade County included, The "Aventura Advantage”, a service that was contracted out to Coach USA at a cost of \$36 per hour. The Aventura Advantage serves condominiums and provides access to shopping destinations, government facilitates, and the local hospital. The service operates on Monday through Friday, from 8:45 am to 6:20 pm and from 8:45 am to 9:20 pm on Saturday. As a neighborhood circulator, it meets the needs of a community with a high elderly population (35.2\%) while providing adequate connection to the regional transit system (Miami-Dade Transit and Broward County Transit) at the Aventura Mall. The service is fare-free. The next circulator in MiamiDade examined was in Bal Harbor. This service also provides fare-free mobility to riders and is operated between 9 am and 1 pm on Mondays, Wednesdays and Fridays. The population of seniors is similar to Aventura (37.5\%) and operates on 60 minute headways. The Brickell circulator operated through MDT has emerged due to recommendations made in the Miami Surface Shuttle Services: Feasibility Study for Transit Circulator Services in Downtown Miami, Brickell, Overtown and Airport West prepared by the Center for Urban Transportation Research. The circulator system implemented in 2001 was financed by federal Job Access and Reverse Commute funds and serves employment centers and multi-family residences in the Brickell neighborhood south of Downtown Miami. The service is provided every fifteen minutes from 6:30 am to $7 \mathrm{pm}$ five days a week. The circulator fare is \$0.25 and has approximately 200 passengers per day. Hialeah, one of the more populous communities in Miami-Dade County was on the verge of implementing a circulator at the time the report was being prepared. The service is intended to serve recreational spots, industrial parks, and government centers. The proposal is for two routes to operate on thirty-minute headways from 6 am to $9 \mathrm{pm}$ during the week and 9 am to $5 \mathrm{pm}$ on weekends, with route design fostering smooth links to the regional transit system (Metrobus, Metrorail and Tri-Rail).

The Miami Beach "Electrowave" circulator service uses electric buses to serve the transportation needs in the South Beach area with headways of approximately ten minutes and a fare of $\$ 0.25$. The "Electrowave" initially provided service designed to attract patrons to the nightlife on South Beach by running until 4 a.m. However, it was discovered through passenger surveys that the primary users were residents who preferred riding over walking or driving short distances. The service is operated by the Miami Beach TMA and funded by FDOT, Miami-Dade MPO, and the City of Miami Beach. In its six years of operation, ridership has been as high as 35 passengers per revenue hour but now operates at a level of approximately 18 per hour. The change in fare from free to $\$ 0.25$ had a major impact on ridership as did reliability problems due to the insufficient maintenance of the electric buses. North Bay Village, another Miami-Dade community operates a circulator service to serve the shopping needs of its residents, though the population of seniors who are seemingly targeted is significantly lower than the other MiamiDade communities examined. With only $12.1 \%$ seniors, it attracts four to six riders daily. The North Miami Beach circulator serves condominiums, shopping centers, commercial centers and restaurants in the area. Although the senior population is only $11.3 \%$ of the city, the service is geared towards serving the needs of the elderly. The hours of service are 8:30 am to 4:30 pm from Monday to Friday. The service is contracted out to Handi-Van. The company provides 15seat handicap-accessible vans with financing provided by the city's general fund. Sunny Isles 
Beach operates a free circulator service that links residents to shopping centers and to the main regional system (Metrobus), using one fixed-route with two minibuses. The service operates weekly during regular business hours at thirty-minute headways. The last community examined in the study was Surfside which operates a circulator free of charge to local residents, with thirtyminute headways. The senior share of the population is $25 \%$. The service gives access to shopping centers and area beaches. Funding is provided from the municipal government.

The local circulators from Broward County are similar in terms of funding, headway, and target populations (elderly, students, and low income) but meet the needs of various distinct communities. The report notes that the Broward County Transit (BCT) Community Bus Program specifically allocated $\$ 20,000$ annually to each participating city per vehicle to provide circulator services to the respective communities. Since the completion of this report by Kimley-Horn, Broward County changed its method of funding circulators managed by municipalities. Since FY 2002, Broward County has reimbursed cities at a rate of $\$ 20$ per revenue hour, which represents a substantial increase in financial support. In addition, the County provides $\$ 12,000$ per vehicle if the city is using a vehicle not leased from the County to provide community bus service. This also encourages cities to provide more hours of service. The County provides vehicles, administrative and technical support, and bus stop signs. The vehicles must be in operation a minimum of forty hours per week and there are requirements for local circulators to maintain a minimum ridership standard of five passengers per revenue hour. The first community examined in the report was Coconut Creek. It operates a free circulator with ninetyminute headways between regular business hours during the week and provides links to BCT. Coconut Creek has two minibuses that cost between $\$ 50,000$ and $\$ 70,000$ annually to operate. Funding comes from the City, BCT and CMAQ funds. Ridership was approximately 10 passengers per revenue per hour (19,700 passengers for 1,902 revenue-hours). Cooper City operates a transit circulator that is also involved with the BCT Community Bus Program. It has forty-five minute headways and operates during the week through Saturday, and no fare is charged. The circulator route is strategically designed to link to BCT and the town of Davie. The senior share of the population is $6.7 \%$ and the goal is to permit residents' access to shopping facilities. The total cost annually is $\$ 47,000$, which includes maintenance, operating, and labor. The county provides $\$ 20,000$ per annum while the City's Division of Health and Social Services fund the remainder. The service carried 4.5 passengers per revenue hour in the year 2000 . The Town of Davie also operates a free transit circulator that is a part of the BCT Community Bus Program. The Town has a relatively small (9.4\%) senior share like Cooper City relative to many communities in Broward County. The circulator provides a connection to BCT routes and the Cooper City circulator. The cost of operation is $\$ 28$ per hour per route charged by A+ Transportation. Fort Lauderdale has six uniquely designed circulator routes that provide access for residents to many attractions around downtown Ft. Lauderdale offices, the beaches, and to the BCT Terminal, Tri-Rail, and park-ride lots. The routes vary in headway times from fifteen minutes on the TMAX Downtown Business Route to thirty minutes for the TMAX weekend route. The service is operated by a contract with Laidlaw and operating costs are approximately \$37.00 per hour. The Lauderdale Lakes area, also operated by A+ Transportation, provides service to shopping centers, medical, and recreational facilities. The circulator system has headways of forty-five minutes and the cost is \$28 per hour. 
The Margate circulator is operated as part of the BCT Community Bus Program and has four routes that serve the needs of local residents providing strategic access to employment, shopping, and residential sites. The Margate circulator has connections to the Coconut Creek circulator at the Margate Terminal and carries approximately 14 passengers per revenue hour. Miramar, another Broward County community, has a neighborhood circulator with two routes that provide service to residents giving them ample access to shopping centers, the civic center, a senior center, and a hospital. The senior share is $6.3 \%$ of the total population. A fare of $\$ 0.25$ is charged and ridership is approximately 5.5 passengers per revenue hour. In Pembroke Pines, the circulator provides access to shopping centers and medical facilities, serving the second largest city in Broward County. There are two routes that operate on forty-five minute headways. A fare of \$0.50 is charged for service that provides links to BCT and the Miramar circulator. The total operational costs were $\$ 200,000$ for the year 2000 with $\$ 60,000$ (30\%) contributed from the BCT Community Bus Program and the remainder funded through fare collection and city funds. The service carried four passengers per revenue hour. Sunrise, another Broward County city, operates a circulator that is not funded by the BCT Community Bus System. It operates six routes on headways varying from forty-five to sixty minutes, transporting residents to shopping and medical facilities. The service carries eight passengers per revenue hour, utilizing vehicles that have a capacity of twenty-four passengers. Tamarac is the last community in Broward County discussed in the study and is a part of the BCT Community Bus Program. The city has a significantly high senior share of the population at $37.8 \%$. The local circulator operates at headways of 45 minutes and charges a $\$ 0.25$ fare. The service carries only one passenger per revenue hour. The route length and increase in travels times were cited as the primary cause for this low rate.

The study also looked at three transit circulators outside of South Florida. The first examined was the Lynx Downtown Circulator in Orlando, Florida. The "Lymmo" serves employment centers, government centers, shopping, restaurants, and parking garages. The service operates on exclusive lanes using traffic signal preemption capability. It targets commuters who drive into and park downtown, then make their way around downtown via the "Lymmo". There are frequent headways of five minutes. The annual operation costs are approximately $\$ 1.2$ million. The Lymmo carries fifty passengers per hour. There were two Illinois systems examined. The circulator in Downer's Grove, Illinois (a suburb of Chicago) transports residents to and from residential areas to the main train station, operating three routes with 45 minute headways. There is a $\$ 1.25$ fare but a monthly pass can be purchased for $\$ 30$. Fare collections and intergovernmental revenues fund the system. Ridership is about 200 riders per route daily. The other system in Illinois covered by the report is in the Village of Niles (another Chicago suburb) operating a bus that is free to its riders designed specifically to provide access to shopping malls, libraries, schools, and community centers. The service has headways of about forty-five minutes and carries approximately 10 passengers per revenue hour.

TCRP Report 55², “Guidelines for Enhancing Suburban Mobility Using Public Transportation" defined three generic types of local area circulators: fixed-route circulators, route deviation services, and demand response or dial-a-ride services. The study found that fixed-route circulator systems are configured to meet the needs of the community being served and are characterized as being non-linear, connecting multiple origins and destinations in the local area. Such services have short headways given the scope of service and are to serve as 
complementary (feeder/distributor) services in a regional transit network. The second type of service is the route deviation service, where a specific route design is in place though deviations can be made at the driver's discretion. The report defined a range of productivity for route deviation between 4.3 to 11.6 passengers per vehicle hour. In terms of operating costs per passenger trip, Broward County had the lowest with ranges from $\$ 1.86$ to $\$ 3.43$. Service guidelines were evaluated based on some "conditions of effectiveness" developed in the report. These conditions of effectiveness are as follows:

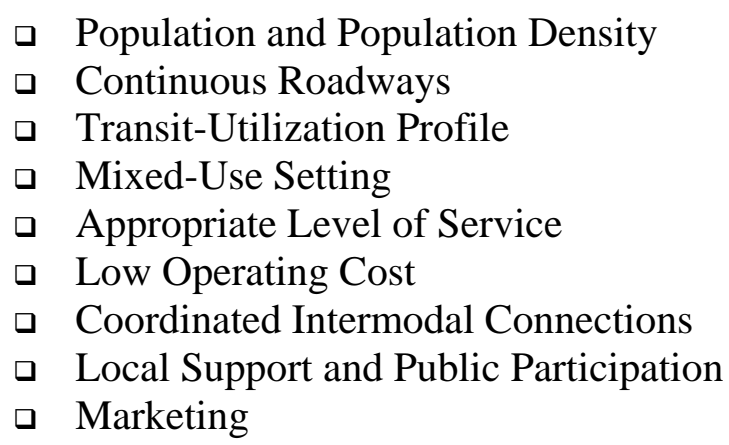

Each distinct measure of effectiveness examines how conducive the environment is for a successful local circulator system. In terms of land use, if helps to have a mix of commercial and residential uses so that there is a need to satisfy mobility requirements between the various functions conducted in these different land uses. A key element to success often not emphasized but captured in the TCRP Report 55, is that of awareness and local involvement. There is vital need for potential users of a service to have full information concerning routes, schedules, and other nuances of service. Extensive cooperation with the parties (local elected officials, city personnel and residents) involved when implementing and operating service is instrumental to success.

In "Suburban Transit Opportunities Study"3, a Boston Regional MPO research project conducted by the Central Transportation Planning Staff, the guidelines for a successful local circulator system are identified via an extensive literature review to examine national as well as state practices, a round-table discussion with Boston-area suburban transit systems, and an analysis of NTD Data on operational costs and case studies (involving passenger surveys). The literature review reflects that previous studies identify the following techniques for success of a suburban transit system:

- A clear focus on adapting transit service to accommodate for possible transit users with "people hubs" or "transit hubs", locating specific sites for transit alighting and boardings.

- Extensive efforts to market the targeted customer/consumer, especially niche specialized transit utilization markets such as elderly and commuters.

a Connections to the regional transit network to ensure efficient and reliable transfers.

a Ensuring cost-effectiveness by determining if there is adequate demand to operate small vehicles

- Include stakeholders in transit and land use planning to ensure transit inclusion in the design stage, especially with strategies for transit oriented development. 
The study in citing TCRP Report 55 notes, "case studies have revealed that planning for suburban transit has been indistinguishable from traditional service planning”, illustrating the lack of uniqueness to suburban systems in terms of methods of evaluation. The traditional methods include a quantitative standard in terms of overall ridership and cost per rider, though these conventional techniques based on cost-benefit grounds provide a challenge for suburban systems that are characterized by small, expensive (relative to transit) operations with low levels of ridership. Further, these systems on equity grounds are geared towards serving the less fortunate in lower density settings incurring relatively high costs in doing so. The study discusses the need for setting service goals (meeting the mobility needs of the community) and objectives for a transparent feedback/evaluation mechanism to complement productivity and cost-benefit reviews. As Alan Black (1995) stated, "people with less mobility have less opportunities to obtain the rewards of life". Hence the local circulator can aid communities in economic development and overall welfare. Researchers such as Minerva (1996) believe that the largest determining factor when marketing services and generating awareness from the niche clientele is the amount of employer support the operator obtains. This support translates into relatively inexpensive marketing with business entities enlightening their employees about the service and with educational and business centers channeling information to students and consumers.

The round-table discussion with Boston-area suburban transit systems identified certain goals such as measuring success, marketing, creating service plans, forming partnerships, and participating in land use decisions. This approach employed in the study was quite successful in that it established dialogue between operators with common goals and facilitated communication for further sharing of information and occasional partnerships that have mutually beneficial outcomes. 


\section{CHAPTER 4- DATA ANALYSIS}

The census data attributes used in this study include median household income, elderly segment of the population, student segment of the population, population density, the number of owner and renter occupied units, and the percentage of renter and owner-occupied units that have either one car or no car. These were hypothesized to be factors that influence transit utilization. The study also explored whether other factors such as marketing efforts, contract management styles, bus operator training and performance, connections to the regional transit network, major trip attractors, fare structure, and equity considerations were also critical factors in ultimate success as measured by ridership per hour. The data below shows the passengers per revenue hour performance of the routes examined in the scope of this study.

\section{Passengers per Revenue Hour Analysis}

The measure of system performance used by Broward County Transit is the number of passengers per revenue hour. The case study sites evaluated report this measure on a route basis every month to ensure compliance with the minimum county standard of five passengers per revenue hour. The table below shows the annual average passengers per revenue hour, the growth rates, the average growth rates, and the average over the four year period and the standard deviations. The chart beneath will show the passengers per revenue hour growth on the routes examined.

\section{Figure 4.1}

\begin{tabular}{|c|c|c|c|c|c|c|c|c|}
\hline Routes & 2001 & 2002 & 2003 & 2004 & $\begin{array}{l}2001- \\
2002\end{array}$ & $\begin{array}{l}2002- \\
2003\end{array}$ & $\begin{array}{l}2003- \\
2004\end{array}$ & $\begin{array}{l}\text { Average } \\
\text { Growth }\end{array}$ \\
\hline Cooper City & 4.5 & 4.8 & 5.2 & 7.4 & $6.67 \%$ & $8.33 \%$ & $42.31 \%$ & $19.10 \%$ \\
\hline Dania Beach & 4.1 & 6.7 & 8.7 & 8.7 & $63.41 \%$ & $29.85 \%$ & $0.00 \%$ & $31.09 \%$ \\
\hline Ft. Lauderdale Manors & 10.8 & 14.8 & 19.5 & 24.7 & $37.03 \%$ & $31.75 \%$ & $26.67 \%$ & $31.81 \%$ \\
\hline Lauderhill-Route1 & & 18.8 & 26.4 & 29.1 & & $40.43 \%$ & $10.23 \%$ & $25.33 \%$ \\
\hline Lauderhill-Route 2 & & 10.7 & 20.9 & 27.7 & & $95.33 \%$ & $32.54 \%$ & $63.93 \%$ \\
\hline Lauderhill-Route 3 & & 6.9 & 12 & 16.5 & & $73.91 \%$ & $37.50 \%$ & $55.71 \%$ \\
\hline Lauderhill-Route 4 & & 6.8 & 16.3 & 17.1 & & $139.71 \%$ & $4.91 \%$ & $72.31 \%$ \\
\hline Lauderhill- Route 5 & & & & 18 & & & & \\
\hline Margate-Route A & & 13.2 & 10.9 & 10.9 & & $-17.42 \%$ & $0.00 \%$ & $-8.71 \%$ \\
\hline Margate-Route B & & & 9.3 & 8.8 & & & $-5.38 \%$ & $-5.38 \%$ \\
\hline Margate-Route C & & & 16.7 & 16.1 & & & $-3.59 \%$ & $-3.59 \%$ \\
\hline Margate-Route D & & & 8.8 & 9.3 & & & $5.68 \%$ & $5.68 \%$ \\
\hline Plantation & & 4.8 & 6.5 & 8.1 & & $35.42 \%$ & $24.62 \%$ & $30.02 \%$ \\
\hline $\begin{array}{l}\text { Coral Springs- Green } \\
\text { Route }\end{array}$ & & & 10.6 & 19 & & & $79.25 \%$ & $79.25 \%$ \\
\hline Coral Springs-Blue Route & & & 7.6 & 12.3 & & & $61.84 \%$ & $61.84 \%$ \\
\hline Miramar Green & 7.4 & 7.8 & 9.6 & 10.2 & $5.40 \%$ & $4.33 \%$ & $6.25 \%$ & $5.32 \%$ \\
\hline Miramar Red & 0.6 & 4.3 & 6.2 & 7.8 & $616.7 \%$ & $44.2 \%$ & $25.8 \%$ & $228.9 \%$ \\
\hline
\end{tabular}


Fig. 4.2

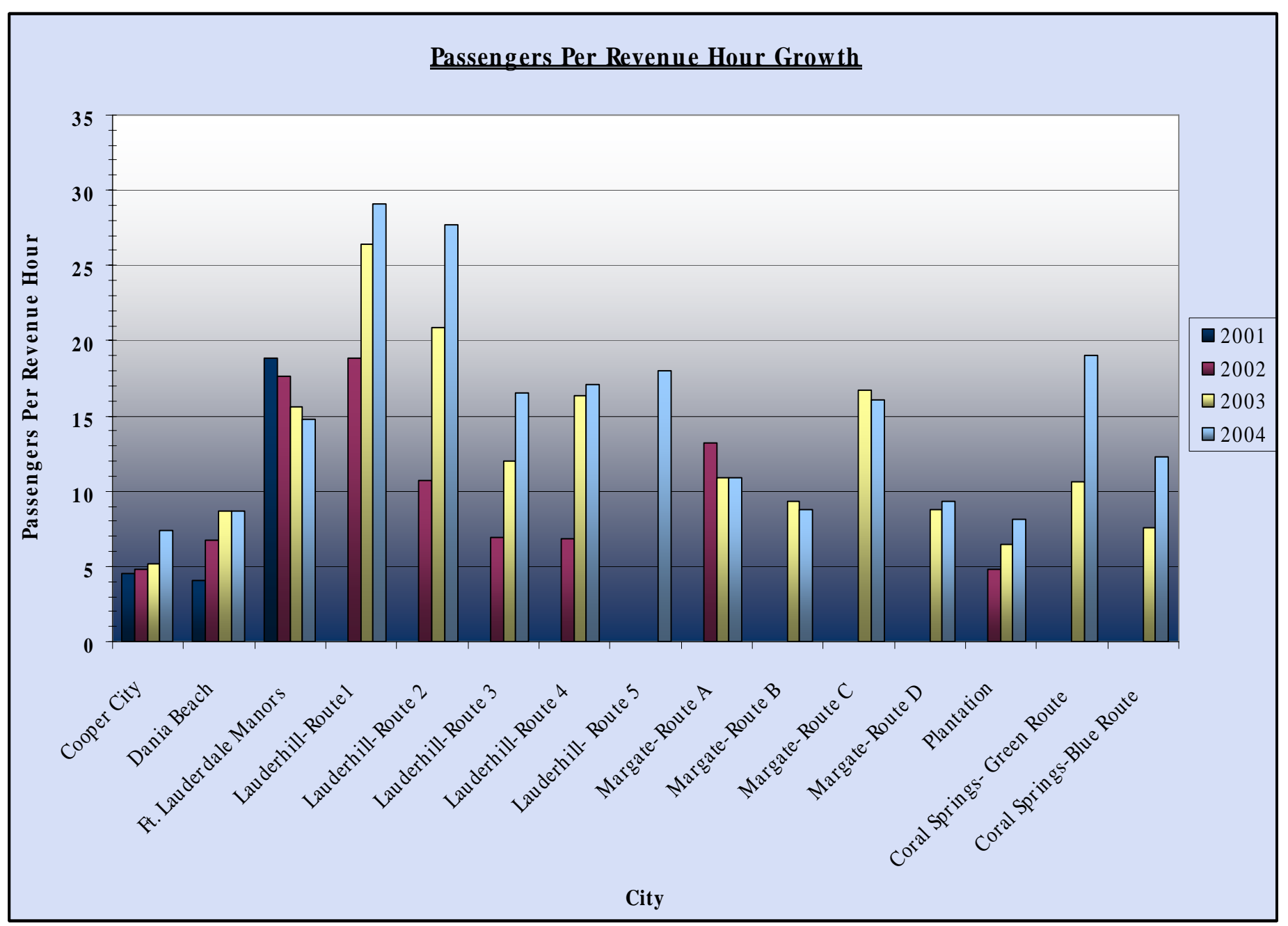




\section{The Correlation between Passengers per Revenue Hour and Transit Utilization $\underline{\text { Factors }}$}

The hypothesized relationships between passengers per revenue hour and such measures as population density, income, the elderly segment of the population, the student-age segment of the population, the number of owner-occupied units, the number of renter-occupied units and car ownership were tested at the route level with data derived from the census blocks which permitted Pearson correlations to be conducted to measure the magnitude and sign of these relationships. The correlation between passengers per revenue hour and income shows clearly that as the level of income declines the passengers per revenue hour rises and this noticeable inverse relationship confirms standard transit utilization theory. The elderly and student age segment are both positively correlated to passengers per revenue hour which also confirms transit utilization, though in this sample set, the relationship is rather minimal to non-significant. However, it is mildly interesting to note that the correlation between student population and transit ridership is stronger than the correlation between elderly and transit utilization. This seemed to be the case in a number of the case studies included in this report. Population density is highly positively correlated to passengers per revenue hour in the routes analyzed, so standard transit utilization theory holds firmly in the local circulator setting as well. Owner-occupied housing units had a mild negative correlation to passengers per revenue hour, showing that as the number of owners rose along the routes examined, it is expected that ridership per hour would decline. The number of renter occupied units was slightly positively correlated with passengers per revenue hour though the magnitude of this relationship is too small to be considered a strong factor. The segment of owner occupied units with no car was strongly correlated to passengers per revenue hour. This finding is again consistent with standard transit utilization theory. The segment of owner-occupied units with one car is also positively correlated with passengers per revenue hour. This might be due to the fact that the owner occupied households with only one car have more people in the household with mobility needs that are not being met with a single car. The segment of renter occupied units with no car is positively correlated with passenger per revenue hour, once again consistent with the notion that the absence of personal transportation, especially in the case of persons renting units, implies transit utilization for many trip purposes. The segment of renter occupied units with one car is slightly negatively correlated with passengers per revenue hour, so as renters get personal vehicles, ridership on the shuttle system would decline. This finding might reflect that renter occupied units have fewer people and less travel demand. The chart and correlation matrix below show the results from the statistical analysis. 
Figure 4.3 Correlation Matrix

\begin{tabular}{|l|l|}
\hline Pass Rev.Hr./Income & -0.57648 \\
\hline Pass.Rev.Hr./Elderly Segment & 0.061163 \\
\hline Pass.Rev.Hr./Student Segment & 0.090209 \\
\hline Pass. Rev.Hr./Population Density & 0.83333 \\
\hline Pass.Rev.Hr./Own-Occupied & -0.39667 \\
\hline Pass. Rev.Hr/Rent Occupied & 0.036481 \\
\hline Pass.Rev.Hr./Own Occupied NoCar & 0.694742 \\
\hline Pass. Rev.Hr./Own Occupied 1 Car & 0.380401 \\
\hline Pass. Rev.Hr./Rent Occupied NoCar & 0.520486 \\
\hline Pass.Rev.Hr./Rent Occupied 1 Car & -0.12368 \\
\hline
\end{tabular}

Figure 4.4 provides information from the U.S. Census that helps compare the demographic nature at all the areas served by the circulator routes reviewed for this report. 


\section{Figure 4.4 Transit Utilization Census Data}

\begin{tabular}{|c|c|c|c|c|c|c|c|c|c|c|c|c|c|c|}
\hline Route & $\begin{array}{c}\text { Transit } \\
\text { Land Area }\end{array}$ & $\begin{array}{l}\text { Transit } \\
\text { Pop. }\end{array}$ & $\begin{array}{c}\text { Pop. } \\
\text { Density }\end{array}$ & $\begin{array}{l}\text { Median } \\
\text { Income }\end{array}$ & $\begin{array}{l}\text { Housing } \\
\text { Units }\end{array}$ & $\begin{array}{l}\text { Owner- } \\
\text { Occ. }\end{array}$ & $\begin{array}{c}\text { Renter- } \\
\text { Occ. }\end{array}$ & $\begin{array}{c}\text { Elderly } \\
\text { Segment }\end{array}$ & $\begin{array}{l}\text { Student } \\
\text { Segment }\end{array}$ & $\begin{array}{c}\text { Avg. } \\
\text { Pass. } \\
\text { Per Hour }\end{array}$ & $\begin{array}{l}\text { Own. } \\
\text { Occ. } \\
\text { No Car }\end{array}$ & $\begin{array}{c}\text { Own } \\
\text { Occ. } 1 \\
\text { Car }\end{array}$ & $\begin{array}{c}\text { Rent } \\
\text { Occ. } \\
\text { No Car }\end{array}$ & $\begin{array}{c}\text { Rent } \\
\text { Occ. } \\
1 \text { Car }\end{array}$ \\
\hline Dania Beach & 3.21 & 10,528 & 3271.6 & $\$ 32,043.00$ & 4,677 & 2,219 & 2,455 & $15.72 \%$ & $9.52 \%$ & 7.05 & $5.41 \%$ & $50.90 \%$ & $19.59 \%$ & $56.13 \%$ \\
\hline Cooper City & 7.8 & 25,897 & 3,317 & $\$ \quad 69,995.00$ & 8,723 & 7,798 & 923 & $7.40 \%$ & $17.00 \%$ & 5.48 & $2.10 \%$ & $23.30 \%$ & $8.30 \%$ & $46.30 \%$ \\
\hline Coral Springs-Blue & 5.1 & 33,053 & 6,477 & $\$ 52,794.00$ & 11,992 & 6,839 & 5,156 & $9.00 \%$ & $14.00 \%$ & 9.95 & $5.00 \%$ & $29.00 \%$ & $14.00 \%$ & $49.00 \%$ \\
\hline Coral Springs-Green & 4 & 27,400 & 6,850 & $\$ \quad 48,137.00$ & 9,858 & 6,884 & 2,978 & $12.00 \%$ & $15.00 \%$ & 14.80 & $6.00 \%$ & $32.00 \%$ & $10.00 \%$ & $45.00 \%$ \\
\hline Lauderdale Manors & 1.98 & 13,085 & 6,542 & $\$ \quad 29,417.00$ & 3,810 & 2,277 & 1,534 & $7.40 \%$ & $18.00 \%$ & 16.70 & $8.00 \%$ & $34.80 \%$ & $32.90 \%$ & $38.60 \%$ \\
\hline Margate-Route A & 3.97 & 23,123 & 5,824 & $\$ 44,243.00$ & 9,537 & 6,868 & 2,673 & $17.00 \%$ & $11.00 \%$ & 11.67 & $7.00 \%$ & $41.00 \%$ & $14.00 \%$ & $46.00 \%$ \\
\hline Margate-Route B & 5.15 & 27,882 & 5,419 & $\$ \quad 42,488.00$ & 12,236 & 9,967 & 2,270 & $25.00 \%$ & $9.00 \%$ & 9.05 & $10.00 \%$ & $47.00 \%$ & $16.00 \%$ & $48.00 \%$ \\
\hline Margate-Route C & 4.99 & 32,615 & 6,535 & $\$ \quad 42,788.00$ & 13,892 & 10,346 & 3,549 & $23.00 \%$ & $10.00 \%$ & 16.40 & $10.00 \%$ & $44.00 \%$ & $12.00 \%$ & $47.00 \%$ \\
\hline Margate-Route D & 3.9 & 22,073 & 5,657 & $\$ 38,128.00$ & 8,349 & 6,384 & 1,964 & $16.00 \%$ & $12.00 \%$ & 9.05 & $9.00 \%$ & $40.00 \%$ & $17.00 \%$ & $48.00 \%$ \\
\hline Plantation-Route A & 7.32 & 36,058 & 4,920 & $\$ 45,272.00$ & 15,276 & 9,798 & 5,479 & $18.00 \%$ & $11.00 \%$ & 6.47 & $7.00 \%$ & $43.00 \%$ & $12.00 \%$ & $53.00 \%$ \\
\hline Plantation-Route B & 6.97 & 34,976 & 5,018 & $\$ 44,805.00$ & 14,662 & 9,374 & 5,288 & $17.00 \%$ & $11.00 \%$ & 6.47 & $7.00 \%$ & $43.00 \%$ & $11.00 \%$ & $54.00 \%$ \\
\hline $\begin{array}{l}\text { Miramar-Green } \\
\text { Route }\end{array}$ & 11.83 & 50,190 & 4,241 & $\$ 45,721.00$ & 17,580 & 12,777 & 4,802 & $12.00 \%$ & $13.00 \%$ & 8.70 & $7.00 \%$ & $34.00 \%$ & $11.00 \%$ & $49.00 \%$ \\
\hline Miramar-Red Route & 6.93 & 41,268 & 5,953 & $\$ \quad 44,787.00$ & 14,209 & 9,713 & 4,498 & $10.00 \%$ & $14.00 \%$ & 5.60 & $6.00 \%$ & $33.00 \%$ & $12.00 \%$ & $49.00 \%$ \\
\hline $\begin{array}{l}\text { Lauderhill-Route } \\
1 / 5\end{array}$ & 2.34 & 23,300 & 9,944 & $\$ 26,078.00$ & 9,801 & 5,641 & 4,159 & $18.00 \%$ & $12.00 \%$ & 24.77 & $15.00 \%$ & $54.00 \%$ & $20.00 \%$ & $56.00 \%$ \\
\hline Lauderhill-Route 2 & 2.38 & 28,623 & 12,016 & $\$ 34,671.00$ & 9,668 & 4,456 & 5,212 & $9.00 \%$ & $14.00 \%$ & 19.77 & $9.00 \%$ & $47.00 \%$ & $22.00 \%$ & $48.00 \%$ \\
\hline Lauderhill-Route 3 & 3.07 & 19,271 & 6,281 & $\$ 32,070.00$ & 9,385 & 6,773 & 2,611 & $32.00 \%$ & $7.00 \%$ & 11.80 & $11.00 \%$ & $58.00 \%$ & $19.00 \%$ & $54.00 \%$ \\
\hline Lauderhill-Route 4 & 2.97 & 17,619 & 5,924 & $\$ 35,811.00$ & 7,484 & 5,133 & 2,350 & $23.00 \%$ & $10.00 \%$ & 13.40 & $7.00 \%$ & $47.00 \%$ & $22.00 \%$ & $49.00 \%$ \\
\hline Averages & 4.94 & 27468.29 & 6128.80 & 41720.47 & 10655.24 & 7249.82 & 3405.94 & 0.16 & 0.12 & 11.60 & $7.74 \%$ & $41.24 \%$ & $16.05 \%$ & $49.18 \%$ \\
\hline Standard Deviation & 2.56 & 10068.31 & 2142.37 & 10305.46 & 3705.22 & 2863.90 & 1464.23 & 0.07 & 0.03 & 5.44 & $2.85 \%$ & $9.26 \%$ & $6.11 \%$ & $4.42 \%$ \\
\hline
\end{tabular}




\section{CHAPTER 5 - CHARACTERISTICS OF A SUCCESSFUL LOCAL CIRCULATOR AND CONCLUSIONS}

This project was undertaken to help determine what factors can significantly contribute to a successful local transit circulator system in a suburban setting. A number of the local circulator services that have been established in Broward County, Florida since 1992 served as the basis for this report. It was undertaken as a synthesis project that included a literature review, GIS/census analysis of demographics around existing circulator routes in Broward County, and site visits to talk with passengers, bus operators, and system managers of eight different local circulator services. Given a very small budget $(\$ 12,000)$, this project could not do in-depth analysis of all the factors that affect transit ridership on circulators. This is in no way an apology for the results of the report. It stands as a very worthwhile synthesis, and identifies more questions that should be asked and answered in future research.

Defining "successful" might ordinarily be cause for debate among transit providers. Every one of the managers of the local circulator systems reviewed would state that their services are successful. They believe they are expanding mobility opportunities within their communities for their residents and for those who work in the businesses of their cities. It is being done at little cost to the passengers and their citizens, and they are providing the service at less than half the cost of regional fixed route transit service. The local circulator routes link to other circulators and the regional transit system, thereby expanding the possibilities for all residents in the county to use transit service. The option of providing local circulators helps free up countywide buses to stay on the major arterials with improved frequency, making regional transit travel more convenient. The local circulators provide opportunities for most of their citizens to access city services and facilities, as well as shopping, recreational, and medical destinations. The availability of these local circulators helps to minimize the expense of door-to-door service for the elderly and disabled, and provides more independence for those who have relied on such service. Businesses that utilize relatively low-cost labor have a reliable way for their work force to get to and from their place of work. Young students who otherwise might have to walk through rush hour traffic to get to school now have a safer alternative. In all of these areas, all of the local circulators are indeed successful. Further, the survey of passengers' attitudes toward the service conducted by the principle investigators of this report resulted in an average rating for all eight local circulators of an impressive 8.95 based on a scale from one to ten, with 10 being outstanding. Hence, existing passengers appear to regard the local circulators as very successful in meeting their needs.

For purposes of this report, "successful” is defined by how many passengers per hour are carried by the local circulator. Broward County is paying for a large portion of the expenses of these services, and it wants to be sure it is investing its funds purposefully. The county has established a minimum goal (five passengers per hour) that 
every city must reach if it is to continue receiving financial assistance from the county. This performance level clearly makes it more efficient than paratransit, but it is still a relatively low figure for a fixed route service. In comparison, the county carries approximately 35 passengers per hour on its regional transit system. However, local circulators are not expected to carry as many passengers per hour as regional transit systems. Part of the intent of the local circulators is to use smaller buses that are more neighborhood-friendly and that are able to maneuver more easily in shopping centers and smaller streets. Obviously, smaller buses have less capacity and are not designed for the full rigors of large transit buses that typically stop every few blocks and carry as many as 70 passengers in crush load times.

The eight local circulator systems reviewed in this report carried an average of 14.2 passengers per hour. By almost any standard of productivity, this can be regarded as very successful. For instance, the ridership per hour figures of these local circulators almost matches the performance of Palm Tran, the countywide fixed route service provider in Palm Beach County. In terms of cost efficiency, the average cost per passenger on the local circulators was $\$ 2.18$ compared to BCT's average cost per passenger of $\$ 1.90$, a remarkably competitive rate, particularly when considering paratransit costs approximately $\$ 17$ per passenger.

While all of these productivity and expense figures are impressive, the purpose of this report was not to compare local circulator performance to regional transit performance. It is also not a critique of the Broward County Community Bus Program. The purpose of this report is to help identify how each local circulator can become more successful in its own community, and what characteristics tend to lead to greater ridership per hour.

\section{Factors That Determine a Successful Local Circulator}

\section{Demographics}

It might seem obvious to many that certain demographic characteristics contribute to better transit ridership, but with such limited experience in the provision of local circulators in primarily suburban settings, it was well worthwhile to confirm if normal indicators of transit potential apply to local circulators as they do to regular fixed route transit service in a more regional setting. As noted in Chapter 4 and Figure 4.3, there is a very strong (0.833) positive relationship between transit use and population density for the local circulators that were studied. In short, the higher the density, the higher the transit ridership per hour was for the local circulators. Not too far behind in terms of relationships was the high positive correlation between lack of car ownership and transit use. Perhaps a little surprising was that the relationship was even stronger for owneroccupied dwellings (0.69) without cars versus renter-occupied dwellings (0.52) without cars and transit ridership per hour. It is hypothesized that rental apartments are usually smaller than owner-occupied homes, and there might be more total need for mobility in an owner-occupied dwelling due to more people living in the owner-occupied home. As expected, there was also a strong negative correlation $(-0.58)$ between income and transit 
ridership per hour. In other words, the higher the income, the lower transit ridership per hour was in the local circulator systems.

There is little surprise then, that transit ridership per hour was most successful in the City of Lauderhill. While the average passengers per hour for all five routes in Lauderhill was 22.0, two of the routes came close to carrying 30 passengers per hour. In Lauderhill, the population per square mile is 8,179, easily the highest among the eight city circulator systems reviewed. The median household income is $\$ 32,070$, which is among the lowest of all eight city systems reviewed. Lack of car ownership $(9.9 \%$ of the owner-occupied dwellings and $12.1 \%$ of the renter-occupied dwellings) was above average, but not extraordinarily so. It is interesting to note that the City of Dania service area has virtually the same median household income as Lauderhill's service area, a similar percentage of renter households without cars, and a better headway (40 minutes versus 45) than most of the Lauderhill routes. However, Dania's population density is only 3,272 persons per square mile, and realizes a local transit circulator ridership per mile that is slightly less than one-third that of Lauderhill. In fact, the listing of cities in order of passengers per mile follows quite closely to the listing of the cities by their population densities, regardless of other demographic characteristics.

\section{Management Technique}

This report also tried to find more subtle reasons for differences in performance among the local circulator systems. Five of the eight systems reviewed contracted out for their service providers, while the other three performed their services with city personnel. Those cities that contract for the service tend to do so in the belief that it is less expensive and helps to minimize their liability in the event of accidents. They also want to leave the details of service operation to a firm that specializes in such things and has experience in doing so. There were some complaints against a couple of the private service providers. One concern was that the private contractor's bus operators might inflate the number of passengers carried in the reports that they submit to the city, perhaps in hopes of leaving the impression that they are performing their service in a way that is attracting more passengers. This could benefit the private carrier in the event the city has the option to extend their contract without the need for competitive bidding. There was also the complaint that private carriers didn't always have the appropriate equipment on the route due to slow repair of regular vehicles. One city did end its contract with a private provider due to poor performance. These comments should not be taken as a criticism of contracting for services. Most of the time, contractors have been very responsive to complaints from passengers or city managers. The city noted above that dismissed one contractor is extremely satisfied with its current contractor. The private bus operators tend to undergo the same training as the public operators. One of the advantages private contractors have is that they can more easily dismiss or reassign a bus operator that has been the subject of complaints. Sometimes it is harder to remove a public employee who has been the subject of many complaints. 
The cities that perform the service with their own personnel agree that their method might be a bit more expensive, but they believe that they have more control over the quality of the service and more flexibility with how they use their personnel for other duties within the city. It appears that the cities that use their own personnel have enjoyed relatively low rates of turnover. This consistency among operators is often appreciated by senior passengers who feel more comfortable with a familiar face behind the wheel. However, in terms of bottom line performance as measured by passengers per hour, there appears to be no noticeable difference between cities that contract for the service versus those who perform the service with their own personnel. For instance, Margate uses its own personnel while neighboring Coral Springs contracts out the service. These two cities have very similar population densities, median household incomes, and car ownership levels (see Table 5.1). They also both operate on 60 minute frequencies. The difference in management style does not seem to be a factor as Coral Springs carries 12.38 passengers per hour while Margate carries a similar figure of 11.54 . The only significant difference between the two cities is that Margate charges $\$ 0.25$ per ride while Coral Springs' service is fare-free, and that might account for the slightly higher passengers per hour in Coral Springs. A similar comparison can be made between Miramar and Plantation. These cities are very similar to each other in terms of median income, population density, and car ownership patterns. One city contracts out the service while the other provides the service in-house, yet the passengers carried per mile are very similar. It appears that the private versus in-house issue is not a major determinant of success as measured by passengers per hour.

\section{Marketing Techniques}

The principle investigators for the report tried to determine if any marketing techniques might have proved more effective than others, in ways that resulted in higher passengers per mile. No city representative could offer proof or conviction that a certain promotion technique made a specific difference in ridership. Most of the cities used the same methods of promoting their services including direct mail notification to households, local newspaper advertisements, placing bus route maps and schedules at all city facilities, placing local circulator information on city websites, meeting with community groups, placing brochures and maps in major grocery stores, press releases and newspaper articles, and advertisements on cable television and public access cable channels. None of the cities involved in this study had the wherewithal to conduct any analysis of cause and effect in terms of marketing techniques. Due to lack of funds for serious advertising, the cities take advantage of as many free opportunities as possible to promote the availability of their service. The community bus program's greater opportunity for face-to-face meetings is a very valuable way of creating a greater sense of relationship and partnership with various groups within the city.

A few of the local managers did state that they felt certain marketing techniques were particularly important that are worthy of note. Margate believes their first and most important selling tool is not advertising as much as it is the bus operator. This is one of the reasons they are strong believers in providing service with their own personnel that 
they can influence and train more directly than they could through a private contractor. Margate constantly reminds their operators to treat the passengers with courtesy and respect, to smile as often as possible, and keep a positive attitude at all times. The principle investigators noted during their conversations with passengers that many of them learned about the system through word-of-mouth. If passengers do not feel comfortable with the bus operator, chances are they will not spread a good message to other prospective passengers. A community bus service is intended to be a bit more personal than a regional transit service; hence it is very helpful for a local circulator to play to that strength. Another point made by the Ft. Lauderdale manager was the advantage of a consistent theme and branding for its services. It is important to have the same color scheme and decorations for all local circulators serving a community to help reinforce that service's image in the mind of the community every day. If effect, the vehicles themselves are moving billboards for the service, and it is important for that message to be consistent day in and day out for people to become more aware of its availability.

\section{Table 5.1}

\begin{tabular}{|c|c|c|c|c|c|c|c|c|c|c|c|}
\hline City & $\begin{array}{l}\text { Population } \\
\text { Density }\end{array}$ & $\begin{array}{l}\text { Household } \\
\text { Median } \\
\text { Income }\end{array}$ & $\begin{array}{l}\text { Owner } \\
\mathrm{HH} \\
\text { without } \\
\text { car }\end{array}$ & $\begin{array}{l}\text { Renter } \\
\text { HH } \\
\text { without } \\
\text { car }\end{array}$ & $\begin{array}{l}\text { Service } \\
\text { Frequency }\end{array}$ & Fare & $\begin{array}{l}\text { Service } \\
\text { Span }\end{array}$ & $\begin{array}{l}\text { Days of } \\
\text { Service }\end{array}$ & Contract & $\begin{array}{l}\text { Pass. Per } \\
\text { Hour }\end{array}$ & $\begin{array}{l}\text { \# of } \\
\text { Connect- } \\
\text { ing } \\
\text { Routes }\end{array}$ \\
\hline Dania Beach & 3,272 & $\$ 32,043$ & $5.4 \%$ & $19.6 \%$ & $\begin{array}{l}40 \\
\text { Minutes }\end{array}$ & Free & $\begin{array}{c}9 \mathrm{am}- \\
5 \mathrm{pm}\end{array}$ & M-F & Yes & 7.05 & 7 \\
\hline Cooper City & 3,317 & $\$ 69,995$ & $2.1 \%$ & $8.3 \%$ & $\begin{array}{l}60 \\
\text { Minutes }\end{array}$ & Free & $\begin{array}{l}8 \mathrm{am}- \\
4 \mathrm{pm}\end{array}$ & M-S & No & 5.48 & 4 \\
\hline Coral Springs & 5,548 & $\$ 52,946$ & $3.9 \%$ & $11.5 \%$ & $\begin{array}{l}60 \\
\text { Minutes }\end{array}$ & Free & $\begin{array}{l}8 \mathrm{am}- \\
6 \mathrm{pm}\end{array}$ & M-F & Yes & 12.38 & 6 \\
\hline $\begin{array}{l}\text { Lauderdale } \\
\text { Manors }\end{array}$ & 6,542 & $\$ 29,417$ & $8.0 \%$ & $32.9 \%$ & $\begin{array}{l}60 \\
\text { Minutes }\end{array}$ & Free & $\begin{array}{l}6: 30 \mathrm{am}- \\
6: 30 \mathrm{pm}\end{array}$ & M-F & Yes & 16.0 & 2 \\
\hline Margate & 5,773 & $\$ 45,697$ & $8.0 \%$ & $12.7 \%$ & $\begin{array}{l}60 \\
\text { Minutes }\end{array}$ & $\$ .25$ & $\begin{array}{l}7 \mathrm{am}- \\
7 \mathrm{pm}\end{array}$ & M-S & No & 11.54 & 9 \\
\hline Plantation & 4,920 & $\$ 45,272$ & $7.0 \%$ & $12.0 \%$ & $\begin{array}{l}45 \\
\text { Minutes }\end{array}$ & Free & $\begin{array}{l}7 \mathrm{am}- \\
4: 30 \mathrm{pm}\end{array}$ & M-F & Yes & 6.47 & 13 \\
\hline Miramar & 4,434 & $\$ 44,786$ & $6.8 \%$ & $12.4 \%$ & $\begin{array}{l}60 \\
\text { Minutes }\end{array}$ & $\$ .25$ & $\begin{array}{l}6: 45 \mathrm{am}- \\
6: 55 \mathrm{pm}\end{array}$ & M-F & No & 7.2 & 8 \\
\hline Lauderhill & 8,179 & $\$ 32,070$ & $15.0 \%$ & $20.0 \%$ & $\begin{array}{l}45 \\
\text { Minutes }\end{array}$ & Free & $\begin{array}{l}\text { 6:30am- } \\
6: 55 \mathrm{pm}\end{array}$ & M-F & Yes & 22.0 & 13 \\
\hline
\end{tabular}




\section{Market Segmentation}

One of the principle investigators of this report was the Director of Broward County Transit when the community bus program was first created in a small number of cities in 1991. It was believed at the time that the majority of passengers would be senior citizens who could shop, go to medical appointments, or attend senior programs via this service. It was hoped that the community bus routes might also help reduce the demand for door-to-door paratransit services, thereby reducing the cost of paratransit to the county.

This report has found that the local circulators are being used by senior citizens today. There is also anecdotal evidence that these services are being used by some of the passengers that might otherwise have relied on door-to-door paratransit service. The surprising finding is that the percentage of senior passengers is in almost all cases far lower than what might have been originally expected. If any segment of the population constitutes a higher percentage than all others among passengers, it appears to be the teenage student segment. Perhaps this should not have been a major surprise. In Florida, school systems do not provide bus service to students who live within two miles of their school. Prior to the institution of community buses, these students would either walk, ride bikes, be driven by their parents to their schools, or take a county bus if it made sense. However, traffic in Broward County can be challenging for pedestrians, particularly at major intersections. Heat and humidity also make walking or biking during certain school months very uncomfortable. Parents with certain work shifts might not be able to conveniently drop their children off or pick them up at schools. County buses might not get near enough to school sites located in communities, and they charge $\$ .60$ to ride. Consequently, many students use the community bus to get back and forth to school. This has created a number of challenges for the community bus programs.

Student passengers have contributed significantly to the passenger count on local circulators, in that sense contributing to the success of these services. However, many of the community bus managers noted substantial problems with the loads of students they carry. Four of the cities in this report cited severe capacity problems either in the morning or in the afternoon due to tremendous numbers of students. Minibuses are not designed to carry large loads, and due to liability concerns, most of the cities adopt policies of not allowing standees. Large groups of students trying to board buses when school lets out can result in pushing and shoving as they compete for limited seating on the bus. One technique employed by or being considered by a number of these cities is to relocate the bus stop nearest the school. By just modifying the route slightly and moving the stop a block or two away from the school, some cities have succeeded in substantially reducing the loads boarding at these stops nearest the schools. One city has used its spare bus and flexible part-time employee to provide tripper service on school days to accommodate the extra demand in the morning. 
In addition to the challenges of capacity, the student ridership has created security issues as well. One city decided to discontinue service altogether in one portion of its city where the circulator went past a high school. The rowdiness and vandalism was not easy to control. Three cities have or will soon install security cameras on board their buses to record the behavior of passengers, with students being the primary cause for this installation of equipment. Some of this behavior has been bullying other passengers, while there have also been instances of upholstered seats being slashed by students with some cutting instrument. Two cities have had plainclothes police ride the local circulator to apprehend troublesome teenage passengers. Another city has arranged for the private contractor to have a supervisor ride the route in the afternoon when school lets out to serve as a deterrent to disruptive behavior. Some cities have also put in place programs that prevent a student that has caused trouble to ride the bus for 90 days. Another city approaches the parents and requires them to pay restitution for any damage their child caused by their child.

Some students have also been an unwelcome presence to other passengers on occasion. There have been incidents of students stealing groceries from senior citizens and simply exhibiting fairly rowdy behavior that make travel far less pleasant for other passengers. Some of the community bus managers indicated that senior passengers are aware of this, and are more selective in terms of the times of day they travel to avoid bus loads of teenagers.

This description of teenage behavior should not be regarded as highly threatening to the success of the community bus services. Apparently turnover among bus operators is fairly low. If conditions were truly horrendous, chances are the bus operators would not tolerate working in such conditions for long. The cities are taking a variety of steps to deal with these challenges, and it appears that they are, for the most part, being successful. Clearly the student ridership helps the community meet its minimum requirement of carrying five passengers per hour. Most cities accept that the service is public, and that the families with children appreciate the mobility the circulators provide for their children.

Another surprise, given the relatively limited hours of service of many of the circulators, was the number of passengers using the local circulators to get to work. The clear majority of these passengers appeared to be service personnel working in places such as restaurants or department stores who made relatively low wages. The availability of a free or near-free transportation service was very valuable to them.

\section{Other Factors}

Demographic conditions certainly contributed heavily to an impressive rate of 22 passengers per hour in Lauderhill, even though most of the headways on the five routes are an awkward and relatively infrequent 45 minutes. In addition, the City of Lauderhill also enjoys proximity to a significant regional bus transfer center at the Lauderhill Mall, where connections can be made with five county bus routes, many of which provide frequent service to major destinations. The fact that the local circulators connect with 
BCT service and with neighboring city circulators expands opportunities to get to and from employment opportunities. In the words of one of the city's circulator managers, "The connections give everyone more reasons to use the service". The availability of connections does not guarantee high ridership. For instance, Plantation enjoys connections with 10 BCT routes, three other city circulators, and the presence of two major BCT transfer centers to make transfers more convenient. However, their ridership is among the lowest of the eight cities reviewed in this report. The city's relatively high income, lower density, and higher car ownership works against a higher passenger per hour figure.

The effect of service span on ridership is difficult to analyze. All cities that offer service at least 10 hours a day enjoy double-digit passengers per hour, with the exception of Miramar. Miramar has similar demographic characteristics to Plantation, noted above, that make increasing productivity more challenging. All cities that offer less than 10 hours of service a day carry fewer than 10 passengers per hour. However, it would appear that the cities that have the better transit demographics would still outperform the other cities even if their hours were more limited.

\section{Fares}

Unfortunately, the universe of data dealing with fares is quite limited in this study. Two of the eight local circulators charged a \$.25 fare. Margate enjoys a healthy passengers per hour productivity of 11.54, while Miramar was experiencing ridership of 7.2 passengers per hour at the time of this report. The literature reflects that even small fares can have surprisingly dramatic effects on ridership. For example, both the Miami Beach Electrowave local shuttle and the Santa Barbara electric waterfront shuttle experienced ridership decreases of 45 percent when they modified their fares from being free to charging $\$ .25$ per passenger. This was not a totally negative experience in Miami Beach, since the small system did not have the capacity to carry all the passengers who wished to use the service. It is likely that both Margate and Miramar would see increased ridership with free fares. However, both cities realize money is hard to secure for transit, and every dollar they can secure will be used to improve service. Miramar has recently instituted a fare-free experiment, and it will be interesting to see if ridership increases substantially. Some of the cities might also wish to consider charging a fare if capacity becomes a critical issue for them.

\section{Concluding Thoughts and Suggestions for Future Study}

Based on the experience of the eight community bus services covered in this report, it appears that the factors that contribute to the success of regional fixed route transit services also apply to local circulators. Demographic factors such as population density, car ownership, and median household income have high correlations with transit use at the local circulator level as they do with regional transit service. One interesting trend noticed by the principle investigators was that senior passengers constituted a 
smaller percentage of local ridership than many would have thought, or even that some cities now think. The results of some surveys of passenger characteristics differed greatly from the observations of bus operators in one city. That might have been due to the timing of the survey, perhaps being done when school was not in session. National research has shown that seniors as a segment of the population, regardless of whether they own a car or not, tend to make fewer trips than other age cohorts. This makes sense since most seniors do not go to work, they don't have to ferry children to destinations, and perhaps because they do not shop as much due either to more limited income or the fact they already have much of what they need. While a city should not ignore the mobility needs of its seniors, this report suggests that a municipality should not design its local circulators exclusively or even primarily for seniors if it wishes to generate higher ridership. The younger age cohorts are engaged in more activities and travel more than seniors. This report indicates that there is a larger demand for local circulators among service employees than had been expected. It also shows the profound demand there is among students who do not own cars.

These preliminary findings, based upon conversations with operators and passengers, would suggest that a more complete survey of passengers of local circulators should be conducted. All the cities relied on the BCT ghost "riders" report as a mechanism for evaluating the service. Officials from BCT indicated the vagueness and ambiguity that such findings give in terms of policy guidance. The ghost rider report is only an evaluation of bus operator performance. It is not intended to gauge customer feedback. Each local system should make the effort to better understand the true nature of its ridership. A thorough survey done each year or two would allow each city to know who is riding the service as well as why and when, how often they use it, where they are going, and what they would like to see in terms of additional service. Even though the passengers gave the local circulators very positive ratings in terms of service evaluation, they also asked for additional service. A sound passenger survey would help take the guess work out of whether new service is justified and where and when it should be provided. Perhaps a single passenger survey effort for all the local circulator systems can be supported by the county for the purposes of consistency, thoroughness, better analysis, and to reduce duplication of effort.

It was clear to the principle investigators that there was a real interest among all of the local circulator managers in the findings of this study. They are anxious to know what is working and what the issues are with peer cities throughout the county. In short, they would like to learn from each other. Some of the managers talk to their counterparts that they have come to know. However, it is suggested that at least annually there be a workshop among representatives of all the community bus programs to discuss topics of common interest, and to share their successes and challenges. In addition, the county might wish to establish an electronic listserv among all the community bus managers so they can share information in this very flexible manner. Among the topics they might want to discuss is how to earn more money through the sale of advertising space on buses, benches, and shelters. They can share their experiences with contract management of private providers to see what types of contracts and communications have been most effective. Certainly they can share what they are doing to address the multiple challenges 
presented by students. In that regard, they should not hesitate to invite representatives of the Broward School Board bus system, to see how they deal with student behavior on buses.

The county should also consider providing "refresher training" to the community bus drivers on an annual basis. Many of the cities enjoy relatively low turnover rates among their drivers, and would appreciate the county's help in keeping their drivers up to date on all driving regulations and safety practices. The cities are self-insured, and they have all experienced accidents of one sort or another. The refresher training would help keep the drivers in the local circulators focused on safety. It would also be beneficial to remind them of effective passenger relations skills as well. 


\section{APPENDIX A}

\section{Passenger Survey}

\section{NCTR Synthesis Project - Year Five}

“Identifying the Characteristics of Successful Local Transit Circulator Systems in Residential Areas of Southeast Florida"

\section{Passengers/Patrons}

1. How frequently do you use this local circulator system (once a day, a few days a week or month)?

2. What is your estimated wait time for a bus?

3. How reliable is the circulator system's service in terms of schedule and mechanical quality?

4. What is the purpose of your trip (work, school, shopping etc.)?

5. For this trip how did you get to the bus stop? Did you transfer from another bus? When you get off the bus how will you get to your destination?

6. Please tell me how you were first made aware of the presence of the service in your community? 
7. Do you believe the drivers provide good customer service (are they friendly, helpful?)

8. Are you generally satisfied with the quality of the service? On a scale of 1 to 10 , with ten being very good, how would you rate it?

9. What improvements would you like to see in the service (hours of service, frequency, new destinations, etc.)? Would you use the service more if those improvements were made?

10. Do you happen to know if there are others who don't use the service that would use it if it were improved? 


\section{Bus Operator Survey}

\section{Synthesis Project - Year Five}

“Identifying the Characteristics of Successful Local Transit Circulator Systems in Residential Areas of Southeast Florida"

\section{Bus Operators}

1. How long have you been a bus operator for this local circulator system?

2. Who in your judgment uses the transit service in this city (elderly, working people, students, etc.) and what percentage does each represent of total ridership?

3. Why do people use the service (work, shopping, school, doctor's appointments, social events, etc.) and could you estimate about what percentage each type of trip is of all trips?

4. Does ridership vary by time of day?

5. Have you heard suggestions for improving the service from your passengers?

6. What are your suggestions for improvement of the service if any?

7. Please provide an estimate of the percentage of passengers connecting from BCT routes. 


\section{NCTR Synthesis Project - Year Five}

\section{"Identifying the Characteristics of Successful Local Transit Circulator Systems in Residential Areas of Southeast Florida”}

\section{Service Administrators}

1. How long has the circulator system and the different routes been in service?

2. Is the following route(s), frequency and span of service current for your circulator system?

3. What is the fare per rider per trip? Has this fare ever changed, and if so, did it have any effect on ridership? Are there any special discounts offered to a sector of the population (seniors, low income, and teens) and if so what is the intent behind such discounts? What is the transfer policy with County bus service or other municipal local transit circulators?

4. Please explain the reasoning for current route design, and who developed it? What were your major considerations as you tried to determine what was attractive to users of the service?

5. What do you think are the major attractors for ridership on your routes?

6. Have you done any kind of surveys to determine who uses your system, why they use it, how often they use it, and what your riders think about the service, or to determine what they would like to see in the service? 
7. Do you have any kind of advisory board or public input process that helps the city design and review the transit circulator services?

8. Please describe what your efforts have been with regard to promotion of the circulator service to the local community (such as, information brochures sent to households, other public relations/awareness efforts, marketing campaigns, advertising, partnerships with other public agencies or private companies)? Have you observed any change in ridership as a result of any of these efforts?

9. What are the total costs/expenses for service and how are they covered?

10. If most of the expenses are actually being paid by the county, do you think the service would be provided if County funds were not available?

11. How do you monitor the quality of the service that is provided? For example do you have any service guidelines or standards that you adhere to?

12. Do you have defined peaks in ridership during the course of the day? If so please indicate how ridership changes an estimate (\%).

13. Do you believe those who provide the service have good public relations/customer service skills? What do you do to try to make sure passengers 
have a good experience?

14. Does the city have a policy regarding tipping drivers?

15. If there is a contractor providing the service, do you meet with them on a regular basis, and how would you judge that relationship to work?

16. Your ridership per hour is approximately Do you believe that that level of ridership is about right? Are your goals for the service being met?

17. What are your future plans for the circulator service?

18. What, if any, unique lessons have you learned that helps explain your system's performance?

19. Are there any questions you would like us to ask to the other cities we are visiting? 


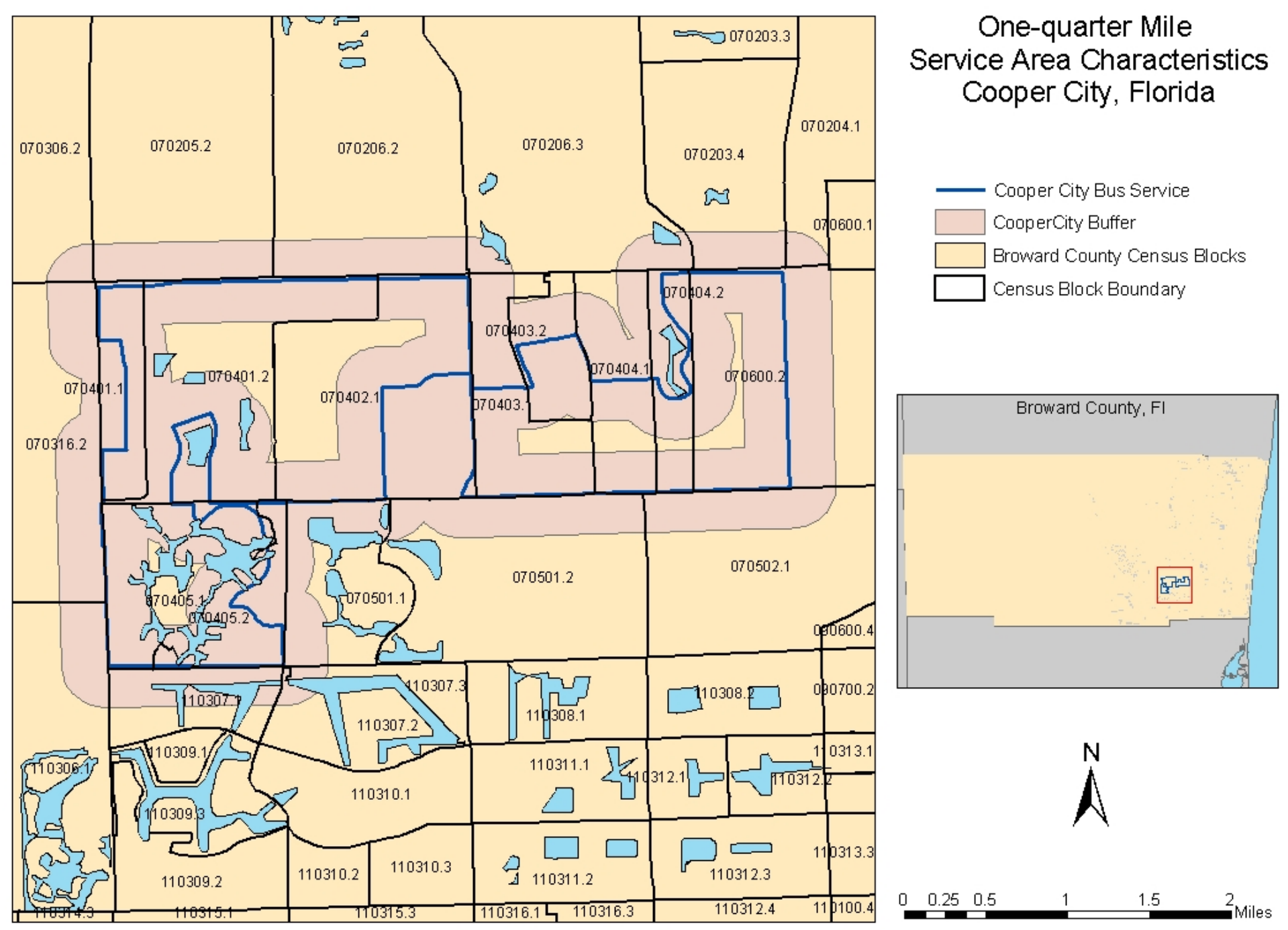

Source: Broward County website (www brow and org)

Data compiled at block group level 


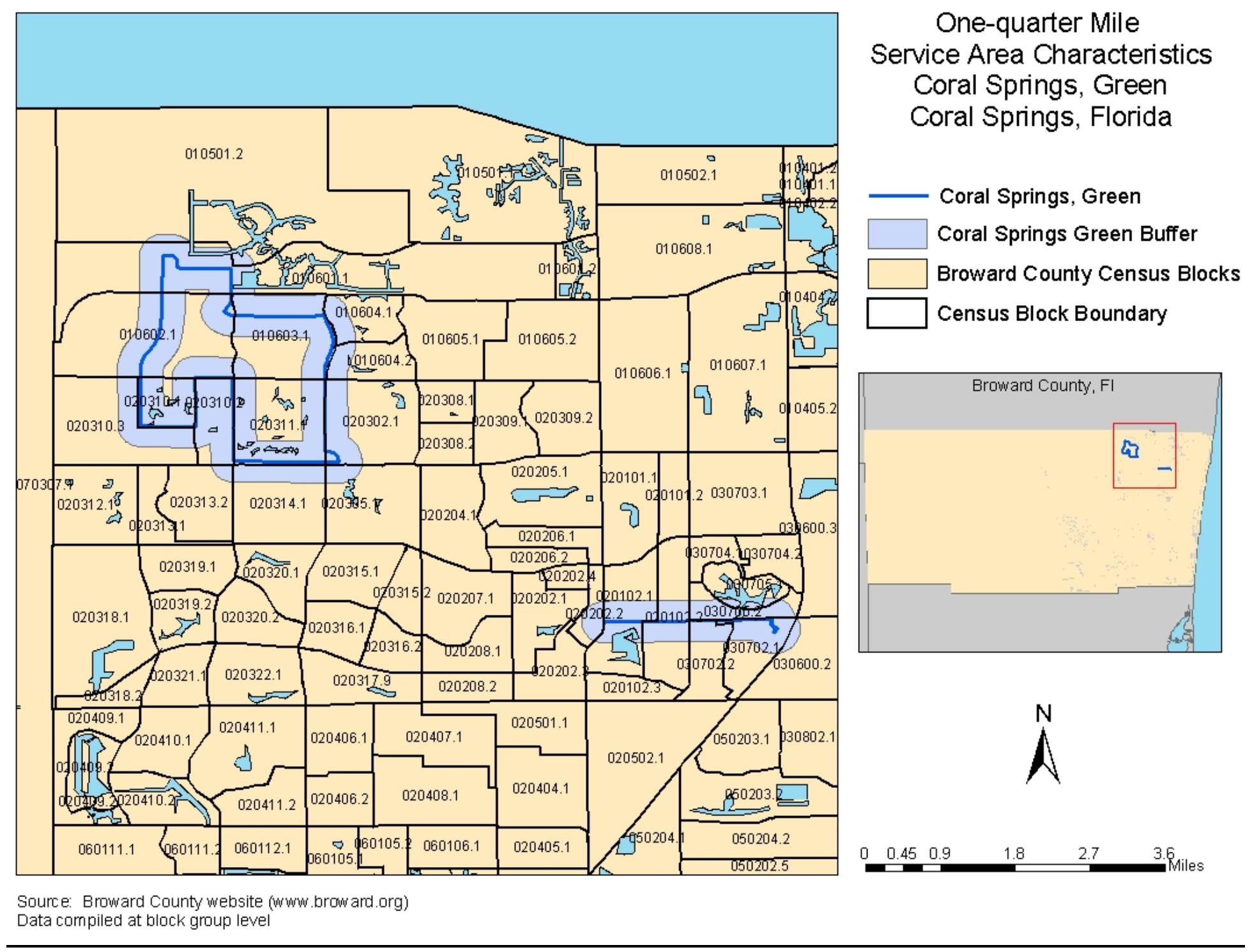




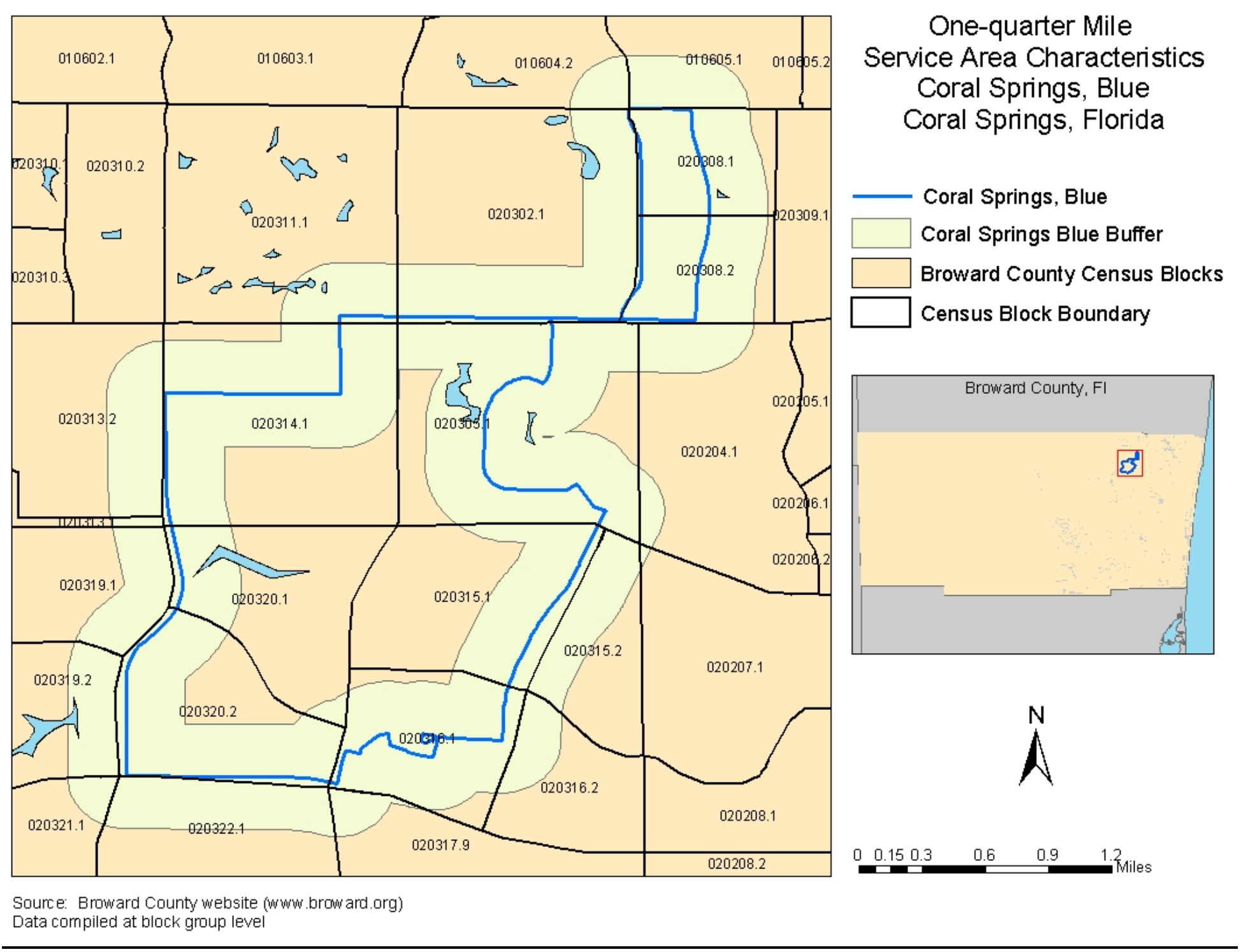




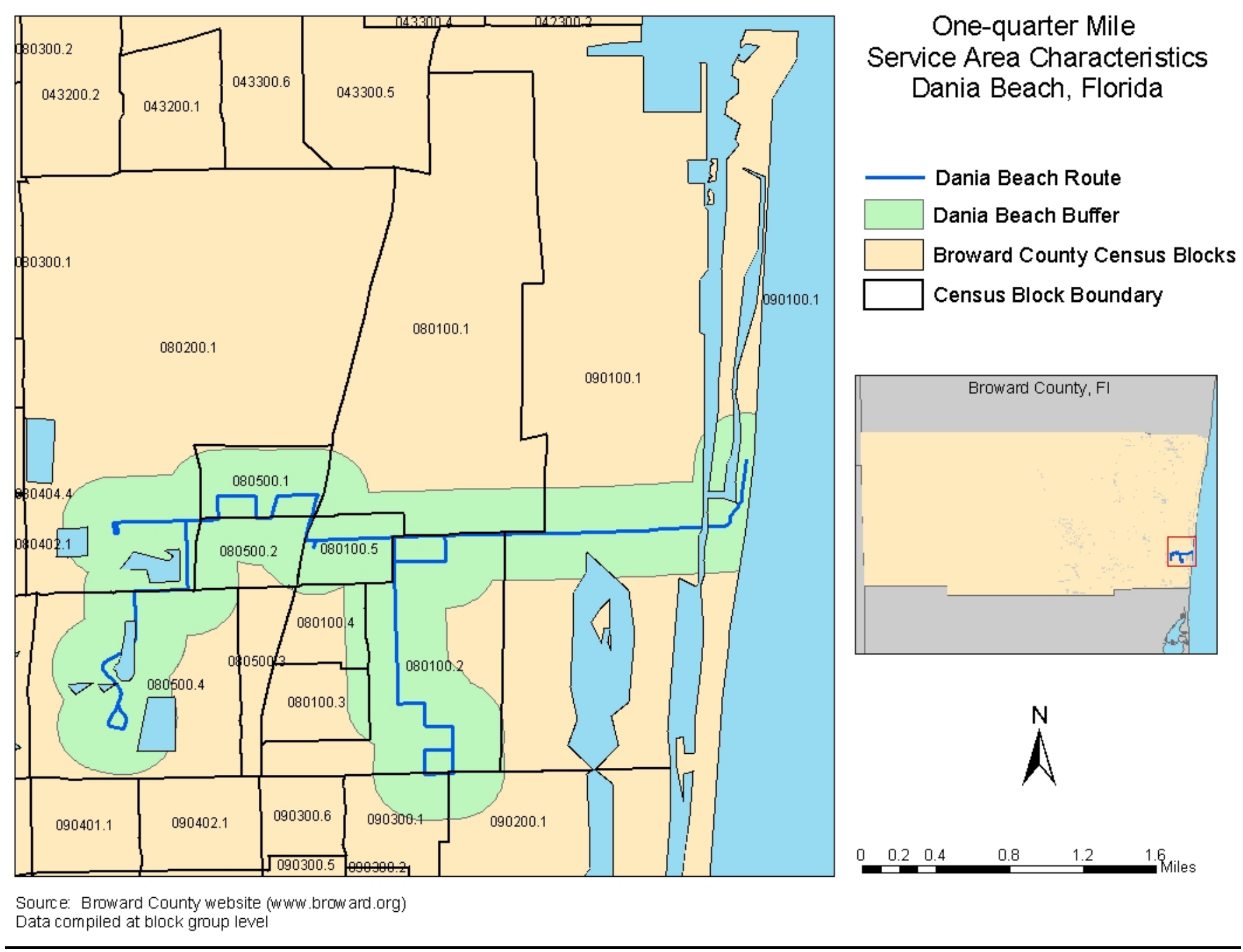




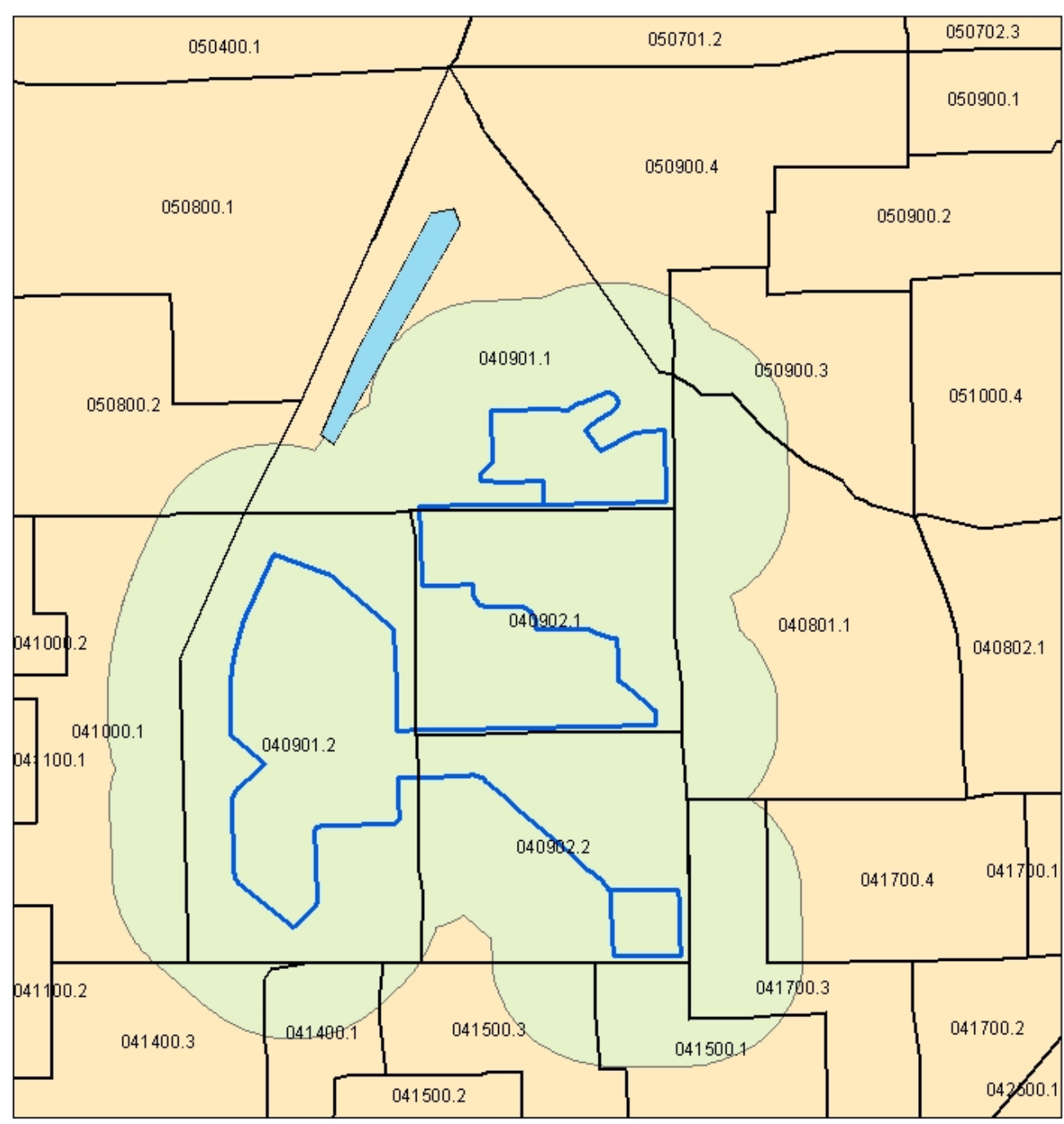

One-quarter Mile Service Area Characteristics

Lauderdale Manor

Fort Lauderdale, Florida

Lauderdale Manor Route Lauderdale Manor Buffer

Broward County Census Blocks

Census Block Boundary

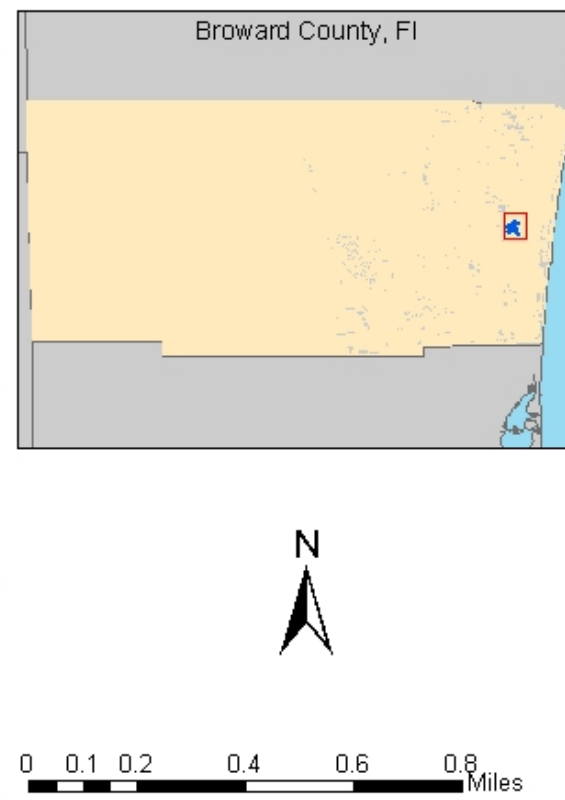

Source: Broward County website (www brow and org) Data compiled at block group leve 


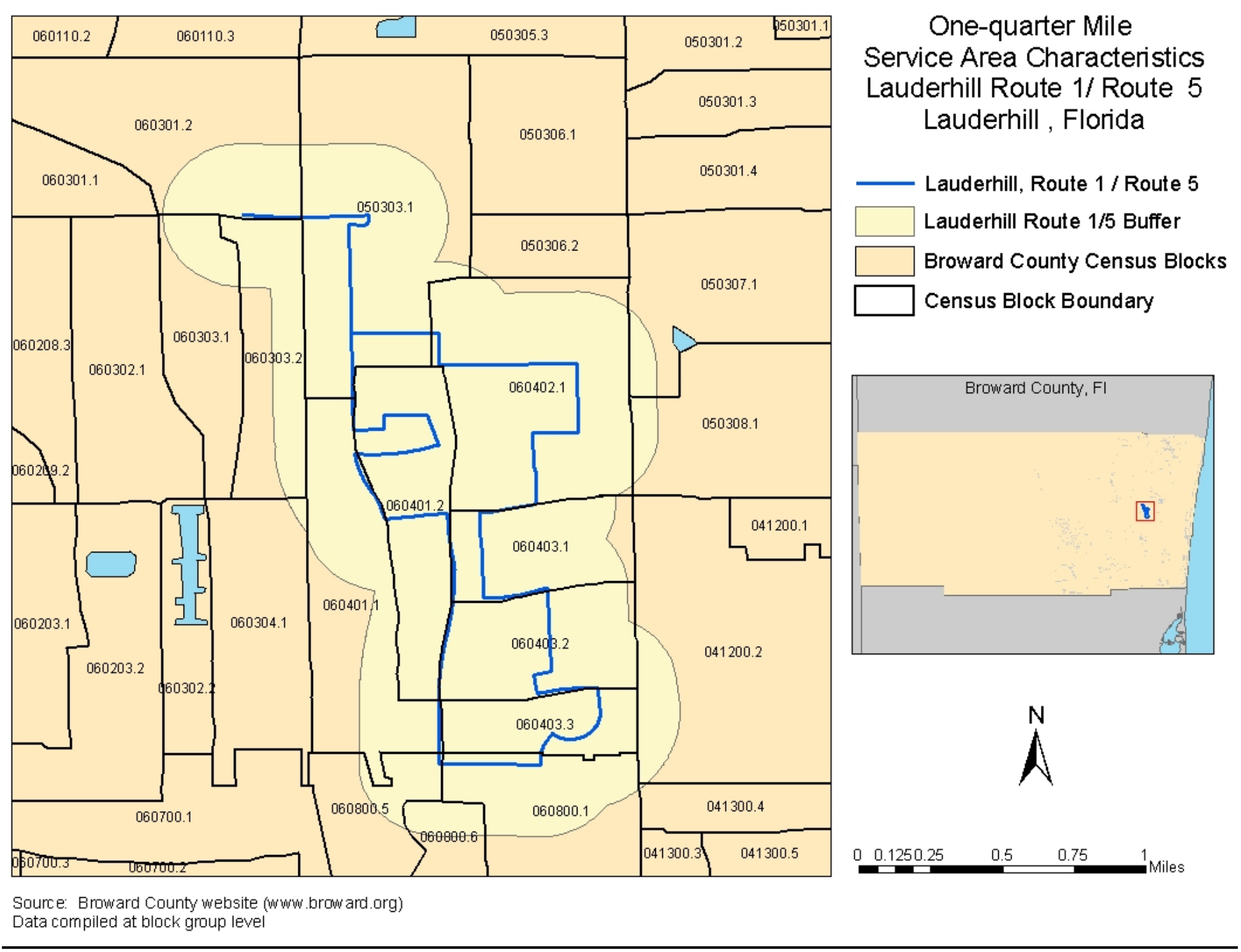




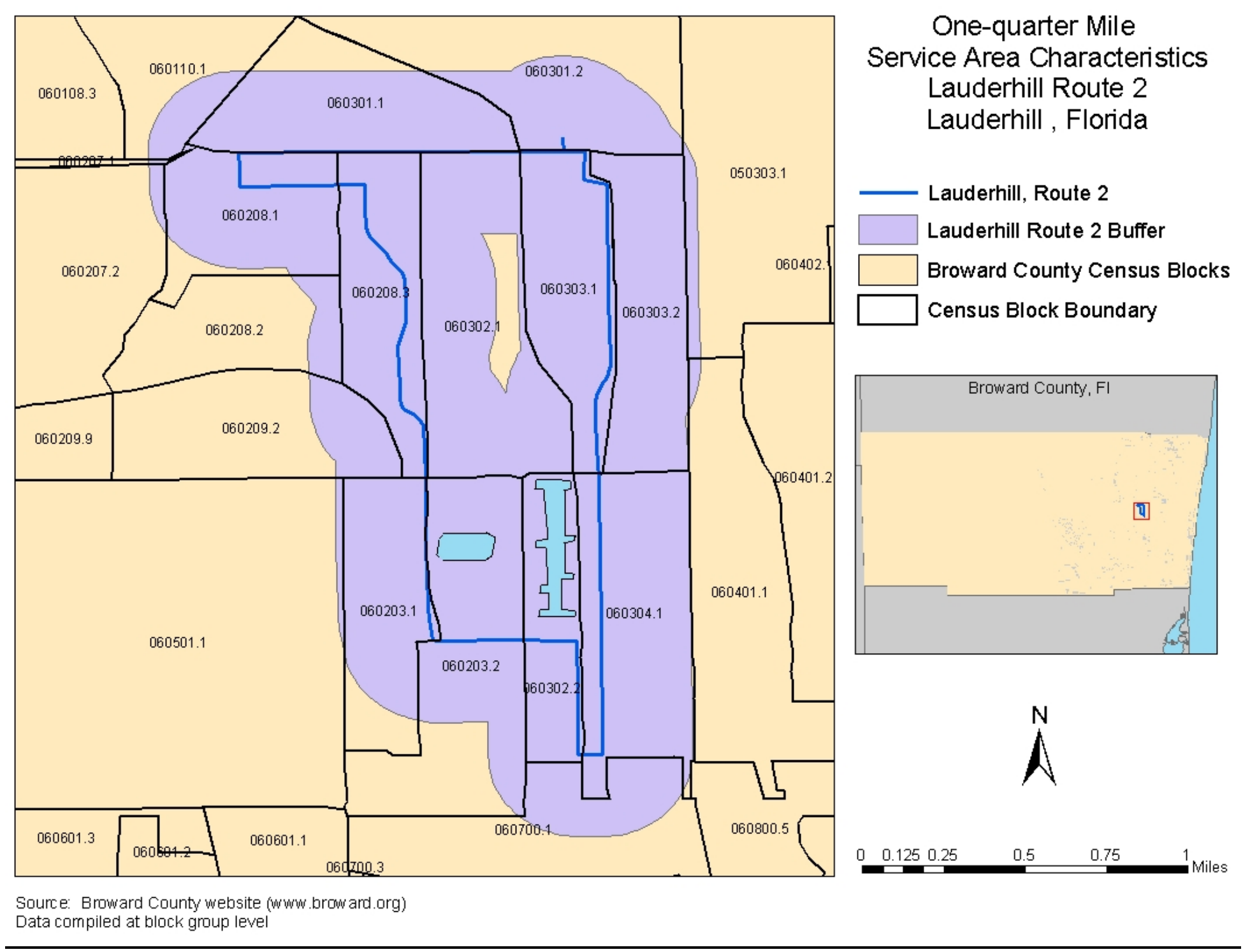




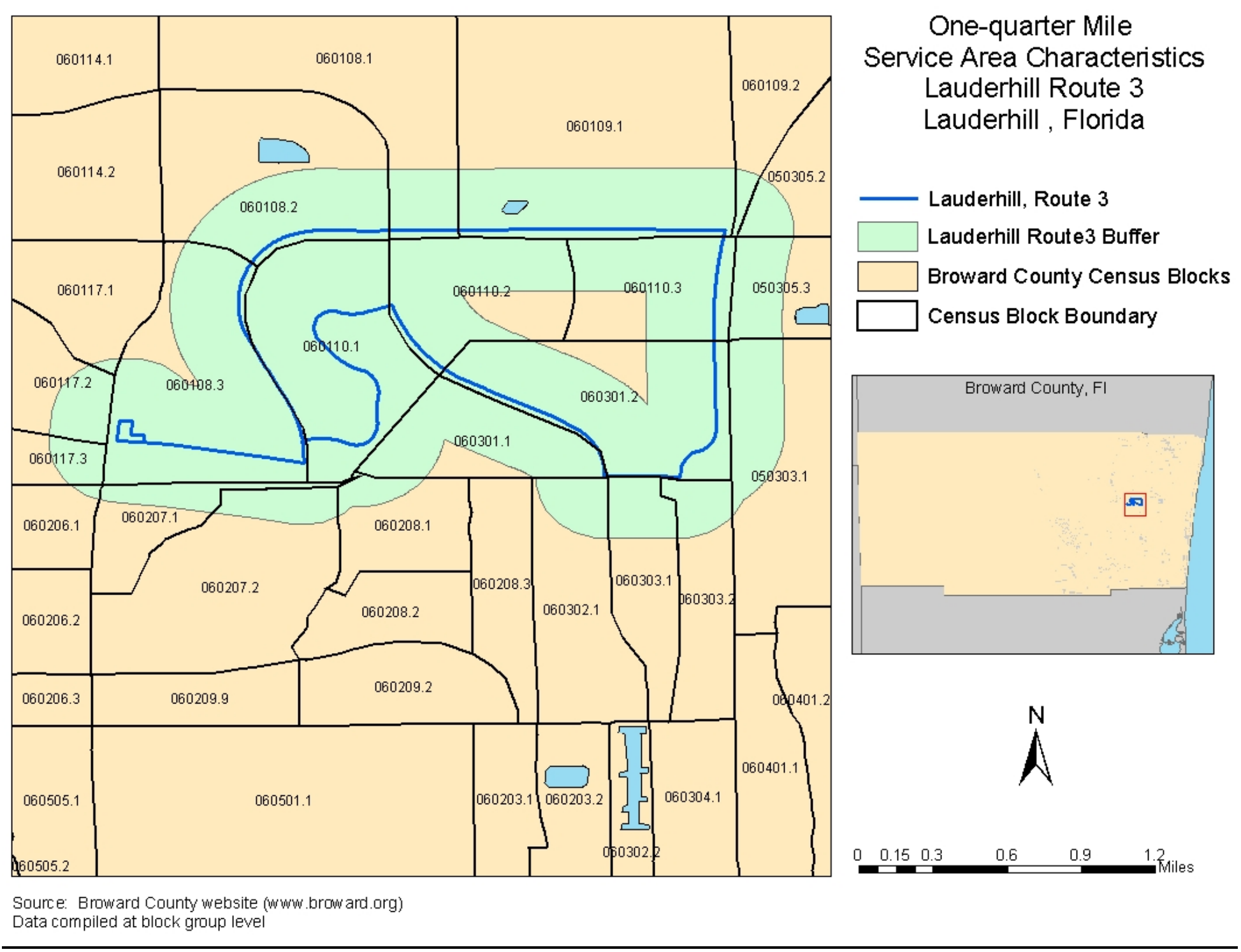




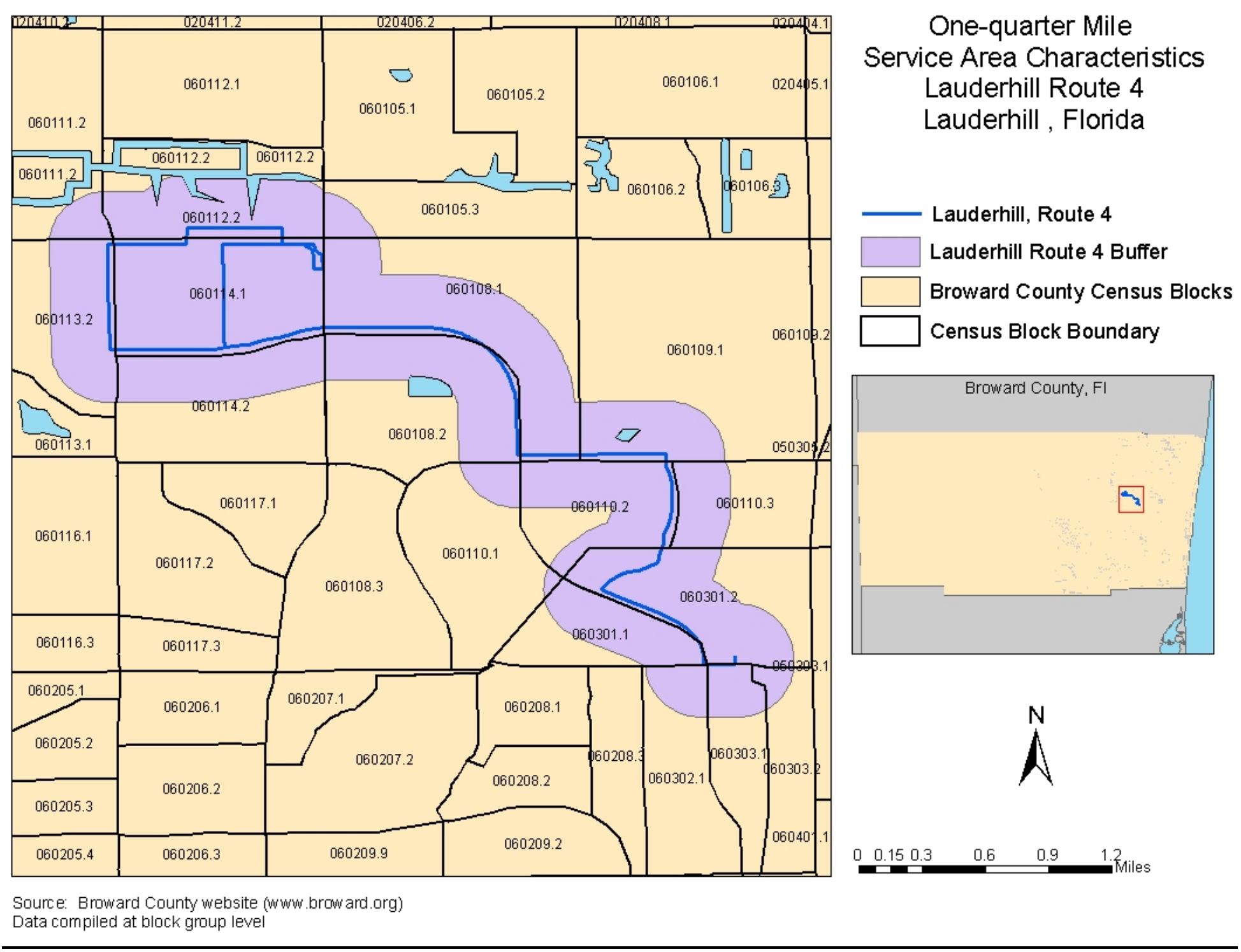




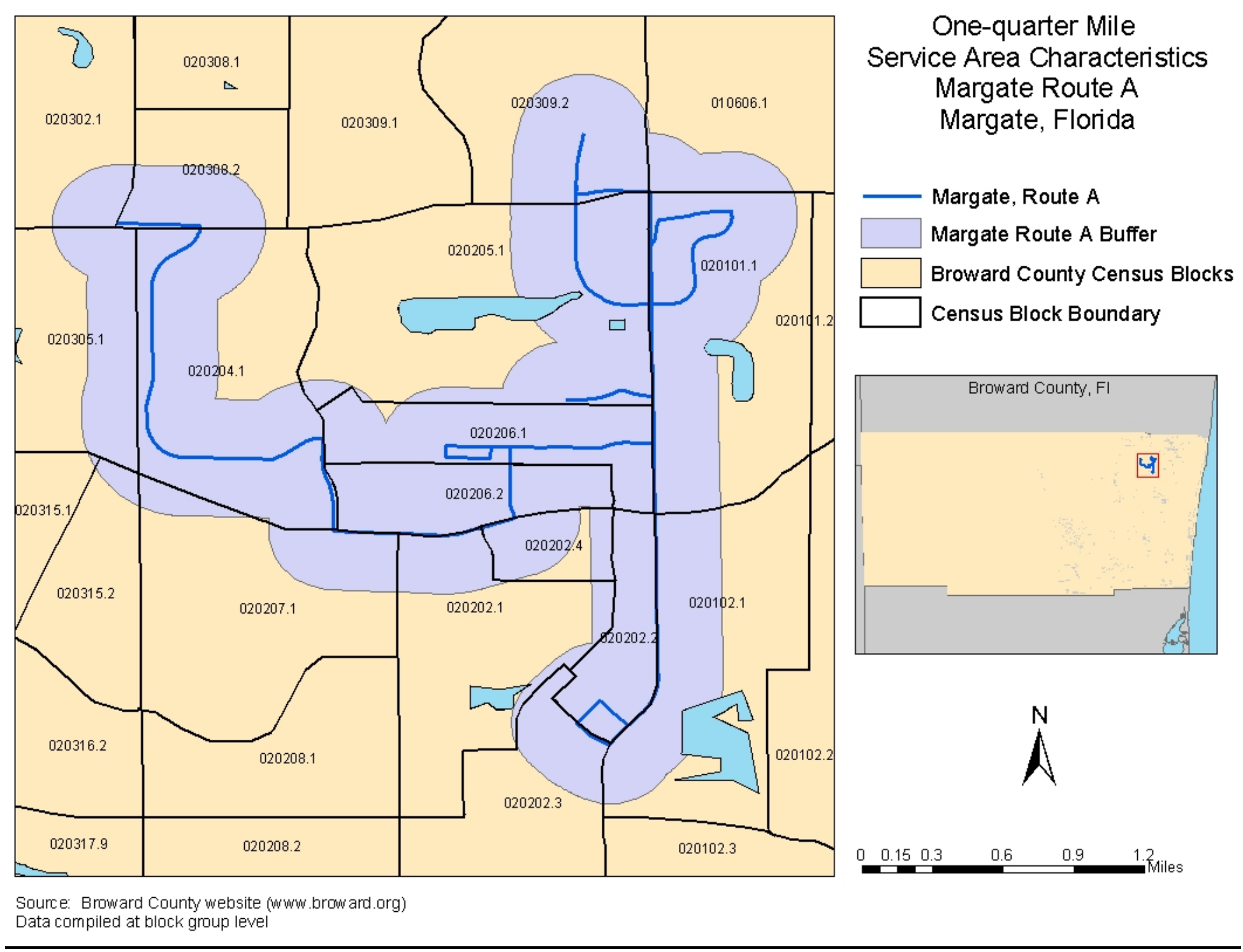




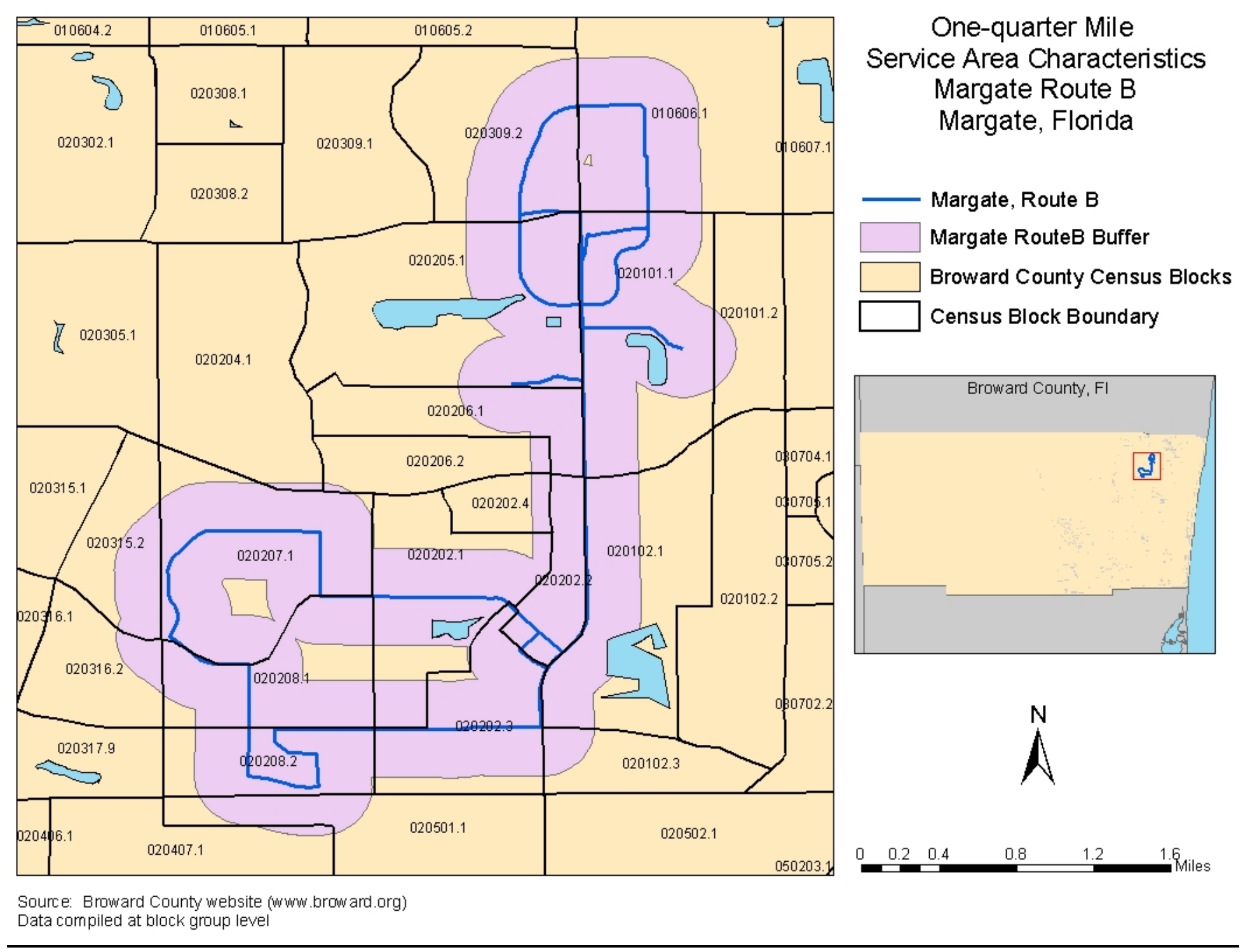




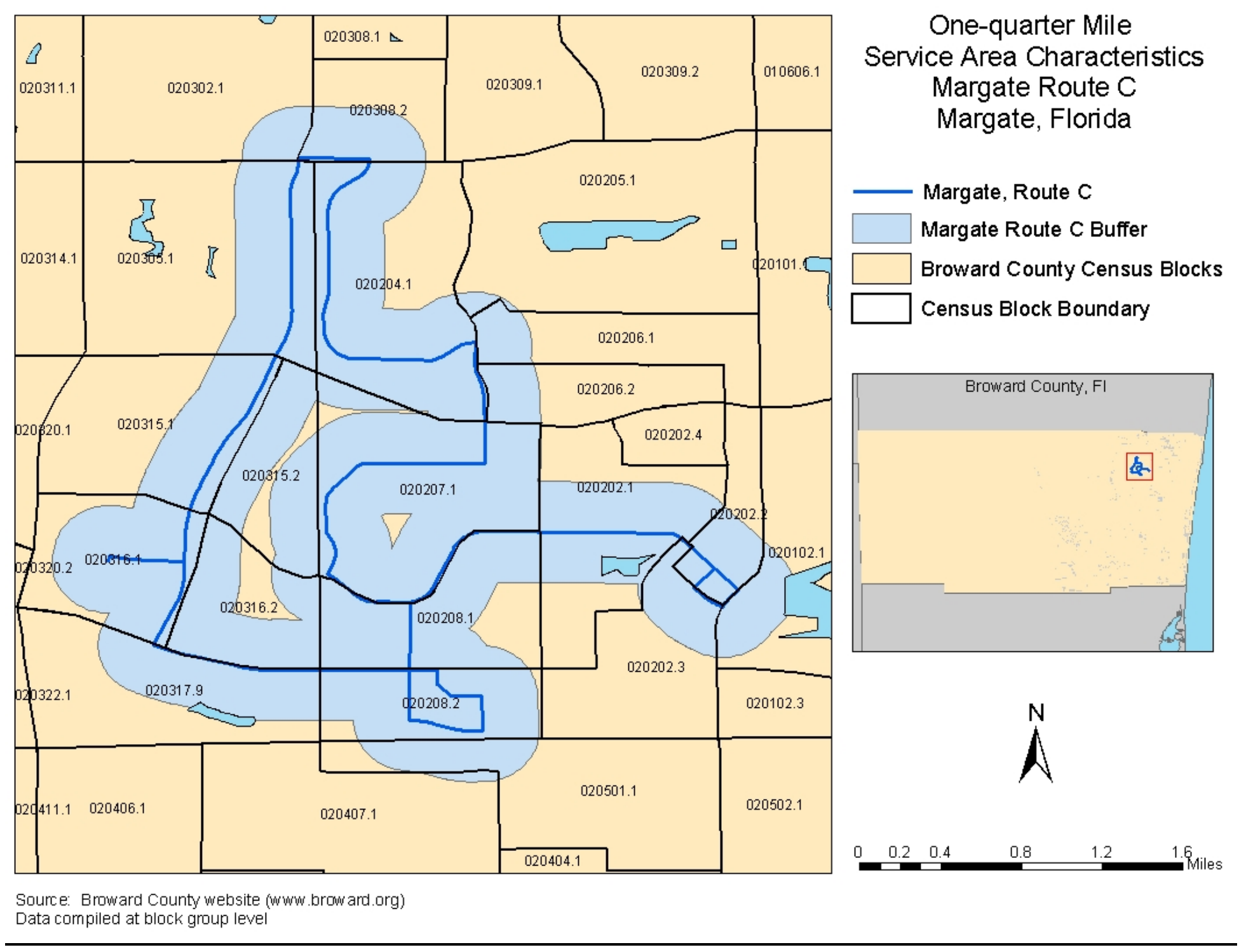




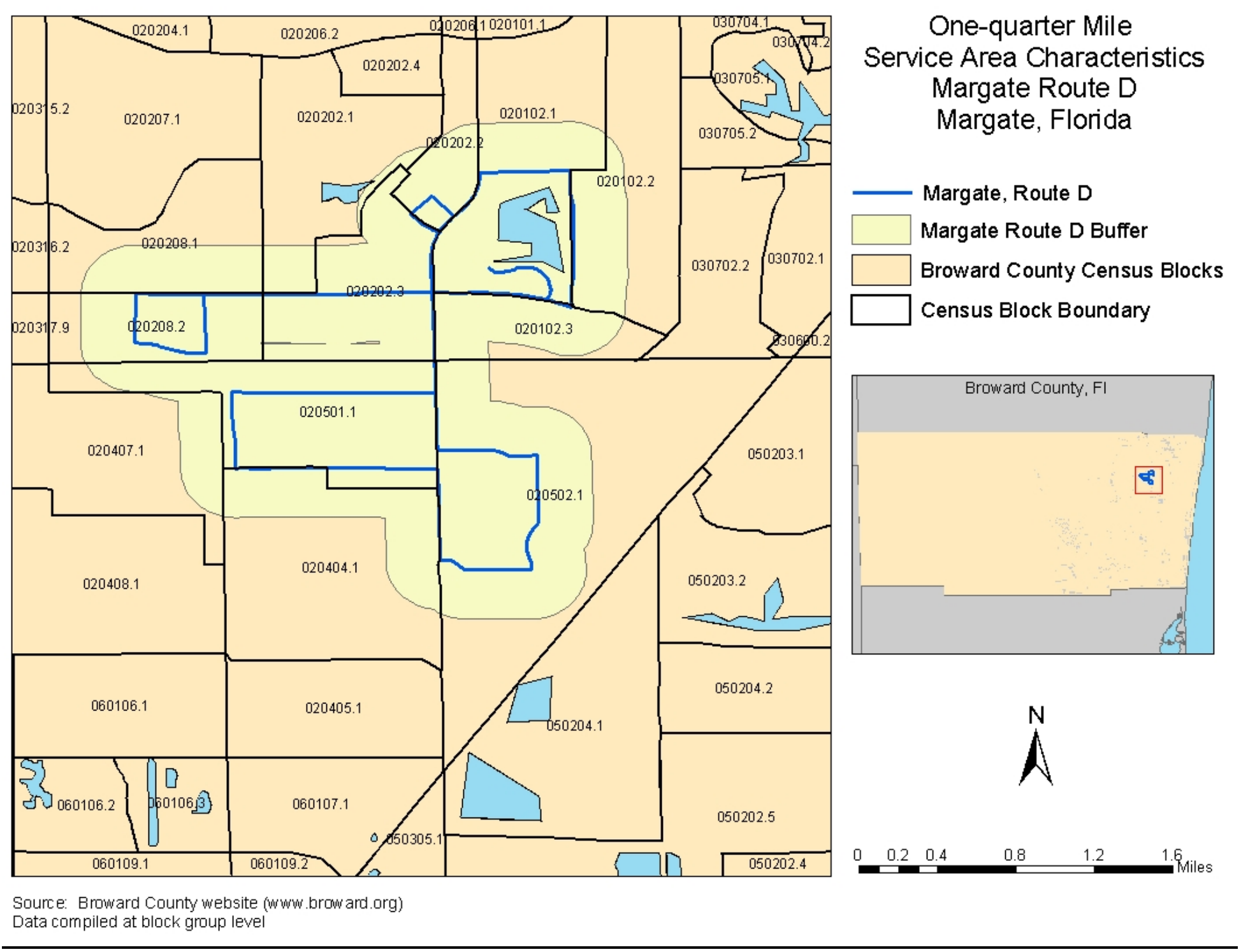




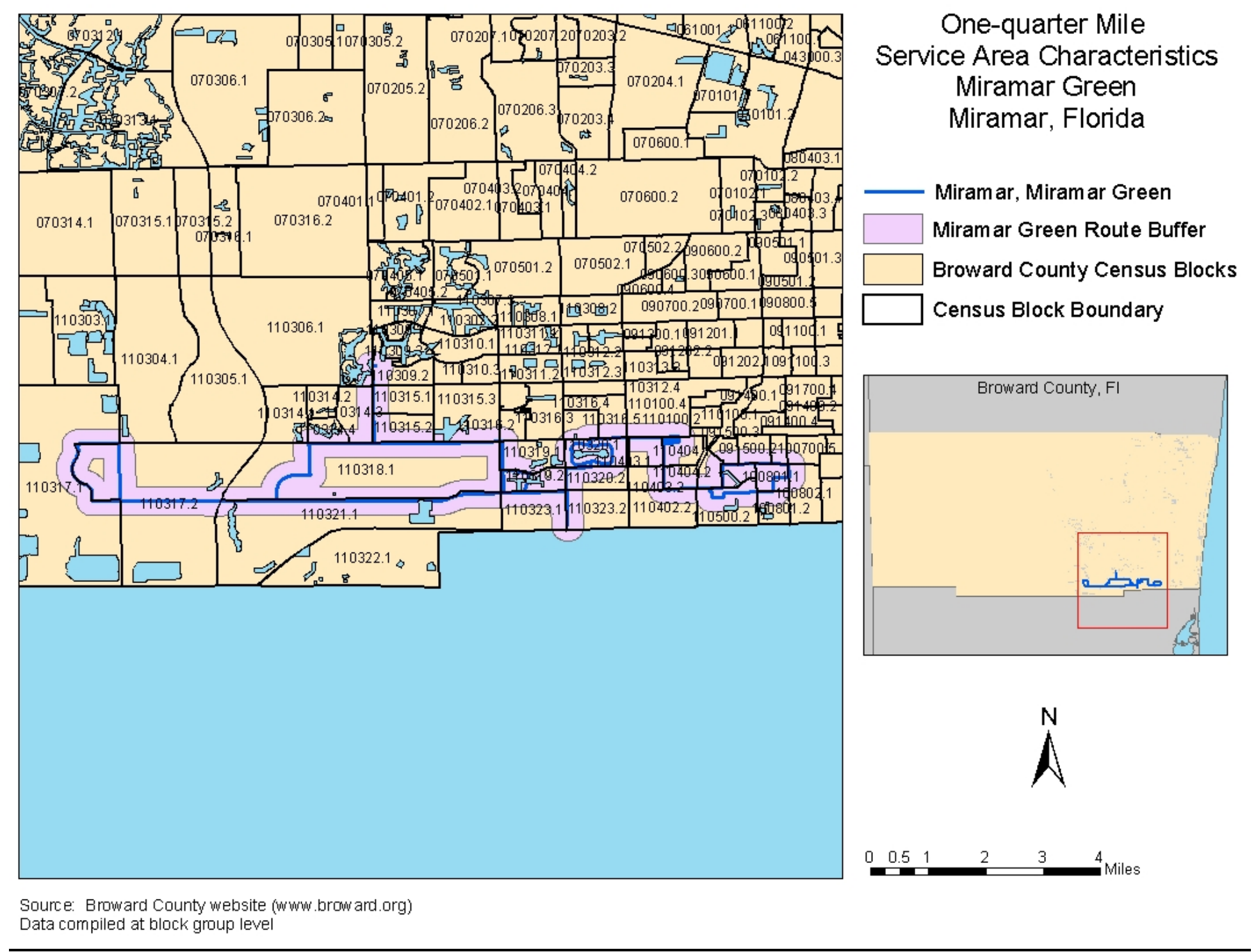




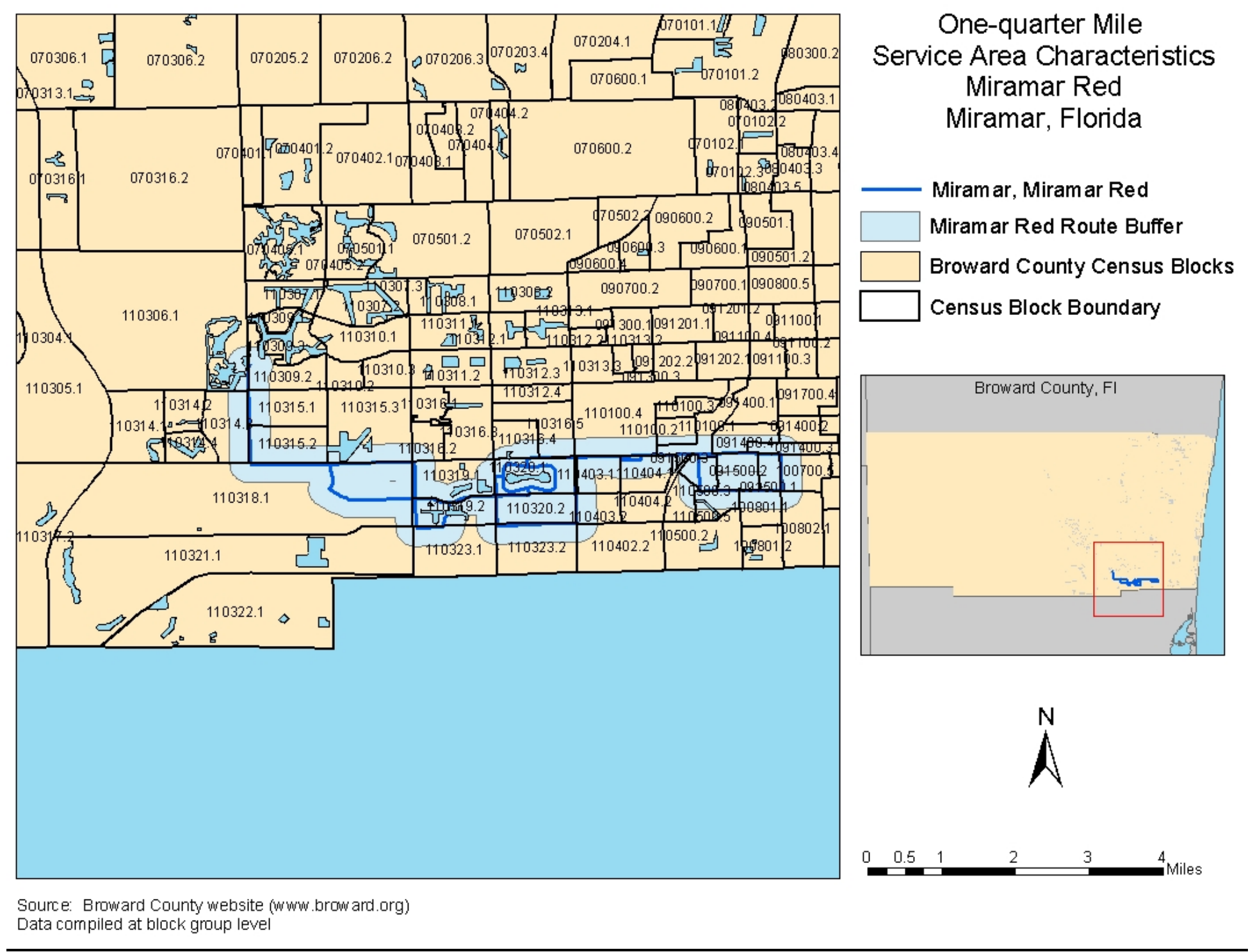




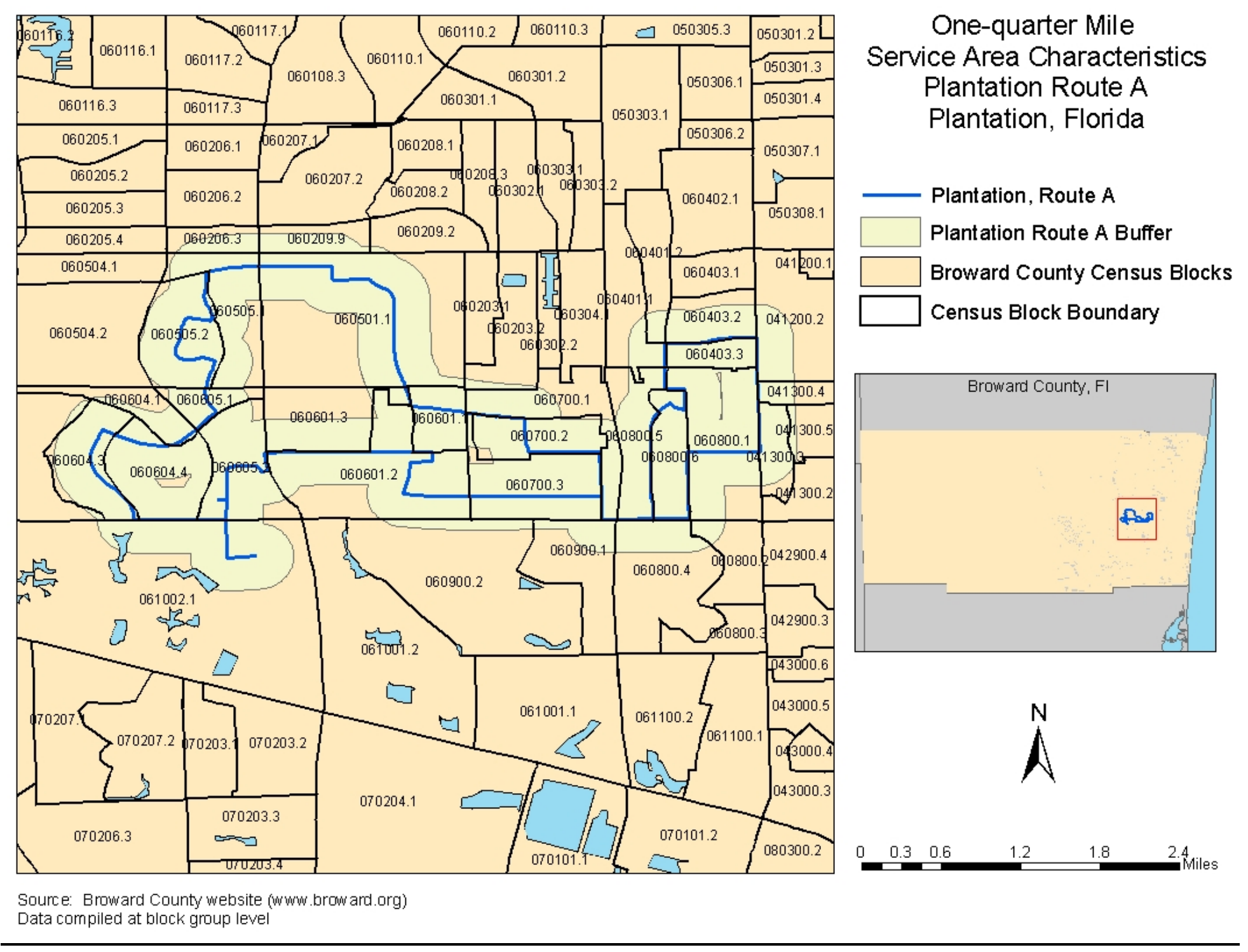




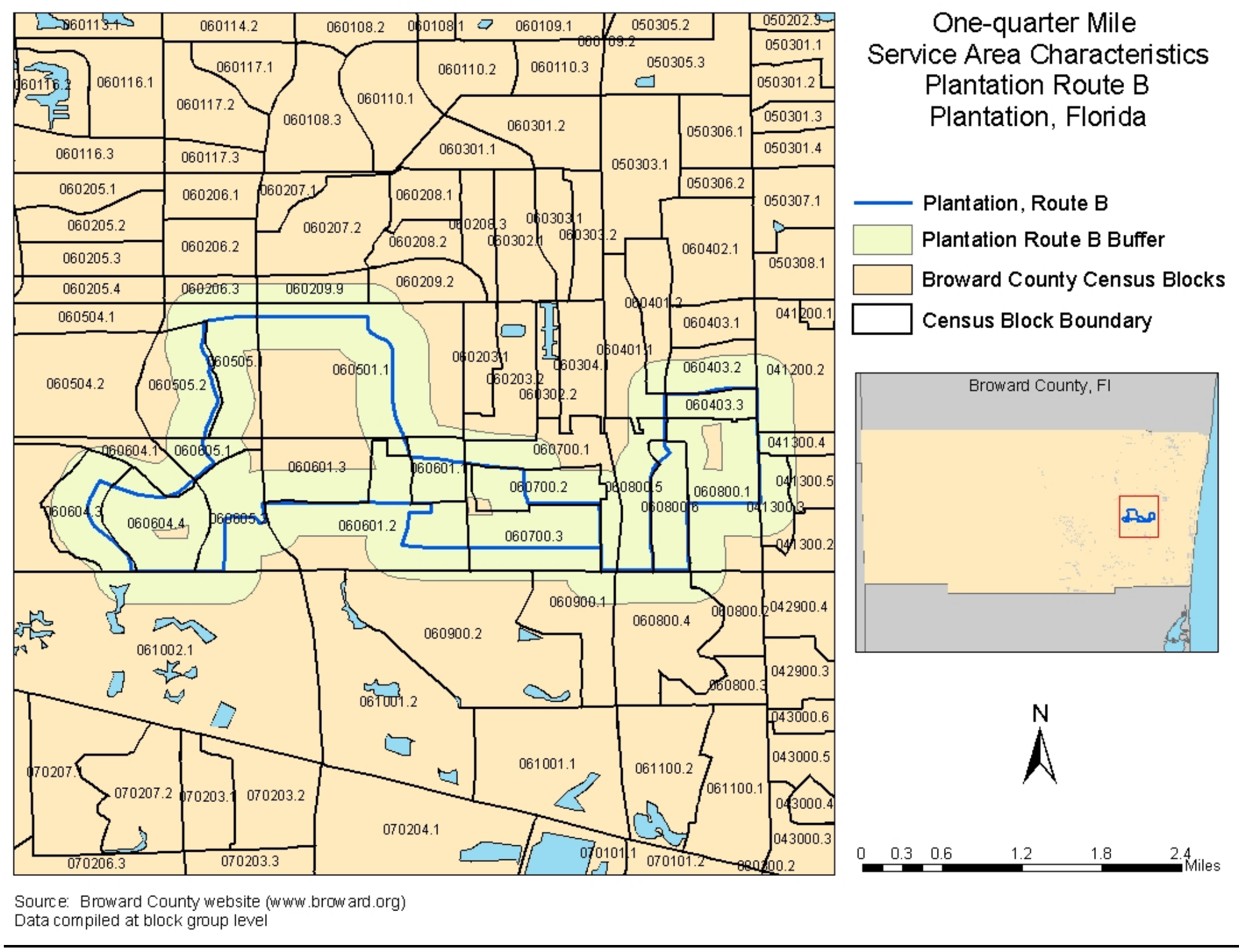




\section{BIBLIOGRAPHY}

1. Kimbley-Horn Associates, Inc. "Local Municipal Transit Circulator Policy Study. http://www.co.miamidade.fl.us/mpo/document/MPO_local_muni_circ_200206.pdf . June 2002. Accessed March $10^{\text {th }}$, 2004 at 2 p.m.

2. Urbitran Associates, Inc. "TCRP Report 55- Guidelines For Enhancing Suburban Mobility Using Public Transportation”. Transportation Research Board. 1999. http://gulliver.trb.org/publications/tcrp/tcrp_rpt_55-a.pdf Accessed March $11^{\text {th }}$ at 3 p.m.

3. Santa Maria, Stephen. Suburban Transit Opportunities Study. Report By The Central Transportation Planning Staff for the Boston Region MPO.

4. Perk, V. Electrowave Shuttle Services Technical Assistance Study. CUTR. May 2003

5. Volinski, J \& Perk, V. "Miami Surface Shuttles: Feasibility Study For Transit Circulator Services in Downtown Miami Brickell, Overtown and Airport West. Prepared For Miami-Dade MPO. June 2000.

http://www.cutr.usf.edu/pubs/miami_shuttlesfinal.pdf 